\title{
ADOLESCENT INTERRUPTED: THE EXPERIENCE OF ADOLESCENTS LIVING WITH AN OSTOMY
}

by

\author{
Susan Carole Garthwaite
}

A thesis submitted to the Victoria University of Wellington

In partial fulfilment of the

requirements for the degree of

Master of Nursing (Clinical)

Victoria University of Wellington

2008 


\begin{abstract}
This study explores the experiences of four adults who reflect upon their experiences, retrospectively, of being an adolescent living with an ostomy. A narrative research approach guided the collection and analysis of data elicited using in-depth interview, presenting each account in the form of a story. The stories serve as a representation of each person's experiences that enables and enriches their understanding.
\end{abstract}

A preliminary literature search revealed a paucity of research investigating the psychological and emotional concerns of adolescents living with an ostomy. This is cause for concern in respect to healthcare, as the knowledge provided by these missing voices does not reach the ears of health professionals. The ability to provide care that is responsive to the needs of adolescents living with an ostomy is therefore diminished, and may have a detrimental effect on coping and adjustment for these individuals.

Six core themes emerged that communicate the essence of their experience. 1) stolen adolescence: the struggle for normalcy; 2) a puppet at the hand of fate: the struggle to gain control; 3), through the looking glass: the person behind the ostomy; 4) the soul held captive by the body; 5) never to walk alone: the struggle for independence and self reliance; 6) disconnection: the experience of loneliness. The interrelationship of these core themes exists as the embodiment of the experiential whole, metaphorically entitled "The Adolescent Interrupted." This metaphorical description symbolises the cumulative effect of disruption, divergence, and disconnection from normal adolescent life as perceived by the participants in this study.

This research contributes to nurses understanding of the physical, psychological, and emotional impact that living with an ostomy has on the adolescent. The findings demonstrate the importance of providing holistic care that addresses, and is responsive to the unique needs of these adolescents in order to lessen the negative impact of the experience and effect positive change.

Key words: Ostomy; Adolescence; Narrative; Life Experience. 


\section{TABLE OF CONTENTS}

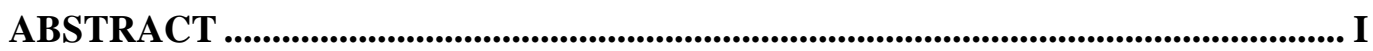

TABLE OF CONTENTS ................................................................................................

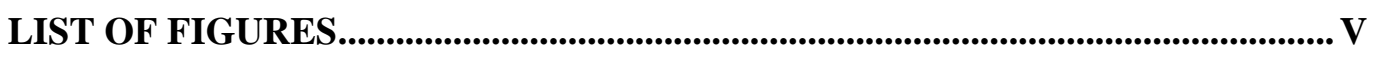

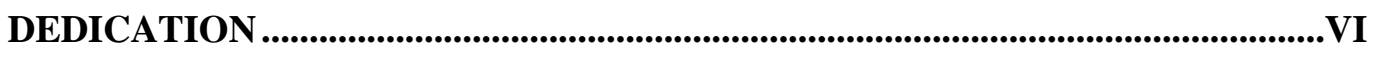

ACKNOWLEDGEMENTS ........................................................................................... VII

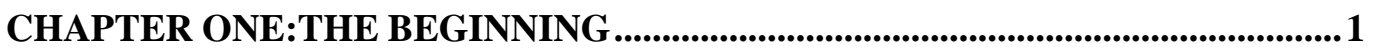

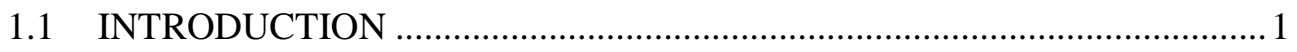

1.2 SIGNIFICANCE OF THE STUDY TO NURSING ..................................... 2

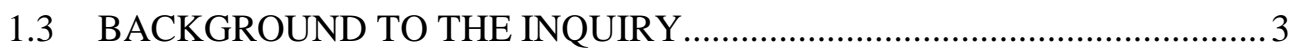

1.4 PURPOSE OF THE STUDY ............................................................... 4

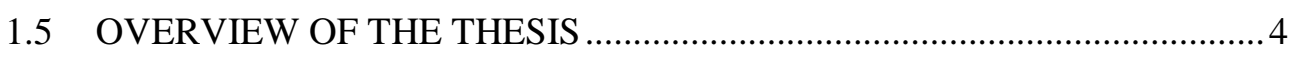

CHAPTER TWO: A REVIEW OF THE LITERATURE.......................................6

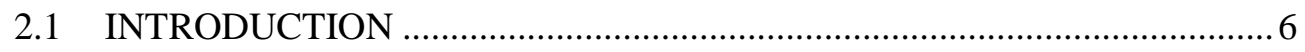

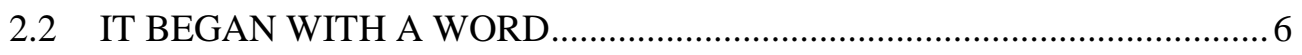

2.3 A TRUTH UNIVERSALLY ACKNOWLEDGED? ...................................... 7

2.4 ADOLESCENT, WHAT CREATURE IS THIS? ...................................... 8

2.4.1 THE DISCOURSES OF YOUTH................................................................ 8

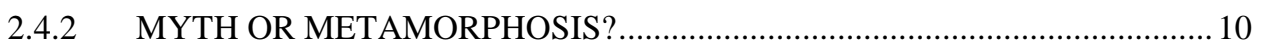

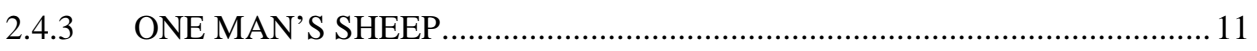

2.4.4 THE ADOLESCENT PHENOMENON ………............................................... 13

2.5 BEING A PERSON WITH AN OSTOMY ……...................................... 14

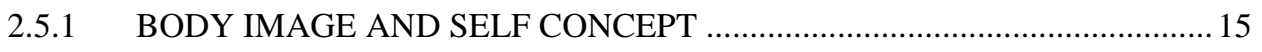

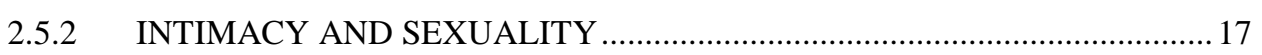

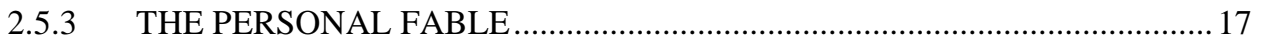

2.5.4 EXPLORATORY HEALTH BEHAVIOURS ……............................................. 18

2.5.5 ALL THE WORLD'S A STAGE .............................................................. 19

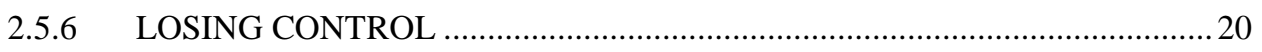

2.5.7 INDEPENDENCE AND NORMALCY …….............................................. 21

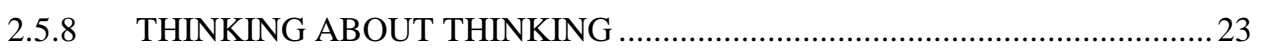

2.5.9 IDENTITY VERSUS IDENTITY CONFUSION ...........................................24

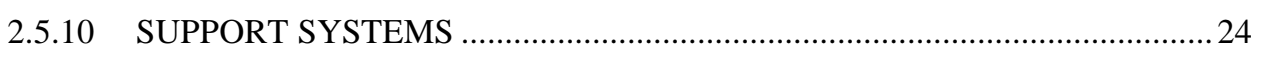

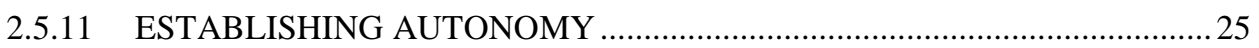

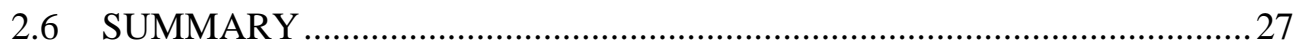




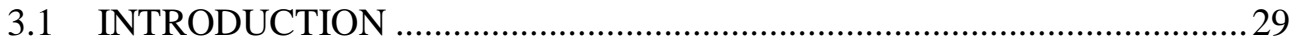

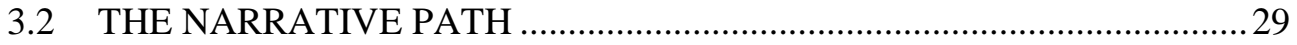

3.2.1 STORY IN NURSING RESEARCH ……………........................................... 31

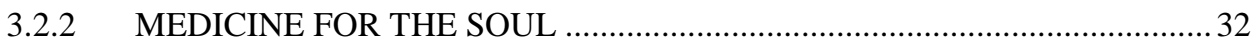

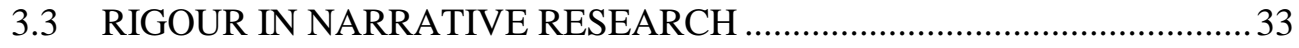

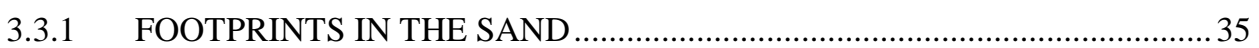

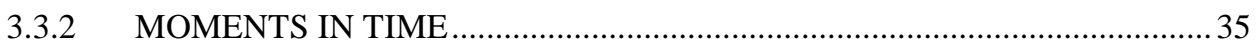

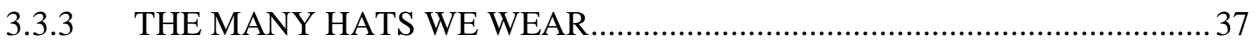

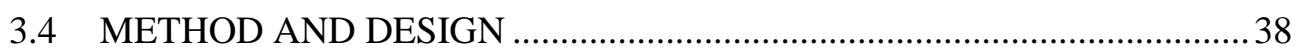

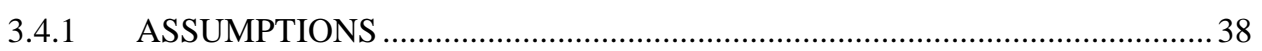

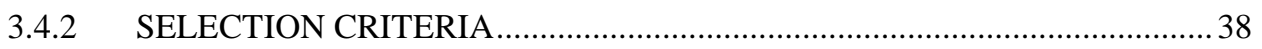

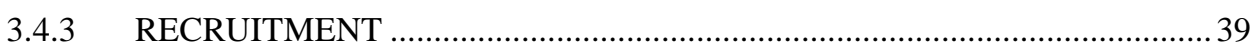

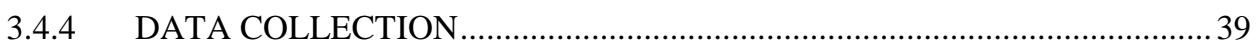

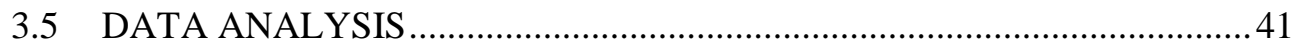

3.5.1 CONNECTING WITH THE PARTICIPANT'S STORIES …......................... 41

3.5.2 THE EMBODIED NATURE OF THE INDIVIDUAL ………........................... 42

3.5.3 CHRONOLOGICAL ORDERING OF EVENTS ............................................ 42

3.5.4 METAPHOR AS A TOOL IN NARRATIVE ....................................................43

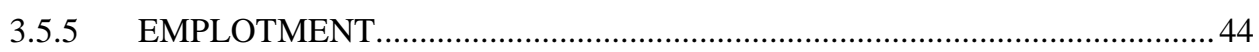

3.5.6 COLLECTIVE WISDOM..................................................................... 44

3.6 ETHICAL ISSUES IN THE RESEARCH …........................................... 45

3.6.1 VULNERABILITY OF THE PARTICIPANTS ................................................ 45

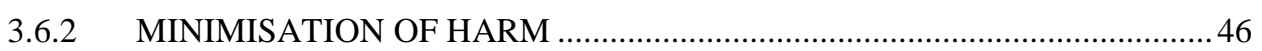

3.6.3 PRIVACY AND CONFIDENTIALITY ……………………………...........

3.6.4 MANAGEMENT OF RISK ……………………........................................... 48

CHAPTER FOUR: ONCE UPON A TIME...............................................................50

4.1 OUT OF THE DARKNESS: JAME'S STORY …………........................50

4.2 THROUGH THE LOOKING GLASS: HOPE'S STORY …………............58

4.3 THROUGH DANGERS UNTOLD: FAITH'S STORY ……......................63

4.4 ONE MOMENT IN TIME: MARKS STORY …...........................................69

CHAPTER FIVE: ADOLESCENT INTERRUPTED ...........................................74

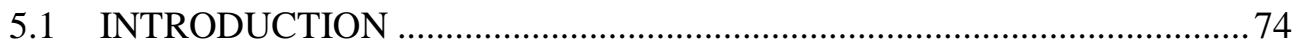

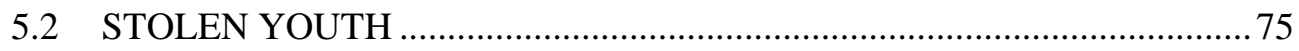

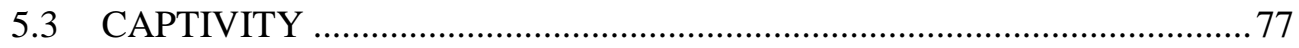

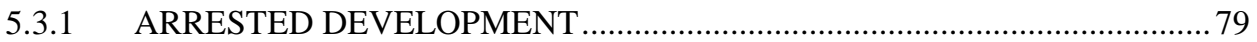


5.3.2 GROWING UP TOO SOON …………………….................................... 82

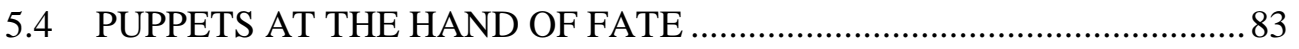

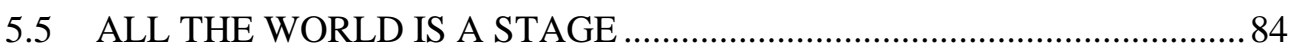

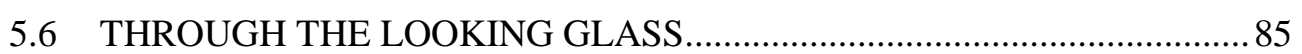

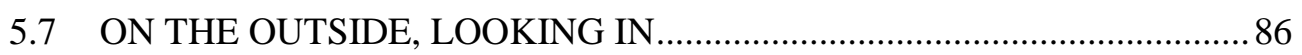

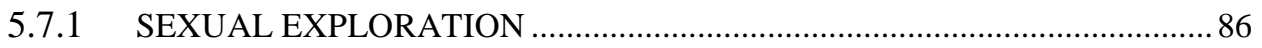

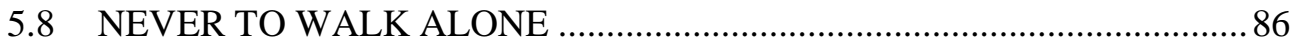

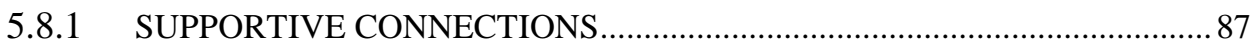

CHAPTER SIX: SIGNIFICANCE AND IMPLICATIONS .....................................89

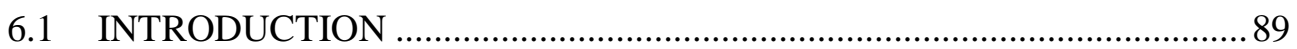

6.2 STRENGTHS AND LIMITATIONS OF THE STUDY ……......................... 89

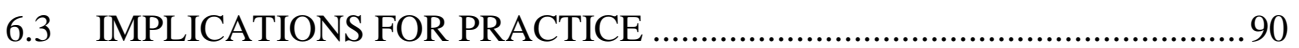

6.4 IMPLICATIONS FOR NURSING EDUCATION_...................................91

6.5 IMPLICATIONS FOR FURTHER RESEARCH....................................... 92

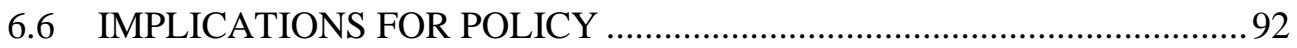

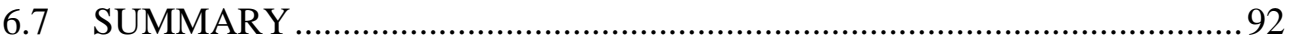

AFTERWORD

APPENDIX A: PARTICIPANT CONTACT LETTER …...................................... 93

APPENDIX B: PARTICIPANT CONSENT FORM ….......................................... 94

APPENDIX C: PARTICIPANT INFORMATION FORM .................................... 96

APPENDIX D: TRANSCRIBER CONFIDENTIALITY AGREEMENT .............. 100

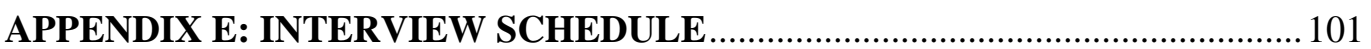

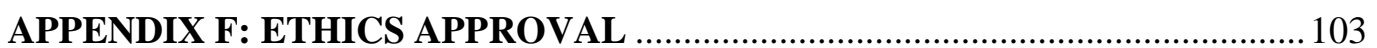

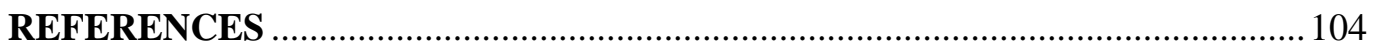




\section{LIST OF FIGURES}

FIGURE 1: ADOLESCENT INTERRUPTED: THE CUP OF STOLEN YOUTH ..............................74 


\section{DEDICATION}

I dedicate this thesis to the four individuals who so generously shared their stories with me. Your extraordinary courage and enduring spirit lives within these pages. Without you, this study would not have been possible.

The rift in the chest of a mountain

The twist in the trunk of a tree

The water-cut cave in the hollow

The rough rocky rim of the sea

Each one has a scar of distortion

Yet each has this song to sing

'The presence of what would deface me

has made me a beautiful thing'

Frank H Keith 


\section{ACKNOWLEDGEMENTS}

This thesis would not have been possible without the assistance and help of others, with which I would like to acknowledge.

Again, my sincere thanks to the four individuals who generously shared their experiences for this research. To my academic supervisor Dr Rose McEldowney, your encouragement, wisdom, and support over the past year has been the guiding light through a dense fog and bought this thesis to its completion. I have not the words to express my gratitude for your patience and selfless generosity. To Dr Kathy Nelson and Dr Denise Blanchard, I am grateful for the invaluable advice and support you gave me as my supervisors during the infancy of this study, and to Dr Margaret Pack, thank you for your words of wisdom on the final stretch. Thank you also to Abbey and all the staff at the Graduate School of Nursing, Midwifery and Health who have assisted me throughout my studies.

To the Stomatherapists and the many other people consulted during the course of this study; your contribution has been invaluable. A significant proportion of the operational costs for this research project were met by a grant from the New Zealand Nursing Education and Research Foundation and Gretta and Harry Hamblin Trust. This contribution and the committee's approval were greatly appreciated.

To the Hutt Valley District Health Board, my second home for nine years, thank you for supporting this researh. Moreover, I would like to acknowledge my colleagues who patiently listened and supported me through this research and my studies; you will always be like family to me. Thank you for your wisdom and for the memories.

My heartfelt thanks go to my parents, Carole and Graham, and my little brother Cameron for their unconditional support and perseverance. You were always there to guide and encourage me on my journey and to catch me when I stumbled.

Finally, to Matthew, thank you for enduring this journey with me. Your patience, love, and support kept me on the path when all but the faintest light had dimmed. They say it is often darkest before the dawn, and they are right. You were my light. 


\section{CHAPTER ONE}

\section{The Beginning}

\section{$1.1 \quad$ Introduction}

Bane of my existence, thy name is stoma

Bane of my existence, I heard this uttered one day by a frustrated young man struggling to stuff the contents of a carefully packed bag of stoma supplies in various pockets of his jeans. Failing abysmally, he settled on one stoma bag jammed tightly in his wallet, hiding the remnants of the supplies under his pillow out of view of his mother, who had packed them for him. Having been granted a reprieve from his hospital bed, he was off to a movie with friends vowing he would not carry anything that might be construed to be handbag. He succeeded in leaving with nothing but the now bulky wallet tucked in his back pocket, a minor victory in a greater battle.

Being an adolescent living with an ostomy, it would seem, is not to be an adolescent at all, in the sense of the word. In my years of nursing, I have been witness to the many effects such a monumental change has on physical, psychological and emotional wellbeing. The ability to adjust to a change of this magnitude is invariably different for everyone; however, from my observation those who endured the most complex, the most disrupting, and the most challenging path to adjustment shared a certain commonality. These most troubled individuals shared a similar period of life I associated to be adolescence. Adolescence as I understand, is fraught with chaos and confusion, representing the slow transformation from child to adult, wherein, a metamorphosis of being occurs. The additional circumstance of having an ostomy, I believed must serve only to escalate that chaos. Adolescence and its all-consuming endeavours to conform to a socially embedded construct of what is normal, what is acceptable, is thwarted when circumstance declares that goal unattainable.

What is created in my mind, when I think of those young people living with an ostomy, is a metaphorical picture of a stone cast in to murky waters. The ripples that ensue in those murky waters of adolescence would impact upon all aspects of life that lay in their path. My desire to understand this phenomenon of human existence is what has led me to this investigation. In comprehending the realities of living with an ostomy during adolescence, I hoped to be better enabled to care for these 
individuals in the future.

\subsection{Significance of the study to nursing}

My search for understanding has culminated in this thesis, an inquiry into the experiences of adolescents living with an ostomy through the re-telling of their stories. In the re-telling of these stories I describe the memories, thoughts and feelings associated with having lived with an ostomy during adolescence. Nurses and other health professionals in a variety of settings are exposed to adolescents with an ostomy. Their experiences are important to understand in order to achieve positive outcomes. The presence of an ostomy has the potential to negatively impact an adolescent's life, affecting relationships, lifestyle, as well as academic and career aspirations. It is the responsibility of health professionals to facilitate the reenvisioning of themselves and their lives in a way that they find acceptable within the complex and often confusing contexts of the society in which they live.

The Federation of New Zealand Ostomy Societies (2008) estimates that there are some 5,000 ostomates in New Zealand, with a population of 3.8 million that is one in every 760 persons. A search of the literature, however, revealed a paucity of research investigating the experience of being an adolescent living with an ostomy. This indicates a need for further investigation into the impact that an ostomy can have on adolescents. Indeed, research studies have explored the experiences of ostomates, but little focus is given to distinguishing the experiences from the perspective of those at different stages of life. Despite a plethora of literature investigating the subject of adolescence and adolescents in general, the voice of the adolescent living with an ostomy is remarkably silent, thus substantiating my motivation for undertaking this study.

Studies done on individuals living with an ostomy revealed that they face many lifestyle challenges that include physical and psychological adjustments (Manderson, 2005; Reynaud \& Meeker, 2002; Rheaume \& Gooding, 1991; Salter, 1992). Others have found that people with ostomies perceived a negative body image and expressed difficulties in accepting the ostomy (Black, 2004; Casati, Toner, De Rooy, Drossman, \& Maunder, 2000; Junkin \& Beitz, 2005; Karadag et al., 2003; Nugent et al., 1999; O’Brien, 1999; Salter, 1992). 
Many published studies have used quantitative methodology, which makes it difficult to extrapolate perceptions and feelings of these individuals. Woodgate (1998) claims quantitative measures are often not equipped to capture the thoughts, feelings and meanings that individuals ascribe to their experiences. It is therefore imperative that more qualitative research be directed towards gaining knowledge about the lived experiences of adolescents living with an ostomy. Several predominant themes emerged from the literature that collectively embodies the lived experience of ostomates across the lifespan. These are body image disturbance, a perceived loss of control, the need for independence and normalcy, the value of support from family, friends, and health professionals, as well as the efficacy of education and communication. In the adolescent population, these themes appear to have a far more pronounced psychological and psychosocial impact. Additional themes emerging from the adolescent perspective include the impact of biological, cognitive, and socio-emotional development, the search for identity and autonomy, the concepts of the imaginary audience and personal fable, the importance of peer relationships, and the attainment of adult status.

By gaining valuable insight and understanding into these experiences, nurses will be able to utilise that knowledge and provide better holistic care to those individuals and their families. Holism is the inseparable connection of mind, body, and spirit of the person in the context of a family and a community. Nurses cannot adequately meet the health needs of adolescents without consideration of the whole person (mind, body and spirit) who lives within a context of family, culture and larger environment (Alma-Ata Declaration, 1978). The findings of this study will assist nurses and other healthcare professionals to better understand the needs and issues of adolescents living with an ostomy, thus enabling these professionals to promote better overall health for this population. It is intended that the information gained will be used to consolidate and improve care through the development of care plans specifically for adolescents. This insight into what adolescents experience may allow us to recognise unhealthy coping mechanisms, develop strategies to manage problems, and provide appropriate support where needed in order to lessen the negative impact of the experience.

\subsection{Background to the inquiry}


My primary interest in exploring the experiences of individuals with an ostomy stems from working with, and caring for people living through this experience for the greater part of my nursing career. I developed an interest in the surgical specialty during my undergraduate studies and accepted a position in a specialty general surgery and gynaecology unit where I remained for eight consecutive years. In January 2007, I gained approval to establish a unit based nursing education role and subsequently took on the position of Clinical Nurse Educator for general surgery and gynaecology. In February 2008, I accepted a position as Clinical Nurse Specialist for Postoperative Surgery within the private sector. I have developed a passion for surgical nursing stemming from my clinical experience; subsequently this has led me to dedicate the majority of my postgraduate study to this subject.

The literature review will demonstrate that experience of adolescents living with an ostomy is not well represented in the research available today. A very small number of studies concentrate on the experiences of adolescents living with an ostomy. Other studies refer to the adolescent experience briefly, though the issue is not explored sufficiently enough to provide insight into their unique experience. It is, therefore, my objective to address this knowledge gap, and to provide insight into how living with an ostomy affects the individuals in the transition phase from childhood into adulthood known in the western culture as adolescence.

\subsection{Purpose of the study}

The purpose of this study is to describe the experience of being an adolescent living with an ostomy by presenting and exploring their stories. Attention has been paid to describing what characterises the experience of living with an ostomy and the meanings these individuals assign to their experiences.

\subsection{Overview of the thesis}

The terms ostomy and stoma are general descriptive terms that are often used interchangeably though they have different meanings. According to the United Ostomy Associations of America (2007), an ostomy refers to the surgically created opening in the body for the discharge of body wastes. An ostomy, descending from the Greek pleural stomata, is the actual end of the small or large bowel or ureter that can be seen protruding through the abdominal wall. Surgical procedures in which 
stomata are created are ended in the suffix 'ostomy' and begun with a prefix denoting the organ or area being operated on. For the purposes of this study the word stoma will be used interchangeably with the words ostomy, colostomy, ileostomy, and urostomy. These words are used to describe any surgical manipulation of the gastrointestinal, or urinary tract which creates an incontinent outlet for waste on the abdomen and is collected in an attachable appliance.

Chapter Two presents a review and discussion of the literature in an effort to gain an understanding of what is known about adolescent experiences of living with an ostomy. The concept of adolescence as a stage of life is explored briefly, discussing the classical debates regarding the universality of adolescence as a distinct period of life and as a period of emotional turmoil. The underrepresentation of adolescents in the literature within the context of living with an ostomy, led me to broaden my review to include research in the area of adolescent development and the experiences of adolescents in other contexts. The purpose of this is to gain a better appreciation of the experience of living with an ostomy from an adolescent perspective.

Chapter Three describes the research methodology, method, and design employed. This methodology section introduces narrative inquiry as informing the methodology for this research and discusses the rationale behind this choice. The method section will discuss research design, data collection methods, and analysis using core story creation. Methodological rigour and ethical considerations are also addressed here.

Chapter Four contains the core stories constructed from the narratives of the four participants. I have given each story a metaphorical title that I feel captures the essence of the experience for that person. Analysis of the data elicited from these narratives is reported in chapter five with reference to the literature.

Chapter Five concludes the research, exploring its limitations and discusses the significance of the findings and the suitability of the methodology. I then explore the implications for clinical practice, nursing education, future research and health policy. My reflections on the research are presented in the afterword. 


\section{CHAPTER TWO}

\section{A review of the literature}

\subsection{Introduction}

This chapter examines the findings of research investigating the experience of living with an ostomy, and relates these experiences to research findings and other literature in the areas of adolescent development, adolescent illness, and disability. I detail how the literature was sourced and then go on to discuss the positioning of adolescence as a distinct period of life with particular reference to Aotearoa, New Zealand society and the developmental models of the classic theorists (Erikson, 1968; Freud, 1925; Hall, 1904; Havighurst, 1952; Piaget, 1969; Vygotsky, 1978).

\subsection{It began with a word}

My quest to locate the literature began with an extensive search conducted using the electronic database CINAHL (Cumulative Index to Nursing and Allied Health Literature), the World Wide Web, and several academic research collections. The keywords of 'ostomy', 'stoma', 'adolescent', 'adolescence', 'youth', 'teenager', 'experience', 'illness' and 'nursing' were employed in the search. The search yielded limited results, sourcing only a small quantity of material focusing on the adolescent experience of living with an ostomy. The underrepresentation of adolescents in the literature within the context of living with an ostomy necessitated broadening my review to include research in the area of adolescent development and the experiences of adolescents in other contexts. The purpose of this is to gain a better appreciation of the experience of living with an ostomy from an adolescent perspective.

I sourced a number of research studies, primarily qualitative in nature, exploring and comparing individual experiences of living with an ostomy across the lifespan. Before immersing myself within the literature, I came to realise that before proceeding further I needed to answer several fundamental questions. Essentially, what is adolescence? What does it mean? And what is my justification for exploring the experiences of adolescents aside from the population as a whole? Why should adolescents be considered a unique group? 


\subsection{A truth universally acknowledged?}

It is universally acknowledged that when the definition of a term or description of a word is sought, one can frequently rely on a dictionary to provide the answer. And so it was with a dictionary my search began. The Oxford English Dictionary (Oxford University Press, 1989) defines adolescence as the process of developing from a child into an adult, originating from the Latin verb adolescere - to come to maturity. The Collins Dictionary of the English Language (Collins, 1979) elaborates to say that this period of human development occurs between the beginning of puberty and adulthood, that being a person between the ages of 13 and 19 inclusive. The Adolescent Health Committee (2008), however, defines adolescence without chronological bounds as "the onset of physiologically normal puberty, and ends when an adult identity and behaviour are accepted" (p. 557). This view is shared by Gray (1988), who reports that in Western society, adolescence refers to a period of approximately 10 years within which an individual transitions from childhood into adulthood.

In considering these definitions, I found myself presented with yet more questions than answers. Specifically, I question what constitutes the beginning of physiologically normal puberty. I am left to consider, whether a girl who begins menstruation at 12 is abnormal according to the chronological time frame denoted in The Collins Dictionary of the English Language. The Oxford English Dictionary (1989) describes puberty as the period during which adolescents reach sexual maturity and become capable of reproduction, the onset of which varies with each individual. This provides a more inclusive viewpoint of what is normal; however it leaves the boundary somewhat vague. The British Paediatric Association (1996) provides a comprehensive definition of adolescence, as a phase of intellectual, social, emotional, and physical change through which an individual progresses in passing from childhood to maturity, and suggests that it cannot be rigidly defined in chronological terms. My search for quantifiable boundaries within which to position adolescence as a developmental period had so far proved fruitless, so instead I turn to the term adolescent itself. 


\subsection{Adolescent, what creature is this?}

Dashiff (2000) declares matter-of-factly that an adolescent is a member of a population group comprising individuals who have reached a certain period in the human lifespan entitled adolescence. The origin of the term adolescent is surprisingly recent, having appeared around the mid 20th century and is often divided by psychologists into three distinct phases: early, mid and late adolescence (Whaley and Wong, 1996). Whaley and Wong claim that historically, the term adolescent has been used synonymously with the terms youth, juvenile, teenager and young person. Indeed, literature emerging in the 1970s and 1980s predominantly refers to teenagers, rather than adolescents. The ages which are considered to be part of adolescence are also varied. According to the World Health Organisation (WHO), adolescence covers the period of life between 10 and 19 years of age (WHO, 2008). The United Nations General Assembly (2008), however, states that youth are those persons falling between the ages of 18 and 24 years inclusive. By definition, Palladino (1997) states, a teenager, or teen, is a person whose age is a number ending in teen, that is to say, someone from the age of 13 to the age of 19. More recent literature however, has trended away from using the term teenager owing to the decidedly concrete boundaries it implies.

\subsubsection{The discourses of youth}

In the mid 20th century several developmental models emerged that have had a major influence on the theories of adolescence, and continue to do so today. These classic theoretical models describe adolescence as the period in which a child matures into an adult. These developmental theories include biological views (Hall, 1904); psychoanalytic views (Freud, 1925); cultural views (Mead, 1928); psychosocial views (Erikson, 1968); cognitive views (Piaget, 1969; Vygotsky, 1978); and moral views (Kohlberg, 1984). The scientific study of adolescence with a biological focus began with the publishing of Adolescence by G. Stanley Hall (1904). Hall used the scientific method to study developmental processes, and formulated the theory that adolescence is a period of extreme storm and stress. Hall's 
claim of adolescent storm and stress is challenged by Mead (1928), who presented an account of the coming of age for Samoan adolescents that showed no indications of storm and stress. Mead explained that Samoan children experienced a very gradual and smooth transition from childhood to adulthood because, from an early age, Samoan children took part in work tasks such as, caring for younger siblings, planting and harvesting, and preparing food that have meaningful connections to the work they will perform as adults.

Freud (1925) saw adolescence as the genital phase of psychosexual development, where the child recaptures the sexual awareness of infancy, whilst Piaget (1969) focuses on cognitive development, seeing adolescence as the formal operational stage where the young person develops the ability to think abstractly and draw conclusions from the information available. Cognitive functioning, according to Piaget, involves an ongoing interchange between assimilation, that is fitting problems and information into existing cognitive structures, and accommodation; modifying and revising cognitive structures that are ineffective or unsuccessful. Piaget described four periods of development beginning with sensory-motor and ending with formal operations. Vygotsky's (1978) theory stresses relationships between the individual and society. To understand a child's cognitive development, there must be an understanding of the culture within which that child exists. Vygotsky proposes that an individual's thinking patterns are the products of cultural institutions and social activities, not innate traits.

Kohlberg (1984) extended Piaget's theory of cognitive development into a theory of moral development that focuses on thinking about moral issues. This theory of moral development focuses on thinking about moral issues not thinking about behavior that is right or wrong. In Kohlberg's view, formal reasoners are able to use high-level moral reasoning. In other words, adolescents begin to understand the relative nature of rules and laws and realise the need to protect individual rights. Formal and moral thinking enables adolescents to begin thinking about their own thinking.

Erikson's theory of epigenesis (Erikson, 1968) proposes a theory that integrates and synthesises past and present experiences. This psychosocial view is composed of eight stages. Each stage is regarded as a psychosocial crisis that arises and demands 
resolution before the next stage can be satisfactorily negotiated. Where a crisis is not resolved, social adjustment cannot progress and an unhealthy outcome occurs that will influence future social relationships. The fifth psychosocial crisis of Erickson's model entitled 'identity versus identity confusion' depicts adolescence. During this developmental period the adolescent seeks to answer the question 'Who am I and where is my place in society?' This stage exemplifies independence of thought. Turner and Helms (1987) state that it is during this time that the values and beliefs of parental figures are questioned, and individual values and goals are formed. The adolescent undertakes to evaluate his/her existence and explore their personal identity in order to establish a meaningful definition of self. Failure to develop independent thought processes and establish an individual identity results in confusion in future adult roles.

\subsubsection{Myth or metamorphosis?}

One issue in adolescent psychology discusses whether adolescence is in fact a discrete developmental period, a point along a continuum of human development, or a social construction. The most fundamental and classic question in adolescent research is whether all cultures in the world view adolescence as a unique life period. Evidence that adolescence is not experienced uniformly has been presented by Mead (1928). Atkinson (1997) reports that in traditional cultures of the past, initiation ceremonies, or rites of passage, were used to guide the individual through the necessary transition from one social status or life stage to another. Martin-McDonald and Biernoff (2002), define rites of passage as "ritualised and institutionalised events in which individuals are taken from one social status to another, moving across thresholds where, temporarily, they are neither the previous status or the new status, but rather in between" (p. 347). Ceremonies marking this event were common in preindustrial societies and are still practiced in a number of non-Western cultures. For males, these rituals often consist of some kind of test and include circumcision. Ritual coming-of-age ceremonies for girls were traditionally associated with the onset of menstruation. One female rite of passage still practiced in parts of Africa has drawn protests throughout the international community: among the Masai and other groups, female circumcision (genital mutilation) is considered the main ritual marking a young woman's transition to adulthood, a sign that she is ready to marry 
and procreate. In many Western cultures, there is no clear-cut point at which a young person becomes an adult and, therefore, no single definitive rite of passage marking the transition to adulthood.

In pre-industrialised societies, Atkinson (1997) reports that children typically did not have formal schooling, and were married at a young age necessitating a sudden transition from childhood to adulthood. Atkinson speculates that in this cultural context, adolescence usually did not exist at all, and if it did it was clearly a limbo period that lasted anywhere from a few days to a few months. New Zealand in itself is culturally diverse and Drewery and Bird (2004) are of the opinion that the various cultural traditions struggle, each in their different ways, to come to terms with the "strong euro-western economic undercurrent about what it means to be grown up" (p. 223). Drewery and Bird claim that the phenomenon of adolescence is a byproduct of an industrial revolution in the late $19^{\text {th }}$ century that swept through the euro-western world. Schooling was made compulsory and in Aotearoa-New Zealand, adolescents were seen as more properly focused on preparing for adulthood and paid work through education. Today however, Drewery and Bird report that events previously considered to be significant transitions in life such as leaving home, gaining employment, marriage, and children are being delayed and their sequence changed. Consequently, these traditional markers of adult status are becoming less directly related to age. The ambiguity of age associated rites of passage is evident among the laws that govern society in New Zealand.

\subsubsection{One man's sheep}

Legislation concerning adolescents in New Zealand is contradictory in nature at best, giving rise to much conjecture and speculation. Drewery and Bird (2004) refer to the stance of the government on the responsibility for feeding and housing young people who move into tertiary education. With certain exceptions, the government lays this responsibility at the feet of the parents, at least until the young person reaches the age of 25. According to the Age of Majority Act (1970) full legal capacity is attained at 20 years of age. However, if statutes serve as the markers of the transition from childhood to adulthood, New Zealand society is a confused society. As a member of present day society in New Zealand the Land Transport Act (1998) dictates that one may obtain a drivers licence at the age of 15 , is one then considered an adult? At 16 
years of age the Education Act (1989) states that one may leave school, the Marriage Act (1955) allows marriage with parental consent, and the Crimes Act (1961) states that one may legally consent to engage in heterosexual intercourse, but not homosexual intercourse. The Care of Children Act, section 36 (2004) states that a person on reaching age 16 may consent to a medical procedure, however, section 38 states that a female of any age may consent to the abortion of a foetus. At 18 years of age a young person may vote and the Prostitution Reforms Act (2003) has pronounced that it is legal to gain employment as a prostitute.

The Sale of Liquor Amendment Act (1999) announced that the age at which one may purchase and consume alcohol is now 18 instead of 20 years of age, though public debate. According to the Gambling Act (2003), however, one remains prohibited from entering a casino until the age of majority, that being 20 years. To add to this ambiguity, if one then travels abroad these legal age stipulations vary enormously. In Canada, for example, according to the Canadian Department of Justice Criminal Code (1985) the legal age of consent to sexual intercourse is 14 and in the United States the National Minimum Drinking Age Act (1984) prohibits the purchase of alcohol by any person under the age of 21 years. Legislation imposed in each country, and indeed even each state or province is diverse. In any one given day, a young person may sway in an out of adult status many times. Atkinson (1997) claims that this ambiguity, this breakdown of significant symbols by which to live, is one of the primary contributors to not only the floundering of youth, but the breakdown of society in general. Without clearly defined guidelines to assist one in a difficult passage of life, Atkinson speculates that the transition from childhood to adulthood will be met with confusion, uncertainty, and inconclusiveness. Indeed, Drewery and Bird suggest that society may need to rethink what it means to be an adult in Aotearoa.

The assignment of fixed chronological boundaries to the period of adolescence has proven ever more difficult. It has become clear to me that adolescence is not merely an inherent process of developmental convention, but that the adolescent is born of a cultural and social phenomenon. The boundaries of adolescence, therefore, are not easily tied to physical milestones. In relation to the development of this study, such a revelation presented an obstacle that would be potentially problematic. Specifying 
the conceptual and operational definition of adolescence, I believed was critical in the design of this study. Without a more definitive chronological description of adolescence, I would be unable to formulate clear parameters within which to define my target population. With this goal still at the forefront, I began to investigate the complex phenomenon of adolescence.

\subsubsection{The adolescent phenomenon}

'Who are you?' said the Caterpillar.

Alice replied, rather shyly, 'I--I hardly know, sir, just at present... at least I know who I was when I got up this morning, but I think I must have been changed several times since then.'

\section{Lewis Carroll, 1865.}

Brydolf and Segesten (1996) describe the period of adolescence as a time of great fluctuation in the biologic, psychological and social realms along with role changes within the family and group of peers. They claim that both the conscious and unconscious realisation of these great fluctuations in the biologic, psychological and social realms can be the source of much anxiety. Everall, Bostick and Paulson (2005) declare that adolescence is a period of self discovery when internal and external factors impact an adolescents awareness of who they are, what they believe in, where life is taking them, and how they fit into a complex society. Successful identity formation according to Atkinson (1997) can be characterised as the process of gradually bringing into accord the variety of changing self-images that have been experienced during childhood. Huebner (2000) proposes that this is one of the most important tasks in adolescence. The question of 'who am I' is not one that the adolescent thinks about at a conscious level. Instead, over the course of the adolescent years, they begin to integrate the opinions of influential others; parents, other adults, and friends, into their own likes and dislikes. The eventual outcome is a clear sense of their values and beliefs, occupational goals, and relationship expectations.

The physical body changes exhibited in adolescence are the most acute, more so than any other time within the lifespan. It is in this period Williamson (1987) claims, that most individuals experience rapid linear growth, weight gain, increased bone development, and the development of secondary sexual characteristics and sexual maturation. Williamson adds that a lack of control over these changes may be a 
source of considerable distress resulting in a feeling of powerlessness in the individual. Those living with a chronic illness or condition often undergo additional physical changes related to treatment, surgery and medications. Decker (2000) maintains that if compounded by illness or the presence of an ostomy, the changes and disruptions of puberty sometimes lead to an overwhelming experience and transition throughout adolescence.

\subsection{Being a person with an ostomy}

The miracle is not to fly in the air, or to walk on the water; but to walk on the earth.

\section{Chinese Proverb}

There are several reasons why a person may need an ostomy, such as birth defects, injury, malignancy or inflammatory bowel diseases. Whether it be temporary or permanent, life saving or to improve quality of life, ostomy surgery is usually accompanied by psychological and psychosocial concerns and can have an impact on an individual's quality of life, body image and self-esteem. The literature review uncovered studies done on both temporary and permanent ostomies (Erwin-Toth, 1999; Kelman and Minkler, 1989; Martinsson, Josefsson and Ek, 1991; Karadag et al., 2003). Brown and Randle (2005) found no conclusive findings in their literature review on living with an ostomy. They did however indicate that, in the short term, most individuals experience negative feelings of resentment toward their ostomy.

Nugent et al. (1999) looked at quality of life in individuals with permanent ostomies and found that many individuals cope extremely well, whereas some have more difficulties. They attributed this to age and reason for the ostomy operation, and that coping in the long term may be enhanced by proper preoperative education. Karadag et al. (2003) and Silva (2003) concluded that having either an ileostomy or a colostomy profoundly negatively impacts on quality of life. This impact resulted from the stoma related problems encountered on a daily basis. Quality of life factors included the effect on the ability to travel and exercise, and on hygiene and sexual relationships. Goozen, Geelkerken, Herman, Lagaay and Goozen (2000) found there was a clear relationship between the number of ostomy care problems and the degree of social restriction, that is the avoidance of social activities and social withdrawal 
leading to isolation.

\subsubsection{Body image and self concept}

Adolescents are very aware of physical changes and often compare themselves to their peers. Freiberg (1992) claims it can be difficult for the adolescent to adjust to all these bodily changes. They are often conflicted about what they perceive to be the ideal body. Ghosh, Drummond and Ferguson (1998) and Rayhorn (2001) report that body image and personal appearance can often become a concern for these individuals at a time where this is considered to be of great importance. The physical processes of illness or disability also have a compounding effect on body image and self-concept. Several studies note how changes resulting from illness and the presence of an ostomy have an impact on one's self-esteem and body image. Shipes (1987) asserts that gradual physical changes in the body, as happens during adolescence, provide the individual with time to adjust to their image. Abrupt changes, however, such as those resulting from ostomy surgery do not allow the same leisurely adjustment. This can result in a distorted body image.

The failure of growth and sexual development are noted to be serious and common problems in adolescents. Simon (2002) and Daniel (2001) claim that illness, both acute and chronic, may delay growth, puberty and the maturation of other biological systems through lack of nutrients or competition for nutrients from chronic inflammation and infection; stress and the side effects of medications such as steroids. Other changes are reported by Brydolf \& Segesten (1996) and Decker (2000) to be rapid weight gain or loss, fluid retention, acne and loss of energy. Casati, Toner, De Rooy, Drossman and Maunder (2000) maintain that these side effects have a significant impact, especially in a society that puts tremendous emphasis on attractiveness. These studies noted that often these changes leave the individuals feeling damaged and different than their peers.

According to Cepeda (2000), delayed puberty may result in low self-esteem in boys, and in difficulty separating from parents due to apparent immaturity. Adolescents affected by delayed puberty may be treated as less mature than real age by adults, and this can lead to an overwhelming experience as the adolescent struggles to adapt to the additional circumstances of illness together with normal developmental 
challenges. The adolescent may also be concerned because they are not physically developing at the same rate as their peers. Huebner (2000) claims that being out of developmental 'step' with peers is a concern to adolescents because most just want to fit in.

Persson and Hellstrom (2002) report that during the initial postoperative period, many people had trouble looking at or touching the stoma. Weight loss resulted in the perceived image of looking gaunt and unwell, and perceived attractiveness since surgery was also found to be markedly decreased. Similarly, surgical scarring was found to be of high concern, particularly among female participants. Klopp (1990), reports that individuals with faecal stomas appear to have a poorer body image perception than those with urinary stomas, whilst those with ileostomies were reported to have a better self-concept than those with colostomies. The study results also reflect that the change from an ostomy to a continent pouch had a dramatic effect on the psyche as one regains control of bodily function, though, it is suggested that significant negative feelings remain even after pouch surgery. The study by Salter (1992) describes expressions of shock, disgust, hate, feelings of embarrassment, abnormality, repulsiveness, devastation, and non acceptance. Participants reported feeling frightened and isolated, particularly as it pertained to their developing sense of sexuality and sexual intimacy. It was also reported that several people felt they were being confronted with society's perceived expectation that one must have a healthy, pleasant appearance as mentioned by Casati et al. (2000).

In studies carried out by Beitz and Rager Zuzelo (2003) and Deeny and McCrea (1991) participants expressed feelings of uncertainty in regard to how to tell people, who to tell and how they would react. Described are feelings of helplessness and grief for the loss of a body part, a feeling of alienation from the body, expressions of loss of control over the body, anxiety, depression, agitation, boredom and surprise over the perceived short length of hospital stay after surgery. Participants in Beitz' (1999) study often used the third person when referring to their bodies and would describe their ostomy as it. In contrast, Lask, Jenkins, Nabarro and Booth (1987) found no evidence that stoma surgery in childhood is psychologically harmful and found no evidence that depression or social isolation commonly occurred. O'Brien 
(1999) and Junkin and Bietz (2005) indicate how, for some, the ostomy is viewed positively. Many look forward to their surgery so they can once again feel better and have a normal chance at life.

\subsubsection{Intimacy and sexuality}

The biological and physical changes that accompany adolescence also bring about an awakening of new feelings toward one's own body. Achieving a sense of intimacy is not just about sexuality but also about the emotional and reciprocal needs within a relationship. Busen (2001) states that for the adolescent, beliefs about body image and social relationships, especially those with the opposite sex, are intense and threats to either may be met with great anxiety. A study by Kelly (1991) revealed sexual relationships were a source of anxiety for some, particularly those who were not married or had no current partner. Erwin-Toth (1999) reported however, that none of the participants in his study felt their ostomy was an issue in their sexual relationships. This was due in part to the lengthy relationships developed prior to beginning any sexual activity. Martinsson et al. (1991) found similar results, with 36 out of 53 participants reporting that their ostomy had no effect at all on their sex life, seven said there had been a positive change and 10 felt that it had a negative effect. It is important to note however that 38 out of the 53 participants were married.

Studies by Beitz (1999), Carlsson, Berglund and Nordgren (1991), and Deeny and McCrea (1991) reported that for women, embarrassment and insecurity related to the stoma was a major concern, whereas for men, impotence was most often revealed as the source of concern. Men who lost the ability to achieve erection through bladder cancer described their partners as the innocent victims of their disease. Findings in a study by Manderson (2005) indicated that some partners have difficulty accepting the ostomy, and are therefore not supportive. Support and understanding from the significant other has been most often revealed as very important in helping to alleviate the fear of intimacy.

\subsubsection{The personal fable}

There are good reasons to believe that adolescence, especially early adolescence, may be a turbulent period. Hall (1904) coined the phrase Storm and Stress that he believed epitomised the experience of psychosocial change in adolescence. The 
phrase is taken from the German Sturm und Drang movement which emphasised the volatile emotional life of the individual. This concept focused on idealism, rebellion against established ways, and the expression of deep passion. The three key aspects of Halls theory are conflict with parents, mood disruptions, and risky behaviour. Hall saw adolescence as the last of four stages of development, the final transitional stage between childhood and adulthood, and the one requiring open rebellion against the established values in order to separate from the parents and become independent.

\subsubsection{Exploratory health behaviours}

"I would there were no age between ten and three-andtwenty, or that youth would sleep out the rest; for there is nothing in the between but getting wenches with child, wronging the ancientry, stealing, fighting”

\section{William Shakespeare}

While many adolescents with chronic illnesses manage their disease and treatment regimens extremely well, Viner (1999) maintains that reduced adherence to medical regimens and poor disease self-management can be seen as developmentally appropriate in adolescence. In addition, Vermeire, Hearnshaw, Van Royen, and Denekens (2001) declare that adherence to a treatment regimen requires appropriate cognitive capacities and personal organisation as well as a personal belief that the treatment is required and beneficial. Kyngas, Kroll and Duffy (2000) assert that young people may have difficulty adhering to treatment regimens devised for them by health professionals and parents because of poorly developed abstract thinking, which may manifest as a relatively poor ability to plan and prepare for different situations using abstract concepts; an immature ability to imagine future consequences; and a concept of themselves as bullet-proof or not vulnerable to the usual rules of life. Together these cognitive issues may mean that the prevention of long-term complications of illness is a poor motivator for compliance. Additionally, adherence may be impaired because of a lack of shared health beliefs and goals with the young person's treating health professionals or family. Or alternatively, health professionals may be exerting parental authority which is rebelled against.

Treatment adherence and chronic illness control can be put at risk by 
developmental needs to explore possible modes of future behaviour, usually derogatively referred to as adolescent risk-taking (Males, 1997; Mischaud, Blum and Ferron, 1998; Ramrakha, Bell, Paul, Dickson, Moffitt, and Caspi, 2007). Much morbidity in young people is generally considered to result from risk-taking, impulsiveness, the rejection of parental values and the testing of boundaries. But the standard conceptions of adolescents as risk-takers with poor future-thinking abilities have been shown to be largely false. Viner and McFarlane (2000) postulate that it is thus more helpful to understand so-called risk-taking behaviours in young people as developmentally-appropriate exploratory behaviours that they may or may not continue as adults.

Atkinson (1997) asserts that some, but not all, adolescents challenge authority or the rules as a means to establish their individuality. Peer relationships are highly revered by adolescents and peer influence, often termed peer pressure can be powerful regarding experimentation with risky behaviours during adolescence. Impatience and impulsiveness frequently affects decision making, and possessing a sense of omnipotence and invulnerability, increases risk taking behaviour. In the realms of developmental psychology, this behaviour is known as the personal fable. According to Elkind (1981), personal fable is the part of adolescent egocentrism involving an adolescent's sense of uniqueness and invincibility. Adolescents often believe that they themselves will never suffer the terrible experiences that can happen to other people. This sense of invincibility is likely involved in the reckless behaviour often exhibited by adolescents.

\subsubsection{All the world's a stage}

All the world's a stage, And all the men and women merely players:

They have their exits and their entrances; And one man in his time plays many parts

\section{William Shakespeare, 1600}

The development of formal operational thought allows adolescents to take the perspective of others and anticipate the reactions of those around them. Elkind (1981) reported that the adolescents' new capacity for perspective-taking is often characterised by the assumption that those around them are as preoccupied with their appearance and behaviours as they are, resulting in the formation of an 
imaginary audience. Santrock (2004) describes the concept as adolescent egocentrism, or heightened self-consciousness known as the imaginary audience. Atkinson (1997) claims that adolescents overestimate their significance to others, resulting in self-consciousness about physical appearance and interpersonal behaviour. Santrock claims that adolescents sense that they are on stage, believing they are the main actors and all others are the audience. Often small embarrassments are seen as enormously traumatic.

Busen (2001) states that the overly self-conscious adolescent may find the scrutiny associated with hospitalisation and surgery overwhelming. The experience of surgery and hospitalisation poses special developmental challenges for adolescents who have increased need for control, privacy and peer interaction. Surgical procedures generally involve dependency on adults, frequent physical examinations, exposure of body parts, and sensitive questions about health history that may be embarrassing to the adolescent. The implications of surgery may be less related to the adolescents physical condition and more related to psychosocial needs such as dealing with pain, separation from peers and significant others, fear of bodily mutilation, and receiving care from strangers. Disruption of normal routine, lack of privacy, lack of mobility, and temporary or permanent disability may also be issues for the adolescent. In examining the compounding effect of the thoughts and feelings discussed in these studies, another dominant theme emerges, this being a considerable sense of losing control.

\subsubsection{Losing control}

The perception of losing of control is also central to the experience of living with an ostomy. Studies undertaken by Brydolf and Segesten (1996) and McVey, Madill and Fielding (2001) report that a number of participants expressed frustration at not being invited or allowed to participate in decision making as regard to their surgery, and subsequently felt isolated and unprepared for the ongoing consequences. This perceived lack of control was said to have resulted in lingering feelings of anger towards health professionals and in the case of children and adolescents, with their parents. The perceived loss of control is said to be exacerbated by the hospital system, the dependency experienced following surgery and in several incidences by seemingly over protective parents, further hindering the ability of the individual to 
manage independently and feel in control.

In many instances the stoma challenged the ability to provide self care along with ordinary activities such as using the bathroom, sleeping, working, engaging in leisure activities and sexuality. Persson and Hellstrom (2002) and Santos and Sawaia (2001) report that frequent absences from school and having to constantly make excuses because of inflexible school rules requiring group showers caused painful childhood memories for more than a few informants. Some also considered the bag as a chastity belt. A majority of informants described choosing clothing to hide the appliance and scars. According to Deeny and McCrea (1991) they avoided certain foods and for those with a urostomy or neobladder they avoided fluids at certain times. Individuals expressed a fear of using the public bathrooms; this was especially evident in men who could not use a urinal. Participants in Beitz' (1999) study that the "desire for control of their bodily functions and the associated freedom from pain and urgency was the overriding impetus for surgery" (p. 191). Similarly, Motta (1987) and O'Brien (1999) found that many individuals afflicted with chronic inflammatory bowel diseases are so ill they actually look forward to having surgery. The attempt to regain a sense of control represents the next major theme revealed in the literature, that of independence and normalcy.

\subsubsection{Independence and normalcy}

Erwin-Toth (1999) and Motta (1987) highlight the importance of being treated as normal and learning self-care soon after surgery. Maintaining a sense of normalcy in life is a key issue. As long as the adolescent could fit in with their peers and maintain everyday activities, they felt normal. Receiving an ostomy was described in a study by Erwin-Toth (1999) as the addition of something to the body whilst paradoxically representing a loss of continence, body boundaries, independence and dignity. This is evident in the experience of one individual whose mother died prior to her surgery and whose father had sheltered her from society and forbade her to care for her own stoma, considering it his responsibility. It was this person who reported the most difficulty in adjusting to her stoma.

Brydolf and Segesten's (1996) study identified the concept of reduced living space; "the sphere one acts within in ones daily life" (p. 42). It includes routine, physical, 
social and cultural activities as well as traditions one has acquired and consider meaningful for living a good life. An example of this is that almost all participants experienced a dependency on being near to a toilet and limited their normal social activity. Studies by Carlsson et al. (2001); Salter (1992), and Thomas, Madden and Jehu (1987) found that most individuals restricted their social and leisure activities significantly as a result of the ostomy. O'Brien (1999) describes how some adolescents are compelled to buy larger clothing to hide the ostomy bag, but this may only exacerbate feelings of alienation and inadequacy. Finding clothes that reflect the style and personality of the individual, yet still conceal the ostomy is very important in maintaining self-esteem and feelings of normalcy.

Erwin-Toth (1999) describes how the inability to participate fully in school was a source of painful memory. When it came to gym class, most were excused from participation even though only two had sufficient medical reasons to be so. In Carlsson et al.'s (2001) study, travelling, going to the movies and theatre was viewed as a great problem for all of the subjects. These limiting behaviours according to Erwin-Toth, result in reduced living space and perceived lack of control.

Wolman, Resnick, Harris, and Blum (1994) studied whether adolescents with and without chronic conditions differed in emotional well-being, worries, concern and body image. Findings revealed that those with chronic conditions had lower feelings of emotional well-being, worried more about dying, school, future work, and had a poorer body image. In contrast, other studies revealed that chronically ill adolescents did not experience increased psychological difficulties. Pless, Cripps, Davies and Wadsworth (1989), in a study which consisted of 5362 children with chronic physical disorders, found that the prognosis for these children was remarkably good. They were shown to have similar chances of marriage and of becoming parents as their healthy counterparts. Throughout the literature there were expressions of frustration with communication between informants and health professionals. Klopp (1990) identified that there seemed to be a lack of opportunity for individuals to express their fears. Also of interest was that one third of subjects were unaware of the type of stoma they had and five percent did not know why they had an ostomy. The literature revealed conflicting findings for the effects of chronic illness on adolescence. Longitudinal research that would allow follow up with adolescents over 
time is needed to understand long term impact on psychological and psychosocial functioning.

An exploratory descriptive study by Reynaud and Meeker (2002) was undertaken to describe the coping styles of older adults following stoma surgery. It is suggested that coping can be enhanced by pre and post operative education and counselling by nurses in order to identify ineffective coping styles, fears concerns and stressors and try to implement more effective methods of coping.

\subsubsection{Thinking about thinking}

I began thinking about why I was thinking what I was. Then I began thinking about why I was thinking about why I was thinking about what I was.

(Santrock, 2004, p. 342)

Adolescence is characterised by rapid transitions in cognitive development, whereby, new levels of intellectual functioning emerge. Michaud, Suris and Viner (2004) maintain that the intellectual maturation that takes place on an inner level for the adolescent is more subtle than biological changes, but just as important. Formal operational thinkers can recognise and identify a problem. Adolescents are thus capable of combining thought processes into self-reflection about vocational goals, personal satisfaction, and social responsibility. Adolescents begin to generate opinions, to examine a situation from a variety of perspectives, to anticipate the consequences of decisions, and to consider the credibility of sources.

Busen (2001) suggests that early adolescents, ages $10-14$, still use concrete thinking and literal interpretation of events and have limited ability to project or anticipate the future. For health professionals, it is important to provide continuous education, communication skills may be lacking and therefore health professionals should look for nonverbal cues. Busen suggests that providing information to groups of early adolescents with similar conditions is particularly useful. Involving peers in teaching or using written or audiovisual material that displays how other adolescents cope with an experience may help decrease anxiety and increase trust. For concrete thinkers the ability to see that others have survived a similar experience is helpful. In order to not to appear weak or childish or admit a fear of injections or dislike of 
swallowing tablets, some adolescents may choose to endure pain rather than ask for medication.

\subsubsection{Identity versus identity confusion}

Erickson (1968) maintains that as the adolescent transcends the journey towards independence and autonomy from parents, they increasingly identify with the culture and norms of their peer group. They assume similar dress codes, styles of communication and behaviour, all of which are dictated by the norms of whichever peer group an adolescent belongs to. Formation of peer relationships is an important task of adolescence, as it provides an environment for the adolescent to challenge personal characteristics, test how others perceive them, and to seek validation of themselves. It facilitates the opportunity for role experimentation, introspection, evaluating and testing one's personal values, morals, and ethics that will define and consolidate their integrated identity. It seems then that an adolescent must face the death of a once-accepted worldview, and as a result of the death of ideals, the adolescent is forced to change and develop. Van Kaam (1969) highlights the need for this living/dying process to occur, he quotes "If I do not die repeatedly I should become capsulated in past forms of life which I have already realised" (p. 64).

During the adolescent decade Peterson, Steinmetz and Wilson (1995) claim that there is a gradual change in the structure of the parent-child relationship, in that the degree of supervision on the part of the parent decreases permitting autonomous functioning on the part of the adolescent. There is an increased emphasis on peer relationships as adolescents begin to spend more time away from the family in extracurricular and social activities. Busen (2001) claims that as middle adolescence is approached, they are less concerned with imaginary audience, and more reality orientated. The real audience or that of their peers takes precedence over the imaginary audience and adult approval. One informant expressed that though he was assured of his family's love, he was concerned about the reaction of potential girlfriends. Busen suggests that conformity to the peer group is of utmost importance.

\subsubsection{Support systems}

Daniel (2001) and Rheaume, and Gooding (1991) maintain that responses to ostomy 
surgery are often dependent on a number of factors such as personality, previous experiences of illness, beliefs and views about their situation, coping mechanisms, and their support networks. Several studies carried out by Bray and Sanders (2006); Brown and Randle (2005); Brydolf and Segesten (1996) and Carlsson et al. (2001) document how individuals stress the importance of having support from family, friends or support groups. Similarly, Erwin-Toth (1999); O’Brien (1999); Salter, 2002, and Shipes (1987) found social support to be fundamental to adaptation as well as their level of self-care. Psychological support and social support from family and significant others especially the mother was reported to be of paramount importance. It was noted, however, that as informants entered adolescence peer approval became more critical than family support.

A cross-sectional study was undertaken by Piwonka and Merino (1999) based on observations of different developmental groups at a single point in time for the purpose of inferring trends over time. The study investigated factors contributing to the postoperative adjustment of patients who had undergone permanent colostomy surgery. More than half of the subjects reported marital problems and low satisfaction with body image. As regard to adolescents, little research exists which investigates the role of family support when adjusting to living with an ostomy. However, the research by Brydolf and Segesten (1996) and McVey et al. (2001), identify areas of caution in regard to the inclusion of the individual in decision making and encouraging independence throughout the illness experience.

\subsubsection{Establishing Autonomy}

During the developmental stage of adolescence, young people strive for independence or autonomy as it is referred to in psychological realms. According to Huebner (2000) some people assume that autonomy refers to becoming completely independent from others. Regression and dependency may occur when adolescents are under stress. Busen (2001) proposes that issues relating to surgery may be threatening to adolescent's sense of control, privacy, peer relations, and body image. Fears related to these issues are not always articulated but may manifest in such behaviours as withdrawal, irritability, and refusal to co-operate with authority figures and hospital protocols. Inadvertently leaving the adolescent out of information gathering and decision-making has the potential to increase dependency and further 
hinder the normal adolescent process of becoming independent. Illness, according to Cepeda (2000) can serve as a constant reminder of vulnerability, deficit, and limitation and may hinder development of independence by creating a feeling of dependency. Adults may treat the adolescent as being dependant and may be overly protective. The natural response by a family is to try to help and protect the affected individual. They may be overlooked as active participants in social and sporting situations resulting in feelings of isolation, alienation, fear and underdeveloped social skills which may persist throughout life.

Sturge, Garralda, Boissin, Dore, and Woo (1997) claim that recurrent illness and the demands of treatment regimens may significantly impact upon school attendance and educational achievement, which in turn may result in vocational impairments and loss of financial independence in adult life. Also, the developmental imperative for educational attainment may affect chronic illness through conflicts of priorities between illness management and schooling requirements

The presence of an adolescent with a chronic condition imposes an increased burden on the parents according to Cadman, Rosenbaum, Boyle and Offord (1991). Eiser and Berrenberg (1995) assert that the demands of managing illness and the restrictions on lifestyle inherent in many disabling conditions increase dependence on the family, and carers, at a time when this should be decreasing. At the same time, Manworren (1996) claims that young people may also become dissociated from their peer group, particularly in those with taxing medical conditions and those that mark them out as very different, for example those with an ileostomy. A common theme according to Brydolf and Segesten (1996), Daniel (2001), and Dudley-Brown (1996), is the expression of fear, embarrassment and humiliation when faced with the potential for or the actual experience of incontinence. Because of disease symptoms and reduced living space, most individuals in Daniel's study felt they had fewer close interpersonal relationships, and that their social interactions were severely restricted. They also described their personal relationships as stressful because they felt they could not discuss their illness socially. As a result, full disclosure to friends was seen as a major obstacle to overcome. Dudley-Brown's research further supports these findings. All participants in this study spoke of a decreased social life and 
difficulty with work or school as a result of their situation.

Given the large range of severity of chronic conditions, as well as differences in measuring family functioning, Blum, Resnick, Nelson, and St. Germaine (1991) maintain that it is not surprising that research findings can be conflicting. Some families cope adequately with this situation while others are overwhelmed by the problems generated by the condition. Most young people with chronic conditions describe the relationship within their family as good, although their parents tend to overprotect them. Studies by Pless, Power and Peckham (1993) and Kokkonen (1995) have suggested that individuals with a chronic condition in adolescence have poorer social outcomes in adult life, face more professional difficulties, are less likely to be married and more likely to be living with parents, in comparison with healthy teenagers. However, these results are based on historical cohorts and modern outcomes may have been enhanced by improved health care and social support.

An important consideration in interpreting these findings is made by Persson and Hellstrom (2002) and McVey et.al (2001). That finding is that a potential influence on the results of these studies is the difference in disease pathology and whether the surgery was planned or urgent. Past research has used sample groups encompassing a variety of different illnesses making findings difficult to interpret. Experiences of people with inflammatory bowel disease for example; who often get relief of symptoms from surgery are different from those with cancer who often have few symptoms prior to surgery, hence the results are confounded.

\subsection{Summary}

There is no single event or boundary line that denotes the end of childhood or the beginning of adolescence. Rather, the passage from childhood into and through adolescence as composed of a set of transitions that unfold gradually and that touch upon many aspects of the individual's behaviour, development, and relationships. These transitions are a part of a metamorphosis involving biological, cognitive, social, and emotional change. The available literature demonstrates significant disturbances in physical and psychological wellbeing because of ostomy surgery. Individuals generally have poor body image and no longer see themselves conforming to a social stereotype that advocates having a perfect, unflawed physical 
body that hides and maintains control over its functions. 


\section{CHAPTER THREE \\ Methodology, Method and Design}

\subsection{Introduction}

This chapter describes the research methodology, method, and design of the study. Here I present the assumptions of the study, its philosophical and theoretical underpinnings, and my rationale for approaching the study using narrative inquiry to inform the methodology. The method section will discuss the research design, data collection, and the analysis process of core story creation and emplotment. Methodological rigour and ethical considerations are also addressed here.

\subsection{The narrative path}

In considering the path to follow in undertaking this research, it was necessary for me to explore my motivation in formulating the research question. This would thereby determine the nature of the information I desired to gather in order to employ a method of inquiry that befitted this. I believe the development of a therapeutic relationship between the nurse and the patient cannot ensue if the nurse possesses little or no comprehension of what the patient is experiencing. Understanding the experiences of patients informs nursing practice, "experience is meaningful and human behaviour is generated from and informed by this meaningfulness" (Polkinghorne, 1988, p. 1). I consider that as nurses we should strive to reach beyond our theoretical knowledge of the patient's journey through illness and endeavour to understand the thoughts, feelings and emotions that are fundamental to the experience.

Nursing as a profession according to Leight (2002), has long voiced a commitment to two epistemological domains; scientifically derived knowledge, or empirics, as well as the expressive, creative, and intuitive application of knowledge; the aesthetics or art of nursing. Healthcare today demands that nurse know two different languages; the language of nursing science with its quantifiable outcomes and distinct terminology, as well as the language of people, replete with experiential observations of health and illness. Hodges (1997) insists that nurses be fluent in each discourse. 
The art of nursing is said by Gillis and Jackson (2002) to lie in aesthetic knowledge, involving perception, understanding, empathy, and intuition and "acknowledges the value of every day experiences lived by individuals" (p. 11). Vezeau (1994) concurs, and proposes that art of narrative is natural to the way that nurses work with people, "nursing is no stranger to narrative; it has always been a part of how we explore the shared world of our patients" (p. 44). Vezeau declares that narrative is intrinsic to the way that people create meaning within the illness experience. Overcash (2004) suggests nurses are well suited to doing narrative research because of their familiarity with the tools that this research adopts such as communicating, listening and interviewing. Nursing is, in this sense, a medium for gathering narrative data. Denning (2004) and Steifen (1997) claim narrative gives a human component to data in a way that assists nurses to relate to situations with empathy.

The narrative approach endeared itself to the aims of this study in that it allows participants the opportunity to share their experiences by telling their own personal stories. McEldowney (2002) describes the telling of one's personal story as

.... conscious act of unfolding, re-membering, and re-discovering past events, that are significant and meaningful. It is a process of re-presenting significant events in a recursive and discursive way. ...The participants become the authors of their own life-story in the telling and re-telling of stories that matter to them. (p. 41)

Adolescents living with an ostomy are a minority group in society and within nursing research, their voices are often not heard or acknowledged. Lincoln and Guba (1985) and Munhall and Oiler (1986), suggest that a descriptive method is appropriate when little is known about a research question and when the focus of a study is to describe the nature of a phenomenon. A descriptive study informed by the principles of narrative inquiry can therefore be considered well suited for this research, as it is congruent with the art of nursing and the aim of the study; to gain a deeper understanding of the meaning of the experiences of adolescents living with an ostomy. The collective voices of these adolescents are silent within the literature and narrative research aims to "give voice to those who are silenced or marginalised" (Richardson, 1990, p. 25). McLaughlin and Tierney (1993) concur that indeed, breaking this silence has been the primary goal of narrative research for several 
decades.

Narrative by definition, according to Redman (2005) is "an account of an individual's experience to make sense of events or actions in their life" (p. 2). Chase (2005) elaborates in saying that through the shaping or ordering of past experience, “narrative is a way of understanding one's own and other's actions, of organising events and objects into a meaningful whole, and of connecting and seeing the consequences of actions over time" (p. 656). Narratives come in numerous forms that Chase claims may be oral or written. Examples include personal and social histories, myths, fairytales, novels, and everyday conversations. Narrative inquiry was initially investigated as a form of research from within the context of the social sciences, it does not have a single heritage or methodology, and has been described by Redwood (1999) as being unclear about its epistemological influences. Priest, Roberts and Woods (2002) claim it draws, among other sources, upon philosophy, anthropology, sociology, psychology, and sociolinguistics. Narrative had until the 1970s, been little regarded by researchers, including those in nursing and healthcare (McLeod, 2001). Since that time, Kelly and Howie (2007) claim there has been an increase in popularity in using narratives as sources of research data. The term narrative is used in many contexts within the realm of qualitative research and is often used interchangeably with the word story (Emden, 1998a; Polkinghorne.1988). Koch (1998) supports the use of the narrative, and advocates story telling as a method for interpretive inquiry.

\subsubsection{Story in nursing research}

Every culture has its fairytales, fables, and oral traditions transmitted from one generation to another. Described more than 2,000 years ago by Aristotle, Redman (2005) contends that the use of stories, or narratives, has been used throughout the ages as a technique to illustrate a moral, to demonstrate how experiences have produced positive or negative outcomes, and to entertain. The premise of the narrative methodology is that individuals are natural storytellers. Lieblich, TuvalMashiach and Zilber (1998) believe that experiences are revealed by stories and that stories provide coherence and continuity to one's experience.

Recent decades have highlighted the benefit of storytelling in the nursing profession 
(Bailey \& Tilley, 2002; Barton, 2004; Leight, 2002; Wood \& Giddings, 2003). Narratives according to Benner (1984) contribute to the science of nursing and define how it is we know what it is we know. When we hear someone's story we have a better understanding of that person as an individual, the experience they have had, and the effect it has had on them (Kelly \& Howie, 2007). This view is shared by Boykin and Schoenhofer (1991) who claim that the use of story in nursing "preserves the integrity of nursing knowledge and enhances understanding and knowledge of nursing" (p. 246). Sandelowski (1991) likewise considers that narratives provide a framework for understanding the person as the subject of nursing inquiry. Boykin and Schoenhofer, state the significance of narrative "lies in its potential for illuminating rather than obscuring the uniqueness, subtlety and depth of nursing knowledge" (p. 245). Heinrich (1992) believes stories have “...the power to inspire, mentor, inform or caution novices, and to validate and honour the practices of more seasoned nurses" (p. 141). Understanding personal narratives in nursing practice is a matter of intuition and art as well as reasoning and science.

\subsubsection{Medicine for the soul}

Gerhart (1990) maintains that narrative data can provide insight into the life of a person outside the examination room, a dimension not often realised health professionals. Research in the field indicates that narrative provides healing within itself, and so has the potential to provide therapeutic effect (Frank, 1995; Hyden, 1997; Pennebaker, 1997; Pennebaker \& Seagal, 1999). By recognising the illness experience, as revealed through the narratives of patients, Gerhart claims this not only creates empathy, but it also keeps the impact of an illness on a person as central to all that a health professional will do. The interaction of a listening nurse with a narrating patient is critical to revealing meaning and to creating new meanings that are necessary to re-envision the story. "Stories are medicine... They have such power; they do not require that we do, be, act anything - we need only listen" (Estes, 1995, p. 14). Estes suggests that by telling their stories, people can express their identity, relationships and emotions. Furthermore, they can orientate life events, in some cases gaining a sense of perspective upon these events, and often solve problems.

Frank (1995) concurs with the belief that telling stories regarding life experiences 
while enduring illness can be therapy, moreover, the illness itself is a call for stories. "Telling stories of illness is the attempt, instigated by the body's disease, to give voice to an experience that medicine cannot describe" (Frank, p. 18). Priest et al. (2002) maintain that communication through telling stories is a natural impulse. Reissman (1990) believes this natural impulse to construct stories helps repair the physical and mental damage that illness has done to the body. Conveying stories through narrative interview can be helpful to the patient by enabling a person to tell an often emotional, stressful account to someone who is an impartial listener such as a nurse researcher in order to provide healing.

Narrative methods offer the ability to give adolescents a voice with which to understand their experiences of learning to live with an ostomy that are not captured by quantitative methods. Narrative "makes individuals, cultures, societies and historical epochs comprehensible as wholes, it humanises time, and allows us to contemplate the effects of our actions and to alter the directions of our lives" (Richardson, 1990, p. 200). Although narrative clearly involves stories, "it is more than a single story...the term embraces the collective stored wisdom of peoples individual stories" (Emden, 1998b, p. 35). Kleinman (1988) suggests that through narratives, nurses and other health professionals "can recognize some of the special concerns-cognitive, affective, moral-that patients bring to their encounters with the events and the career of chronic illness" (p. 233). By giving nurses access to the stored wisdom of adolescents living with an ostomy, narrative research has the potential to provide insight into patient decisions, behaviours, and strategies that are central to the development of holistic nursing care.

\subsection{Rigour in narrative research}

There has been much debate on the matter of rigour in qualitative research. Indicators of rigour developed for the quantitative research paradigm are recognised as invalid for qualitative methods of research. Traditional ideas of validity, reliability, and generalisability arising in many quantitative research projects do not apply in the same way to the narrative. The findings cannot be generalised to other populations or situations, nor do they represent any one truth. Bruner (1991) argues that narratives are a version of reality, and their acceptability governed by convention, rather than quantified evidence. Individual accounts are a representation 
of reality rather than a universal reality, therefore not true or false. Krefting (1991), however, emphasises that just as there is a need to address rigour in quantitative research, there is also a need to look at qualitative data to ensure the quality of the finding.

Lincoln and Guba (1985) propose a model to address issues of rigour in qualitative data based on four aspects of trustworthiness: credibility, confirmability, transferability, and dependability. Trustworthiness in research relates to the methodology, method, research design, and processes having integrity. Credibility, or truth-value reflects an effort to establish confidence that the data had been understood as the narrator had intended. Van Manen (1997) maintains that the essence or nature of an experience has been adequately described if the description reawakens, or shows the significance of the experience. The researcher assures the study findings reflect accurately the experience described by the participants and that these experiences are ascribed meaning that allows for understanding.

Confirmability is achieved if another researcher can confirm the findings of the inquiry. Narrative research is not quantifiable in this way; however, Koch and Harrington (1998) say that confirmability can be achieved through reflexivity, the reflections of the researcher throughout the research. Reflexivity is measured by the degree of transparency of the research process wherein the decisions and actions of the researcher are visible in the reporting. This allows the reader and other researchers to measure the quality of the findings by evaluating the methods used to discover them, essentially providing an audit trail to follow. Transferability refers to the likelihood that the research findings have significance and meaning to others in similar situations and the term dependability encompasses the entire process of establishing credibility of the research, concerned with the stability of the data over time.

To ensure trustworthiness and dependability in this study I have endeavoured to describe and explain the research process with absolute clarity and provide justification for the decisions made and actions taken. Transparency of the process was assisted by keeping a ledger of notes throughout the course of the study. The ledger acted as a kind of informal journal of notes and memos recording thoughts, 
ideas, feedback, and information gathered. The journey to completing this research has been a lengthy one, with waxing and waning bursts of enthusiasm and periods of concentrated effort. When immersed in the research, I would spend endless hours writing and re-writing, encircled by a mountain of paper, often sitting motionless in thought. I found my ledger to be invaluable as a means of recording various thoughts and ideas developed during my conscious and unconscious ponderings over the many months. The journey of this research was periodically interrupted along the way as I battled illnesses within my own life story. The ledger allowed me to return to patterns of thought, regain knowledge and rebuild a weakened memory to reemerse myself within the research after periods of inactivity or illness. I have used the compilation of thoughts in my ledger to assist in the writing of this thesis, thus evidencing reflexivity in my use of reflective comments in my writing.

\subsubsection{Acknowledging two sets of footprints in the sand}

Memories and experiences are grains of sand in the hourglass of time and when communicated through story, Gaydos (2005) claims that they become the experience of two people; the narrator and the listener. The footprints of the participant as the narrator and me as the listener will be visible in the sand that is the story. Narrative research acknowledges that participants' stories become intertwined with and interpreted through the lens of the researchers own personal story. As lives are lived and change, so narratives of lives will change. Reissman (1993) declares "the historical truth of an individual's account is not the primary issue" (p. 64). Bailey and Tilley (2002) assert that it is the reconstruction of meaning, not truth, the researcher wishes to understand. Mischler (1991) proposes that reality at any given time will be different from any other time. Sandelowski (1993) concurs and suggests that elements of a story will change from the telling to the retelling of the events. Thus, any story will be a representation of a particular episode, or moment in time and any later review of the narrative, will by its very nature, engender another narrative. Silverman (2000) states that "by abandoning the attempt to treat respondents accounts as potentially true pictures of reality, we open up for analysis the culturally rich methods through which interviewers and interviewees, in concert, generate plausible accounts of the world" (p. 122).

\subsubsection{Moments in time}


In considering the concept of bounded narratives, that is that a story will change with each retelling, I was mindful of how I would ensure credibility of the data without altering the essence of the stories conveyed at the point of their telling. Koch and Harrington (1998) propose that a "research project not only has the right to assert the interests of those studied but it is unavoidable that our interests are incorporated into the inquiry" (p. 888). Sandelowski argues "research is both a creative and a destructive process...we often inadvertently kill the thing we want to understand in the process. ...The choice is ours: rigour or rigour mortis". (p. 8). McEldowney (2002) claims that in eliciting the stories from the participants I become the interpreter whose task is to translate their stories in a way that speaks to a wider audience. McEldowney used the term "licensing stories" (p. 227) to describe how the researcher becomes the co-author of a story. Ellis and Bochner (2000) propose that "the mode of storytelling is akin to the novel or biography" (p. 744), data is presented in a way that evokes emotion through the power of language that in turn generates meaning.

The participants in this study were offered the opportunity to review the digital audio files and transcripts and make any changes they thought appropriate. Two participants accepted the offer and made no changes to the transcripts. They were primarily concerned with ensuring they had not said anything that could reflect badly on their family, as they did not intend to make any such inferences. The other two participants said they were satisfied with what they said and were happy for me to proceed. I did, however make several further phone calls to one participant, as I was feeling uneasy about reporting some of the data in her interview. I address these issues later in this chapter in considering the ethical aspects of the study.

I realised it was impossible to make the research process transparent without centering myself within the research, that is, declaring my position as the researcher and co-author of the stories. Clandinin and Connelly (1994) suggest that we must "acknowledge the centrality of the researcher's own experience: their own tellings, livings, relivings, and retellings" (p. 418). I have an immense appreciation for the power of language and have read and studied many of history's great novels. The language of descriptive metaphor shapes my personality and I use it every day to communicate and convey knowledge as I feel it can best be understood. My co- 
authorship of these stories is evident in the descriptive, metaphorical language I have used to tell the stories and convey the essence of the experiences as I have interpreted them. I justify the use of metaphor in storytelling and my choice to employ it in the telling of the stories further in the method section of this chapter. The participants were given the opportunity to review the transcripts and make any neccessary changes, which I have discussed in the ethics section. However, I chose not to return the final stories for adjustment so as not to lose their essence by revising parts of it. I felt confident that the stories were accurate representations of the interview data and that I had abided by the participants particular requests to ensure that their families were portrayed in a very positive light as they intended. I remained mindful of the participants vulnerability at all times, and the outcome of this was the co-authored or licensed narratives. "In the final analysis, the work is ours. We have to take responsibility for its truths" (Riessman, 1993, p. 6).

\subsubsection{The many hats we wear}

A further consideration is the possibility of role ambiguity as a nurse and as the researcher. I foresaw that, due to my profession as a nurse, difficulty could arise in separating my role of researcher from my role as a clinician. What Silverman (2000) suggests may be difficult, is stepping back from the role as nurse and into the role of researcher. That is, not performing nursing interventions in response to the problems put forth in a person's story. To intervene while interviewing could influence the credibility of the data, as it would change the participants experience and therefore the data. Silverman advocates that distinctions and boundaries that deal with nurse versus researcher may be blurred, particularly if the research participant has known the nurse researcher in the earlier nurse role.

Two of the participants in this study were previously known to me in my role as a nurse. I address the issues surrounding this in a discussion of the ethical considerations later in this chapter. On reflection, though I was not deeply involved in their care on those occasions, I must acknowledge that elements of their life story that I witnessed at that time may have shaped, in some way, the understandings I have come to in this study. In creating the stories, the main source of data was the verbatim transcripts of the interviews and my field notes recording observations and reflections on those interviews. However, my interpretation and illustration of the 
meaning of their experiences in these stories cannot be ignorant of this prior knowledge. Little often in life are the boundaries of moments in time clear, but by acknowledging these blurred boundaries I add justification to my findings in this study.

\subsection{Method and design}

This study set out to answer the question, what is the experience of adolescents living with an ostomy? The purpose of the study is to describe the experience of being an adolescent living with an ostomy by presenting and exploring their stories. The objective is to address the knowledge gap in relation to the experiences of adolescents living with an ostomy. By describing the characteristics and meanings these individuals assign to their experiences, I hope to provide insight into how the experience affects the individuals in the transition phase from childhood into adulthood known in the western culture as adolescence. Inferences may then be made for future research based on the results of this study.

\subsubsection{Assumptions}

The major assumptions of this study were that every person has a story to tell and that stories are creatively authored by participants. There is no single absolute truth in human reality, narratives are subjective, and therefore there is no single correct reading and interpretation (Lieblich, et al., 1998, p. 5). Meanings given to experiences can be rigidly held open to modification over time (Riessman, 1993).

\subsubsection{Selection criteria}

A purposive sample of four participants were recruited for the study. In considering the size and scope of the study, it was determined, that four research participants would generate enough data from which to develop a discussion. In the first instance, the requirement for inclusion was that the participants had experience of living with an ostomy during adolescence, and that they were willing and able to share their interpretation of that experience. For the purposes of the study, I deemed it necessary to create clear parameters concerning the period of adolescence. I have therefore, stipulated adolescence to be between the ages of 12 and 19. I chose this age group because it represents the traditional early, middle, and late adolescent years detailed by Whaley and Wong (1996). 
The second and final requirement of participants relates to the nature of the study. The investigation intended to focus on the memories, thoughts, and feelings of the adult reflecting on their adolescent experience. The purpose of this approach is to gain a thoughtful, retrospective look at the experience and avoids the legal implications surrounding consent and entering into a contract. I have stipulated that participants be aged between 18 and 35 years to ensure that the subjects are adult and that the ability to recall the experience is not affected greatly by memory. I acknowledge that other variables including gender, diagnosis, form of stoma, age at which the stoma was formed and whether the participant had the stoma reversed may have influence on the individual experience. However, whilst these factors may have influence, the size and scope of this study precludes a thorough investigation of their effect. The consideration of this reality is reflected in the selection of narrative as the methodology for this study. Instead, the aim of this study is to capture four individual experiences and examine them for what they entail within themselves.

\subsubsection{Recruitment}

A search for eligible participants was made by means of the regional Stomatherapist to whom it was requested to circulate a letter (Appendix A) inviting study participants to persons fitting the inclusion criteria set out. This method I regarded to be the least intrusive, avoiding the potential for participants to feel coerced into taking part in the study. An information package (Appendix C) was then distributed by the Stomatherapist to those expressing interest. Permission was given to forward contact details to the principal investigator to ascertaining willingness to participate. A period of seven days was given prior to phone contact to allow sufficient time for the information to be absorbed. An initial phone call was made to each interested individual to discuss the purpose of the study, the nature of the interviews and the time requirements. The respondants were encouraged to ask questions and express any concerns. A time and place to meet for further discussion in person was arranged if the respondent was willing to proceed. Further discussion took place at this meeting and written consent to participation in the study was requested upon agreement to be interviewed.

\subsubsection{Data collection}

Data collection utilised semi-structured interview, allowing each story to unfold 
within the context of conversation. Atkinson and Silverman (1997) maintain that narrative data are usually derived by asking open-ended questions, which can be a part of structured or semi-structured interview. The open-ended, semi-structured interview offers the opportunity according to Atkinson and Silverman, for "an authentic gaze into the soul of another" (p. 305). They conclude that research cannot provide a mirror reflection of an experience, but it may provide access to the meanings that people attribute to their experiences and social worlds. In order to bring forth the narratives each participant was invited to tell the story of their experience. This was achieved through the use of the following open ended question:

"Please describe your experience of living with an ostomy as an adolescent. Include anything that you think would help me to understand what it is like to be an adolescent with an ostomy"

I undertook two practice interviews with colleagues, and it became apparent that the unstructured approach to interviewing would be problematic. My male colleague would often stop and wait to be prompted, or asked what other things he should talk about. My female colleague kept the flow of conversation well, but also asked for prompting questions. On reflection, I feel that as a novice at formal interview, I was not perhaps so adept at the interview process. To overcome this I decided to use semi-structured interview where I employed prompting or probing questions to keep the narrative flowing. An interview guideline (Appendix E) aided the flow of the narrative and ensured exhaustive exploration of the experience. The participant was asked to address changes in social situation, school and work life, how or if they told friends, concerns about socialisation and reaction of friends, altered body image, and expectations for the future.

I discovered that the male participants' responded well to the slightly more structured approach and was pleasantly surprised that the interviews flowed with ease and produced some very descriptive data. With the two female participants I had little difficulty keeping the flow of the interview going. Digital audio files of the interviews were transcribed by a person skilled in the transcription process. In the follow-up phone call, participants were offered the opportunity to review the digital audio and transcription. A letter of thanks was sent to each participant following the interviews and a koha was made in the form of a book or fuel voucher previously 
selected by the participant.

\subsection{Data analysis}

The analysis strategy for this research has been adapted from several recognised narrative sources (Dollard, 1949; Emden, 1998a, 1998b; Goodfellow, 1997; Lieblich et al., 1998; Polkinghorne, 1995; Reissman, 1993). Riessman maintains that within any story, a beginning, middle and end can be identified. Furthermore, a plot or core story, in other words, the main point or meaning that the teller wishes to convey, can be determined. I have adapted Australian Nursing scholar Carolyn Emden's (1998b) analysis strategy of core story creation and emplotment. Core story creation is a means of reducing stories to shorter, more concentrated ones in such a way that no key meanings are lost. As with any story, there are plots and subplots, key characters and events. The process of working with plots and sub-plots to unfold the significance of the women's stories is termed emplotment (Emden, 1998b; Polkinghorne, 1988). The procedure described by Emden involves the following steps. First, the text is read several times. Interviewer questions and comments are deleted, as are words that detract from the key idea of each sentence or group of sentences. The remaining text is read for sense, and any further detracting words or phrases deleted. The content was checked for any information that might identify the participants. This procedure was repeated as often as necessary until fragments of themes (sub-plots) remained. These sub-plots were then moved together to create a coherent core story.

\subsubsection{Connecting with the participant's stories}

The interview transcripts were read whilst listening to the digital audio recordings for the purpose of reconnecting with the participant's stories. Features of discourse such as pauses, inflection, and silence, according to Jack (1991), provide context that can be essential to interpretation and were therefore incorporated into the written text. Jack describes this as attending to meta-statements, whereby, the researcher tunes in to the storyteller's stops and pauses in the narrative and reflects on what is disclosed. For example if there was a pause in the conversation, the word pause was put in parentheses; if there was a silence in the conversation, the word silence was put in parentheses. The transcripts were then re-read several times to facilitate immersion in the data. Statements that appeared to be particularly revealing about 
the experience were highlighted. Brackets were put around text that did not relate to the research question. Because there was very little transcribed text that did not relate to the research question, the majority of the text was used for analysis.

\subsubsection{The embodied nature of the individual}

Consideration is given to what Polkinghorne (1995) describes as the "embodied nature" (p. 17) of the individual, including factors that may influence their personal goals and life concerns, such as the influence of significant others. Polkinghorne proposes that the researcher consider contextual features described by Dollard (1949), including cultural context, values, beliefs, social rules, and meaning systems. Dollard used as a tool for assessing life history, Polkinghorne suggests these contextual features serve to provide an alternative perspective, increase familiarity with the data, and to deepen understanding of the participant's meanings inherent in the data. I chose to use these features as a lens through which to view the data and guide to developing the narrative.

\subsubsection{Chronological ordering of events}

Dollard (1949) maintains that the data sit within a "bounded temporal period, being that it needs a beginning, middle, and end" (p. 17). The transcripts were re-read with the contextual features in mind and portions of the text that related to these were highlighted in pink. A summary of my reflections of how the data related was made alongside the text in the margin of the transcript. Polkinghorne (1995) maintains that a story requires data elements to be arranged chronologically. This involved attending to the data using a framework of headings relevant to before, during, and after certain key events in the story. This stage of the technique was supported by the interview technique, where the participant was invited to discuss experiences under respective time markers. Subsequently, many of the transcription data were in chronological order; however some were not. Within the context of each individual's interview, the participants responses did move outside of these time markers. Creating a chronological order of events and experiences was achieved using the chronological headings as an organising template. The transcripts were re-read and, with further highlighter pens, the data was colour coded with regard to the time period to which it belonged. The colour coded segments were then cut and pasted in electronic copy of the transcript under headings relevant to each chronological 
marker. This produces a new, chronologically reconfigured document.

\subsubsection{Metaphor as a tool in narrative}

As previously mentioned in this chapter, I chose to approach the telling of the stories using descriptive metaphorical language to illustrate meaning within the stories. Richardson (2000) refers to metaphor in qualitative research as "a literary device, the backbone of social science writing" (p. 926). The word metaphor, according to Hawkes (1972) is derived from the Greek word metaphora, meaning 'to carry over', and refers to a linguistic process in which "aspects of one object are carried over or transferred to another object, so that the second object is spoken about as if it were the first" (p. 1). Hawkes says that the effect of metaphor used properly "is that by combining the familiar with the unfamiliar, it adds charm and distinction, to clarity" (p. 9). Lakoff and Johnson's (1980) view is that metaphoric language holds clues to the hidden subtexts in theoretical writing. In this sense, the metaphor can act as an explanatory device.

Metaphoric language is also an important feature of Te Reo Maori and Pacific languages (Drewery and Bird, 2004). Polkinghorne (1988) maintains that language is one of the primary tools used to communicate people's stories and influences how the individual sees the world. Lakoff and Johnson (1980) believe that metaphor is a key element of narrative, because the metaphors indicate the underlying thought processes of the individual. Therefore, the relationship of metaphor to language is central to narrative theory. Coffey and Atkinson (1996) claim that "metaphorical imagery can provide a useful way of thinking about and interpreting textual data" (p. 85). In its simplest form, a metaphor illustrates a likeness, or conversely, a dissimilarity of two terms. Coffey and Atkinson claim that the way in which metaphors are used and understood reveals "shared understandings and situated realities of the social group, revealing common knowledge" (p. 86).

This view is shared by Clandinin and Connelly (2000), they note that researchers use metaphor to help them think about their work. Metaphor is used to develop theory and guide analysis; communicate insights, and describe an experience to gain a greater understanding of it. Personal narratives, as described by Polkinghorne, contain figures of speech, metaphor, simile, and other linguistic devices used to filter 
and organise the personal story. I believe the importance of metaphor in uncovering meaning in a story is enormous. The imaginations ability to create and understand metaphor is universal, through metaphor, something is understood in terms of something else. I

\subsubsection{Emplotment}

Emden (1998b) describes emplotment as the process involved in making sense of the story. The emplotment process of narrative analysis has similarities to the thematic analysis proposed in phenomenology; the plot in narrative analysis is a similar concept to a theme (Emden, 1998a). The process requires the identification of one or more plots (themes or main points) or plotting as Polkinghorne (1988) suggests. The stories were examined for the specific purpose of making connections between the events described by the participant and the derivation of themes by the researcher. Coloured post-it markers were used to identify the various themes and fragments of constituent themes (sub-plots) which were then clustered together diagrammatically, linking events and influences to subsequent outcomes, thus, serving to provide visual clarity. Finally, the text highlighted under each theme was used descriptively to formulate a picture of the theme that spoke of each individual's experience. Each group of themes were given a heading depicting the major theme within which each sub-theme was positioned. This process resulted in the creation of four core stories.

\subsubsection{Collective wisdom}

I was hesitant to begin comparing the themes in each interview, for fear of somehow detracting from their powerful stories. I began looking for commonalities and differences, and identifying any themes shared collectively, or experienced singularly in a way I considered would be meaningful to others in a similar situation. With the themes identified, then began the process of illustrating the themes and describing how they are interrelated. Rewriting continued until it was felt that the themes and the relationship between the themes were captured as accurately as possible. The finding of the data analysis process presents the collective wisdom contained in each of the four stories. I chose to give each theme a descriptive title rich in metaphor, not only to enhance its impact to the reader, but also to further illustrate my own interpretation of the experiences as they were told to me. The themes are illustrated using quotes from the transcriptions, and discussed with 
reference to the literature in chapter seven.

\subsection{Ethical issues in the research}

Ethical approval was granted by the Victoria University of Wellington Human Ethics committee and the Central Regional Ethics Committee where final approval was granted to actively begin the research (Appendix F). The application was returned in order to make some minor amendments in wording as requested by the committee. The ethical aspects of this study involved entering into a relationship with the participants of the study, and therefore required accountability and responsibility. Newton (1995) claims goodness criteria emerge for the qualitative inquirer, such as considering the participants' rights, interests and sensitivities; communicating research aims; protecting the privacy of participants; not exploiting participants; and making written material available. The participants were invited to have a support person with them during the interviews, which one participant, Mark, chose to do. I think the support of his wife made him more at ease in telling his story.

\subsubsection{Vulnerability of the participants}

Vulnerability of the participants is an important ethical issue and one of my principal concerns as a researcher. Gillis and Jackson (2002) identify several concepts; autonomy, dignity, uniqueness, and freedom and choice which are inherent in protecting the vulnerability of the participant. Participants have the right to make autonomous decisions free from undue pressure or coercion by the researcher. As a researcher my duty involved providing the participants with enough information to make an informed choice and to ensure that they comprehend the implications of these choices. Those individuals expressing a willingness to participate in the study were given a verbal explanation of the purpose and process of study and invited to ask questions at this time. This was carried out during the initial contact phone call or at an information meeting held at the request of the participant. At this time they were given the option of proceeding or taking a further two weeks to consider if they wished to proceed. This process was designed to protect the vulnerability of the potential participants, offering ongoing opportunity for withdrawal. Those that wished to proceed at this point were requested to give written consent. The consent form (Appendix B) details the title of the study, personnel involved, statement of the study's purpose, procedures, duration and requirements as well as how the 
information is to be used or reported. Participants were advised that at any time during the interview they had the right to pause the recorder and, if desired withdrawal from the study at any time without prejudice.

\subsubsection{Minimisation of harm}

The concept of beneficence is described by Gillis and Jackson (2002) as the researcher's duty to "promote or do good" (p. 332). The concept of nonmaleficence denotes the obligation to "not inflict harm, either emotional or physical" (p. 332). It is the responsibility of the researcher to minimise risk and maximise benefit to participants. The risks and benefits of the study to the participant were detailed in the information sheets and discussed with the participants in person prior to obtaining consent to proceed. During the consent process the participants were informed of the possible psychological and emotional risks that may arise in discussing topics or disclosing personal experiences which may be sensitive in nature. As the researcher, I gave assurance of my sensibility to any discomfort and readiness to offer emotional support. It was my intention to stop the interview if necessary, for reasons such as overt or non verbal signs of anxiety, increasing reluctance to reply, or inability to answer questions. The participants were also assured that access to support and counselling would be provided at no cost should the interview may raise matters which are upsetting or which may require further help. Interviews were conducted at a time mutually convenient to the participant and myself at a venue of the participants' choice. One interview was conducted with each of the four participants, each of approximately 60 to 90 minutes duration. All participants were contacted one week following the interview, to check for any adverse effects from the interview and remind them of the availability of counselling and contact with the research supervisor.

One participant voiced some very tragic and negative experiences in relation to aspects of her community health care over many years, and I wanted to discuss the implications of my reporting these considering her vocation. We talked about this for a while and she made it clear that she wished for me to report her experienced as she had been open with her feelings to those involved. I assured her that I would not depict those negative experiences in anyway that would identify specific persons, and that I would not infer generalisations toward practices today. In fact, two 
Stomatherapists contacted this participant on my behalf, and mentioned that they were aware of her grievances with the service in the past. They expressed that they wanted her to have the opportunity to tell her story to help them understand it from her viewpoint and use the knowledge to educate new nurses using this example. I was relieved after these conversations, and after discussing it with my supervisor I was comfortable to tell the story unedited.

\subsubsection{Privacy and Confidentiality}

In the ethics application for this study, I stated that the possibility existed that one or more of the participants would be known to me. During the recruitment process, respondents were made aware of this in an important disclaimer stipulated in the information sheet. During my initial contact with respondents I discussed the probability that I may have at one time shared a nurse/patient relationship with them or may do so in the future. Owing to this circumstance, the potential to achieve anonymity would not be a possibility. New Zealand is a small nation from which to recruit participants from a population ratio of $1: 750$, so the risk of identifying a participant, even when using a pseudonym, or revealing their identity, is high. I ensured that this was understood fully before any consent process was entered into.

Privacy and confidentiality were observed through the use of data coding. Tapes, discs and transcripts were labelled with a number and pseudonym and are stored in a locked filing cabinet and any identifying information within the data was omitted or assigned a pseudonym. The data was viewed by my academic supervisor and myself only, and the transcriber was required to sign a confidentiality agreement (Appendix D). I ensured that no identifying material, including; geographical location, names of institutions, employers, colleagues, family and friends, and intimate, personal and professional information was present. In order to adhere to this, I have not given a demographic profile of the study participants, as this would likely identify them. The four participants understood that identifiability would be a possibility in a study of this kind. Each agreed to continue with this in mind, satisfied with the measures employed to preserve confidentiality. During the follow-up phone call after the interviews, I again addressed the issue of identifiability and repeated the offer to review the audio and transcripts. This offer was accepted by two of the participants. They did not wish to omit or erase any of the data and accepted that the transcripts 
were a true and accurate depiction of their experience. Their primary concern was that they had not inferred any ill feeling toward their families. I discussed one particular interview transcript with my supervisor as I was uneasy about presenting findings which would put certain persons or groups of people in a negative light. This was primarily due to protecting the participant from harm as a result of being identifiable in this study. I had a further discussion with this participant, who reaffirmed that the views expressed could be presented and that is was their particular wish. The participant did not feel at risk of harm as the views were known and acknowledged by the person or persons concerned.

\subsubsection{Management of risk}

Earlier in the chapter I began a discussion about managing my dual roles as a researcher and a nurse and the fact that two of the participants were known to me in my role as a nurse. I considered carefully, the positive and negative possibilities that could ensue. Role ambiguity was a central issue as I have mentioned. I concluded that to manage this, issues or difficulties a person may verbalise during their account would be addressed through their designated healthcare provider and not taken on by myself as the researcher. Silverman (2000) maintains that wherein a participant considers the researcher a person who can influence or make changes in the healthcare process, the data may be presented differently. Distinction may be blurred, particularly if the research participant has known the nurse researcher in an earlier nursing role as a patient.

Distinctions and boundaries in regard to myself as a nurse versus myself as a researcher were established prior to obtaining informed consent. Clarification was given as to my role as a researcher and the participants verbalised their understanding. I made every effort to be consciously aware of not interjecting or making comment in the role of a clinician. The positive aspect of this situation were that a trust relationship had already been established in the past with these two participants and I felt that they were more at ease talking to me. I believe this was not only because I was a familiar face, but also because I was a nurse. All of the participants had had extensive interactions with nurses in the past, and it is nurses to whom they have revealed things most intimate and private. A nurses is viewed as trustworthy, someone who aims to do no harm. I believe that the unique dual role did 
indeed create an instant trust and rapport. 


\section{CHAPTER FOUR \\ Once upon a time}

\subsection{Out of the darkness: Jame's Story}

At the age of 12 as James prepared to embark upon his journey through adolescence, the shadow of an unknown foe began to emerge. This shadow became ever more present as the days unfolded, dimming the light on his path to adulthood a little more with each passing day. As a proverbial monster slowly emerged from the depths, James became ever more shrouded by the growing shadow that would soon engulf him and plunge his adolescent journey into darkness.

James developed an anal fistula at 12 years of age whereupon suspicions were raised as to the identity of that unknown enemy hiding in the shadows. This was the first of many investigations James would undergo. A colonoscopy two years later confirmed what had been feared, the monster bearing over him had a name...Crohns Disease. James was forced to lift his gaze toward the shadow he had been avoiding, to look into the eyes of his oppressor and acknowledge its presence. He had a disease...but why, why did he have to have it, other people got diseases, old people...not him, not now. What was it, how did he get it, and why couldn't the doctors just do something to fix it. Why?... disbelief...denial.

It had only been a couple of years and I'd been on prednisone a lot of the time and that wasn't, you know, at that time so severe I guess.

James' specialist conveyed to him and his parents the full gravity of what was upon him, the likely unfavourable prognosis, and the probability that surgery would be required in the very near future.

The doctor said, "Oh you're going to have to get an ostomy you know," but that was when I was 14 and it was heck no! What are you talking about, you know, there was no way I was going to get it done back then...no way.

As the months passed by James pressed on through his adolescent journey, constantly battling to keep the monster; the Crohns, at bay. The pain, James grimaces, lowering his eyes, slowly shaking his head as he describes the memory, 
That was agony, you know, sometimes, you're walking in the street and you get it, this...this pain, and you can't really stop in the middle of the street sort of holding your stomach so you have to really grin and bear it.

His face contorted with a look of physical pain, James continues, reliving the memory as he retells it. Sometimes it was just unbearable and I'd just stop, you know, just stop and give in to the pain...curl up in agony. James pain was relentless, indiscriminately interrupting his days and his nights with suffering.

I would wake up during the night constantly, even if I was so exhausted, this gripping pain would drag me from my sleep. I missed a lot of fifth form, especially for the first and second spell because I needed to get control over it to function.

The colonoscopy performed on James showed that his Crohns disease was predominantly the colitis form; inflamation and severe ulceration. Most of his colon, or large bowel was affected by this colitis, with extensive involvement of the terminal ileum; the junction between the small and large bowel commonly affected by the disease. As well as the standard treatments; Prednisone, a synthetic corticosteroid; Azathioprine, an immunosuppressant; Mesalazine, an antiinflammatory drug used to treat inflammation of the digestive tract; and antibiotics, James was also able to access a relatively new treatment; Infliximab, a drug used to treat autoimmune disorders. Each dose cost several thousand dollars and was initially funded through a compassionate use programme and then by Jame's parents who paid personally for the medication in desperate hope it would help their son. James received infusions of Infliximab and also Methotrexate, a drug used in chemotherapy and to treat autoimmune diseases, four times during exacerbations of his disease, until sadly no further doses would be approved.

I was having Infliximab which made everything fine, as good as gold, but they had a six month ban on it, or something, and it was starting to wear off and I was completely to the point where no drugs were helping and it was either that or nothing pretty much.

After three years of sleepless nights and terrible pain, the disease had worn James 
down, I just sort of said to myself okay just do it, I can't be bothered with it any more, you know. James underwent surgery at age 17 and a diverting loop ileostomy was created. An upper endoscopy also revealed small bowel disease and involvement of his oesophagus which was painfully inflamed.

Initially it was quite scary, mainly because it [the stoma bag] was full and it was gigantic. I thought I hope it goes down because it's so huge. But, you know, at the time it was sort of like I had to get it done and it did make me feel initially so much better even though it was strange having it there. I wasn't sure what the future was going to be at the time, so it was more relief than anything.

James enjoys a very close relationship with his family, his mother especially, provided a lot of hands on support and guidance when James first got his stoma.

Mum, she used to help me do it [change the stoma bag] in the beginning because it would pretty much always go during a change, you know, and you'd need someone to catch it before it happened. I suppose it sounds a bit weird, being 17 and having your mum do that kind of thing, but, when you're really sick and all your energy is just drained, I don't think it's worth being stubborn and not accepting help. It's like everyone says, sort of thing, your dignity kind of gets left at the door.

At the time James had his stoma created, there was something else also playing on his mind.

I had just started going out with my girlfriend and yeah, I was a bit nervous about that, but she was really good about it all, she was great in fact. I can't say I've had any problems with the stoma affecting my relationship, she's been really accepting of the whole situation. I suppose to some degree that was because she was there from the beginning, when I was having all of the problems, I guess". I suppose it would have been more difficult if I met her after the surgery, I mean the scars aren't really a problem, for a guy, they're just like battle wounds you can show off. The bag though, the bag would be hard to explain because it's not really normal is it. I suppose I'd be afraid 
that she'd be grossed out, the whole rejection thing, i'm so glad it happened the way it did for me.

Even the usual incidents and sometimes chaos the bag causes don't seem to bother her too much. One time, I was getting changed and and I don't know what happened, it [the bag] just built up and it just went wooshh! exploded out like a projectile and it went all over her and all over me and she was just pissing herself laughing, she didn't care. I was the one getting angry and upset about it you know and she was just laughing her head off, she thought it was hilarious. She's always been good and sometimes if i'm a bit stuck and need an extra hand she helps me change it [the bag], she doesn't mind at all.

After the surgery James found that having the stoma gave him back some of the freedom he had forsaken long ago. The perceived burden of having an ostomy lessened in his mind when he recounted days gone past.

The seventh form wasn't too bad because I'd just had it done and that was probably one of the better times. It was easier once I had the stoma because I had had so many problems with my bowel at that stage, the bag meant that I could go [to the bathroom] more discreetly where before it was like, well if I didn't go I would need to rush and could have a mess. If I had to choose, I'd say probably living with a diseased bowel is far worse than living with an ostomy, definitely. I mean, the fact that it made me feel so much better made it easier to accept I think, whereas if it hadn't made much difference I would have been more frustrated.

Living with his stoma did still harbour some unpredictability, almost always at the most inopportune times. The seventh Form ball will always stick firmly in his memory, and Murphy's Law is now a phrase often cited by James.

The night I went to go to the ball, the seventh form ball, it (the stoma) prolapsed and it was just like...great...it had to happen tonight, Murphy's law and all that. I was panicking, and ringing people, and, you know, I just wanted to know what's going on here!? I was really freaked out about it but, eventually, the stoma nurse came and put ice on it and I lay down 'til it went 
back in. In the end I went to the ball, but I'll never forget that aye, always at the worst possible time.

These little incidents often necessitated James making a hasty beeline for the bathroom with his trusty just in case supplies.

Sometimes I feel a bit weird because of the amount of time I'd be in the bathroom, to someone else it's really a strange amount of time you know, people would say what's going on? That's why most of the time I'd just try and get it out up front with people, as soon as I could. I have no problems telling people about things like that because, you know, once they know then you can just get on with it and don't have to worry about it. I remember one time I was up in Auckland and I had this card game and it leaked. I sort of went guys, it was about five of my friends that were playing this card game with me, and I just went if you're not too squeamish or whatever you know, just come in the bathroom and see what an ostomy looks like. They all looked in the bathroom and were like, hmm..., okay pretty strange, you know and walked out, that was funny, a useful parlour trick. I did the same thing with my sister's boyfriend, I don't mind at all if people see it, it helps them understand it a bit more and you don't get an inquisition every time you spend ages in the bathroom.

After finishing his seventh form year, James travelled with his girlfriend to begin the obligatory student experience in the dormitories at University.

It was kind of bad going there because you couldn't just change it [the bag] when you wanted to because of classes and things. I mean it's ok explaining everything to people who know you and see you all the time because it's just easier that way, but out there in the wide world it's different. There are a lot of people in a place like that, a lot of people looking at you, making judgements and you can't explain the whole thing to every person you meet. I mean, everyone just wants to fit in and be normal, you know, and you don't want all these rumours that get exaggerated going around about you when you can't set them straight. I just wanted to travel under the radar and do my thing like everyone else, and not walk around with a big sign on my back that 
says I have a bag. I felt really like I had no control of things, I need to know that I can go and deal with things if I need to aye, and down there I didn't. Sometimes during the day I wouldn't know when it [the bag] was going to go, and if I'd eaten a certain amount of time before or if I had something that didn't agree with me it was bound to go during class. It was really stressful especially if I had a leak, everyone's eyes are on you if you have to interrupt and excuse yourself. I was just completely out of my comfort zone in that kind of environment, no control there at all. I think, yeah I guess for the most part it [the stoma] made a reasonable impact on my study which does affect my career goals. That time at Uni was probably one of reasons I was keen to get the stoma reversed, I sort of got the impression that the Crohns was improved because I felt so much better.

James had his ileostomy reversed 18 months after the initial surgery in which it was created. He was so glad to be back on the straight path he was up out of bed and off to the movies with his friends within a day or so of the surgery. Unfortunately, within a few short months the light on his path had dimmed once more. He was, however, determined not to stray from his path and struggled on into the darkness where, inevitably, he began to lose his way.

I didn't have a choice about surgery the next time, I was so sick by that stage that they couldn't even actually do it because of the condition I was in, you know. I wasn't strong enough to have the surgery so thay had to feed me through the drip. I weighed 37 kilograms or something, I suppose I just ignored the disease flaring up again because I didn't want to know, I just stopped really eating anything to try and control it. There was no choice there, when I finally saw my doctor again he was pretty shocked at my condition. I didn't really want an ostomy again but it had to be done or they told me I would just die. My parents always wanted me to do the things that I wanted to do, they would always talk to me about things afterwards, you know, because they were older and understood things from a different perspective, but I was always allowed to make my own decisions. This time, though, I was really, really, really sick and probably dying and I was just didn't care anymore, I didn't care if I didn't wake up. Mum and Dad just 
said this is the end of it, you're going to have the surgery, they didn't want me to die. I think I needed at that time for them to take control because I'd lost all control, the disease had taken over my body and I was just numb.

James was hospitalised and received intravenous nutrition until he was strong enough to undergo surgery. The ileostomy was formed for a second time. For me it was back to the bag again, nothing changed at all you know, I had dealt with it all before. It took many months for James to recover from the grave physical condition he was in at that time. Further investigations after this surgery revealed that not only had the Crohns disease not improved, it had deteriorated markedly. The only option to prevent his health further declining was radical surgery. James underwent an elective total colectomy and formation of an end ileostomy, where his large bowel and some of the small bowel was completely removed leaving only a small stump of the rectum behind. This time the stoma was permanent, the option of having a continent pouch formed was entertained, however, the nature of the disease was likely to mean that this would also become affected. Today James still has his stoma and is looking positively toward the future.

If a new treatment or surgery was discovered, of course, i'd give it a go. At the end of the day if it didn't work I'd just go back, but I don't sit and hope for it sort of thing, better to just move on and keep going.

There are still things, aspects of James's life that are affected by having the stoma, things he reflects upon often.

I used to play soccer and other things like that, and I know I could probably protect it [the stoma] but I don't want to risk getting hit or the bag exploding or something so I flagged that. It's a bit sad but that's life. Even with the stoma I still get flare ups and find it hard to eat, that's the only frustrating thing is that I've had all of this stuff done and just sometimes I wish I could catch a break. I mean I wouldn't mind being able to put on a bit more weight because I hate being this ridiculously skinny. It does really affect my energy and concentration, and looking back I suppose it could have affected my studies to some degree. I can't say if I would have done better without Crohns or without the stoma, I don't know that. But sometimes it's 
like, oh maybe if it hadn't happened I would have been able to do better at school and do all the things I used to like doing. I haven't been swimming since I was in the seventh form, and I hadn't realised until recently, that I had been avoiding it. It's just that the bag sticks out and I hate getting it wet because it's really uncomfortable and you can't dry it [the bag] properly. I was actually thinking about giving swimming a go again, I used to swim a lot and I enjoyed it so maybe i'll give it a try.

James experienced many trials during his adolescence, but amazingly, he overcame them all and can look back on his journey positively. His journey is what has made him who he is today, if he had not taken the path that he did, he would possibly be another person entirely. James is happy being the person that he is and goes forth still on his journey in life, though he holds his own light now to shine on his path, lest he get lost again when the light dims. 


\subsection{Through the looking glass: Hope's Story}

At six years of age, Hope began to experience problems with her bowel and bladder. Troubled by constipation and difficulty passing urine, her parents took her to see a doctor, and then another, and then another. I went to heaps of doctors and none of them knew what was wrong with me. Eventually a specialist diagnosed Hope with Spina Bifida Occulta. Occulta, Latin for hidden, is one of the mildest forms of Spina Bifida. In Occulta there is no opening of the back, but the outer part of some of the vertebrae are not completely closed. Many people with the mildest form of this type of Spina Bifida do not even know they have it, or symptoms do not appear until later in life. Up until that time Hope had not displayed any symptoms of the condition. The specialist advised that she needed to have an ostomy, and so at age seven, a loop colostomy formed.

I remember before I went in [to the operating theatre] they drew on me with a red vivid and showed me what it [the stoma] would look like, I was so young I really didn't know what was going on. They told me I would have a bag there and I was thinking like a plastic shopping bag or something. I remember looking at it [the stoma] after the surgery, but then I didn't really understand that this thing was part of me, it was just a bag on my tummy. Mum looked after the bag at first, but after a while I learned to do it by myself. I saw an ostomy nurse when I first got the stoma, but then they just sort of stopped coming to see me. I suppose they thought I didn't need them anymore because I could look after it by myself.

When I was at primary school it wasn't so bad because the other kids didn't really notice the bag and, really I didn't entirely understand that what I had was different than anyone else. I just carried on with everyday life like a normal child would, if it leaked I would have to go home for the rest of the day. Later on you learn about the body and things at school and I sort of realised that no one else had this bag and that it wasn't normal.

When Hope got to college, however, it was harder, much harder to deal with because she now understood that she was indeed different, in a physical sense, and she wanted to hide it from everyone at all cost. 
I had to think about everything I was going to wear and make sure it wasn't noticeable. I used to get really upset because I wanted to wear the same kind of clothes and, you know, bikinis and tight things that the other girls were wearing, but the bag would poke out so I couldn't. I could never go swimming anyway back then, because the bags I had didn't stick properly if they got wet. I wore heaps of layers of clothing, baggy clothes, to try and hide it especially going into the changing rooms and getting your PE gear on and stuff. I'd have to go to the bathroom before and get changed so that it wasn't obvious that something was there.

A few of Hope's friends knew about the stoma because her mum would talk to their parents, explain it to them in the hope that they would explain it to their children. In this way Hope wouldn't yet find herself in a situation where she would need to find the words to explain this thing...this hidden thing.

Except for my family and a couple of friends I stopped myself from getting too close to anyone, especially boys, because I didn't really know how to tell people about it, it was just easier not to. I had a couple of well... I suppose you would call them boyfriends, but I never told them about the bag, we just sort of hung out together. I was always paranoid about the noise from the stoma, especially if I had just eaten something it would always make a really loud noise when wind went into the bag. It always did it when it was really quiet, sometimes I could try to muffle it with my hand if I felt it coming, but usually it just happened without any warning. That was one of the worst things about it, you couldn't control it.

One aspect of having an ostomy bothered Hope significantly, making her always conscious of herself. Another thing she couldn't control, that dreaded odour, that which she thought was ever present...foul...lingering.

The smell, that smell...it's awful,...really awful. When I was at school, I'd hear someone say oh what's that smell?...and I just have to get out of there right then and sort it out, the filters on the bag weren't very good back then. What was really scary, is that after a while you can't really smell it yourself, but you know it's there, someone must be able to smell it. I used to always 
ask mum if she could smell it, she always said no, of course, but I had a hefty supply of deodorants and perfumes. It's funny really, now I think about it, people used to tell me I smelled like those perfume departments, the ones you need a gas mask to walk through. I probably did overdo it... a bit, oh well.

To add insult to injury, Hope discovered she had Type 1 Diabetes Mellitus when she was 12 years old.

That just made everything worse, I suppose I rebelled quite a lot with that because it was sort of invisible, not like the stoma. It felt like I was always on this schedule, this controlled timetable of medications and finger pricks and the bag on top of that. I was never good at taking my medication or doing the sugar tests, I just sort of ignored it, pretended it wasn't there. I'd eat all the bad things as well, even though everyone told me that it was bad I always thought that I would be ok and they were just nagging. I got a bit sick sometimes with high blood sugars but I never really thought of it like damaging my body or dying. I didn't think any of that stuff was going to happen to me, I never really thought about the long term affects.

In the six years Hope had her stoma, no one had ever entertained the possibility of getting the stoma reversed. It was the accumulation of too many bad days, too many incidents, which wrenched forth a determination in Hopes's mind. She wanted to be rid of this thing...this stoma, she demanded it begone. As Shakespeares's Desdemona said so aptly “Out, damn'd spot! out, I say!”.

I was at college one day and it leaked everywhere. I had to go home and I just like melted down and wanted it gone right then and there...it was pretty hard, I went to the doctor a few days later to see what options there were. That's when I found out that I maybe I didn't need it, in fact this specialist, which wasn't the one who made the stoma, couldn't really explain why I had it done in the first place. That made me really, like just angry that I maybe never needed to have it. My parents were really irate that they might have been given the wrong advice, they felt really terrible that they had relied on this doctor to give them the right information, you know. Mum especially, is really protective, cautious with that sort of thing now, she always likes to 
know what's going on and make sure that I get all the information before there are any decsions. My parents were really supportive of me wanting to get it [the stoma] reversed, I asked them like, what their opinion was and they'd they'd tell me but otherwise they'd just sort of explain things that I mightn't have understood and stuff like that. I got to make the decisions in the end and they would support whatever I decided. They were really good.

This new specialist gave Hope just what she needed,...hope.

My specialist did a lot of tests and things to see whether everything like, you know, with my bowel could work properly without the stoma. I know that, doctors and nurses aren't really bothered by that kind of thing, bowels and gross stuff like that, but it was really embarrassing when I had fluid sort of injected up my butt to see if I could hold on to it. I just focused on getting rid of the bag to get through it all, they always were pulling the sheet up and forgetting it and I was worried someone would walk in. I suppose when you see naked people all day long you don't really notice but I still was really uncomfortable. They found out that some of the muscles down there, the bladder muscles were kind of tight so they injected like, Botox in them to loosen them. That was freaky, having Botox up your butt, I always joke about that.

I went and had the stoma reversed when I was 17 but it all went wrong. Four hours after I got home I had to go back. They took me back for more surgery to find out what was wrong, it was really hard like waking up and not knowing what was happening and then asking what had happened. There was a rupture in it apparently and the join where they sewed up the bowel was leaking poo in to my tummy... gross, any way, they made the stoma again. I was pretty gutted and real quiet for a few days because I just didn't really know what to do. They were still saying that they could do it [the reversal] again and it would probably still work but it knocked my confidence in whether it would actually work or not again. The nurses and mum did everything for me, I just didn't even want to look at it [the stoma]. It was a few days before I actually calmed down after the doctors explained what 
happened, I think they were really afraid of telling us actually because they were the ones who said this would work.

I was pretty used to being in hospital, but it's just really boring and I hated just like lying there the whole time waiting for something to happen. Luckily I had my own room, I never wanted to be in with all the sick people or anyone really. I didn't want to talk to anyone, I just wanted it done. I ended up missing two months on college in the end because my diabetes played up too. I had to go to the ICU because my blood sugar went really high and I got really really sick. That was scary, especially for mum and dad and my boyfriend because I was out of it. I'm still pretty bad with managing my diabetes though, which is stupid because I know how sick it made me.

Hope successfully had the stoma reversed a few months later. After so long staring at her reflection in the mirror, she would soon be able to step through that looking glass, into a whole new world.

I used to look in the mirror and try to imagine just the half of my body without the stoma and what it would look like on the other side as well. Even with the scars, they look much less than they were, they seem nothing to me now. I don't know what I'd do if I had to have it again.

That other person, the reflection in the looking glass was now gone. In Hope's mind they were two different people altogether, she wasn't that girl anymore. Her eyes were blind to the scars now, blind to any faint reflection of that other self, nothing more did she have to hide. I hoped she would not forget the thing that had always been hidden, that thing which continued to hide. Hope can no longer see that other self in the mirror, but she remains there still. For even as I sat listening to her story, I could hear another voice, the voice of her other self, and she was screaming. Strange I thought, that Hope could not hear it too. The stoma, its presence once so commanding was no more, but the greater of the two evils would never leave Hope, the Diabetes would always remain. It was Diabetes that brought her within view of her own mortality but its pleas often fell on deaf ears. The future now lays unwritten, the pages of her story, her life, from that point on are empty, sat waiting to be filled. 


\subsection{Through dangers untold: Faith's Story}

Illness has been a part of Faith's life for as long as she can remember,

I started to get sick when I was really young, I had a lot of tummy pain and had to go to the toilet sometimes more than a dozen times a day. I went to heaps of doctors up and down the country just trying to find the cause of my pain. Some said it was growing pains and another doctor told my mum that kids just get tummy pains and that she was overreacting. All of these doctors were convinced that the pain was in my head, and after being told that so often, you know, you sort of start to believe it yourself. I even had to see a psychologist who made me feel like such a dick, it wasn't like he was trying to find out if I had a psychological problem, it was more like he was trying to convince me and my parents that I did. He said that some people like me overreact to little things like a sore tummy and think they have a terrible disease or are going to die.

In Faith's opinion, the specialist concluded that she needed counselling to overcome her obvious fixation with normal bodily functions.

I started to doubt myself, wondered how other people managed these normal bodily functions and why I couldn't cope. I thought, I must be retarded or something and felt like no one believed me when I said I really didn't feel well. One doctor asked if I was acting out this way to gain attention or was I inventing these pains to avoid something like going to school or tests or whatever.

Eventually Faith ended up in the Intensive care unit because her bowel had perforated.

I think, strangely that I was more relieved than anything else. There was a real physical cause for my pain, it wasn't in my head, and I wasn't wasting everyone's time.

Faith had surgery to repair her bowel and form an ostomy, which at the time they said would be temporary. 
I remember looking at it [the stoma] the first time, it was a hundred times bigger than I expected. It was explained that my tummy was all diseased and like, rotten from something called Crohns.

She was fed parenteral nutrition, food through the drip, for three months and had only broth to eat.

I can remember on Christmas Day going out with the family, I could have a chicken cube or a beef cube with my water because I wasn't allowed to eat solids. I was on so much prednisone I got osteoporosis, and after the surgery I couldn't move from the neck down for six months. I think I spent something like two years pretty much hospitalised, I went to the hospital school and I had back braces and crutches until I was 17 years old.

Faith needed to have more surgery to remove diseased bowel from the Crohns Disease. After, so many years of being in pain, constantly needing to go to the toilet, not sleeping, and losing so much weight, she was just a shell of the healthy child her parents remembered.

I was also so swollen with steroids that I didn't even look like the same child, my parents were pretty much at the end of it you know. The doctors had to eventually remove all of my colon and my rectum so that it was sewn shut. There wasn't really a choice to be made there, it just eventuated that that's what needed to be done and they did it, I got a permanent ileostomy. I'm glad that decision was made for me, really, because if I had the option of having it reversed I think I'd have lived my life waiting for that day, to be normal again whereas now I know that's not an option and I can move on and not dwell on what might be.

It was hard growing up with an ostomy. When she eventually went to a regular high school, Faith was still in a wheelchair, and remembers the other kids were so cruel.

That's what I remember the most, I felt like a leper and would often go home crying because of the teasing. Before I got sick my whole life was gymnastics, I'd get up at five in the morning, go to gym before school and then go to gym after school and compete in the weekends and I'd be in the nationals. I 
got second in New Zealand for floor and it was my biggest achievement just before I got sick. After the surgery, I just couldn't do it anymore, my bone and joints just wouldn't hold up because of the osteoporosis. I wasn't used to such restricted environments like it was at high school because I had most of my schooling in the hospital. The teachers used to make a big deal every time I had to get up and go to the bathroom, demanding the reason in front of the class every time.

I was very conscious of how I looked, I hated that the bag poked out in my clothes and so I'd always wear baggy things. Then as I was getting older I lost all my weight from the steroids I had been on and all of a sudden I was getting all this attention from guys for the first time in my life, it was really sort of foreign and so I went to the stoma nurse for advice on how to deal with, like having a boyfriend. I know I sound sort of bitter about it, but I didn't get a lot of support from the stoma nurses. They don't deal specifically with younger kids because it's the older people, like people that have cancer who mostly have bags and I don't have the same issues as younger kids. When I've gone to ask them for advice you know, especially with my first boyfriend they said: 'oh yeah bring him in and we'll sit down and talk about it, well, I'm like you're joking aren't you?' I wasn't just going to just sit him down with the stoma nurse and bear all the ugly details. I'm not that sort of a person, I think everyone has their personal boundaries and that approach just wasn't right for me.

I ended up struggling with it and keeping many people at a distance, making excuses you know. I did learn to find my own way of telling people but it often would end in tears. The first thing they'd say is 'oh can I see it', which I thought was just weird because you wouldn't go asking to see someone's butt would you? Sometimes they'd go and look on the internet and then they'd call me and say 'oh don't worry', but never call me again. I'd see them on the street and they'd say 'oh sorry I lost your number' or whatever excuse they could think of. I've had a guy tell me that I should stay with him because he will be the only one that loves me, and when I was 16 I was like...oh my god will I ever get another boyfriend? I ended up coming to the conclusion 
that I'd rather be by myself than with a loser like him. It's not worth it. The most ridiculous thing a guy has ever said was... 'oh don't worry I know a girl that's had a caesarean', which was obviously his way of his saying don't worry you're not the only abnormal person I've been with.

I was always so nervous if like a guy would want to take me out to dinner. I'd always say I've already eaten or I have to eat later at my parents or whatever...you know, just avoid putting food in the equation. The problem with having an empty stomach, though, is that you still get the "bag farts"...that's what I call them...sometimes you just don't know when it's going to happen. I was really conscious of my body and the stoma, I had some real issues with food back then. I'd pretty much stop eating solids on a Friday night and I'd start eating solids again on a Sunday night because during the weekend I just wanted to wear nice clothes, so I'd just live on black coffee. I took up smoking as well which is like...really bad with my Crohns, I know. I just knew if I didn't put too much solids in, the bag would stay flat and not do anything much. Then I could pretty much wear tighter clothes and do what I wanted without it showing up or having to deal with it. I had a boyfriend break up with me and tell all of his friends that I had this plastic grocery bag in my stomach, like, this huge plastic bag sticking out! I knew they were going to be at the beach one day and I wanted to wear a bikini just to prove to them that I didn't have this grocery bag. I heard that eating marshmallows thickened it [ the stoma output] and slowed it right down so I ate a whole bag before I went to the beach... and it worked, I think the others thought he was just full of it aye...they couldn't see my bag at all. I paid for all the marshmallows later though...got pretty blocked up, but it was worth it to salvage my reputation. I wanted everyone to think I was normal and not a freak with a shopping bag full of pooh taped to me.

The main reason I am so bitter about stoma nurses is that I had a see through bag my whole life until I was 19 and went on a youth camp. The first time I had sex with my boyfriend I was wearing a see through bag that I tried to keep hidden. Every boyfriend I've had my whole life from agel6 to when I was 19 I could see through my bag. I'm still so angry about it, I don't think 
I'll ever let it go because my stoma nurse knew that I had a boyfriend, knew my anxieties and knew I wasn't eating in the weekends. How could someone be that cruel? I don't mind expressing my opinion because they know that's how I feel, I have no concerns about that you know, I'm just being honest so that maybe it will make a difference for someone else. I went back to my stoma nurse and I said oh hey I hear that there are different types of bags, can I have a look at a kind of catalogue or something to see if there is something that could conceal the faeces from my boyfriend? The reply I got was I prescribe the appliances, I know what best suits you, this best suits your skin and you can't just have anything because that's not what's funded, you have to make what you're given last three months. I know I'm lucky to have stoma bags when I know there's people in the world who don't have access to them, but at the same time I live in New Zealand and I wouldn't tell my stoma nurse here's one no frills toilet roll, go and make that toilet roll last you three months. I don't mean to imply that all stomatherapists would treat a person in this manner, that's just what I experienced and I think I suffered a lot, unnecessarily because of ignorance to my situation. I don't think I would make a very good stomatherapist, it would be hard to keep my personal opinion away from my professional judgment.

Despite her tribulations and misfortunate experiences, Faith managed to survive her adolescent years and overcome her illness. At the time I spoke with her she had just recently married and was planning to have children.

That will be a whole other experience I'm sure given my circumstances. I'm looking forward to it, but am hesitant at the same time because I have scar tissue where the rectum is sewn shut it could tear during delivery, or I could have a caesarean which might interfere with my stoma, so i'll just have to wait and see.

A few months later, Faith rang to tell me that she was pregnant and very happy.

I don't see the stoma as a reminder something of illness, I see it as something that gave me a life to live, it made me healthy again, it's part of me. It doesn't run my life anymore, but I definitely know it's still there. It's kind of 
like having a really bad haircut, you really want to try and hide it but you can't so you live with it. I always think to myself, if I didn't have a bag what would my life be like, would I have gone down the same pathway or would I have done something different. If I had I might not be where I am today, with my husband whom I adore, and planning for a family. I would never have made it this far if it weren't for my family, they've been there with me through all of it and I can't forget that. I lost my childhood and my teenage years to this, but I can't change any of that now. I think that you have to have faith that there is a light at the end of a dark tunnel, faith and determination. I had to believe that I would one day conquer my disease and realize my dreams, and I have. I hope that by sharing my story I can change something for the better in someone else's. 


\subsection{One moment in time: Marks story}

At the age of 17 Mark described himself to be an outgoing, and relaxed sort of person who was "just coasting along pretty smoothly" in life.

I would have considered myself to be a popular sort of guy, didn't really have any enemies and I wasn't someone that, you know, got picked on by other people. I was in the first eleven cricket team and spent most of my spare time at practice or hanging out with mates, going out to parties on the weekend, that sort of thing. I was a pretty average student, I'd say, not really good but doing ok. Probably would've been a bit better, but, you know...when your're that age you just want to have fun...so studying sort of came second I guess. I had a lot of friends, not really close ones, but kind of acquaintances I suppose. Everyone was your friend when you were on a school sports team, but the people I'd most relate to were the other guys on the team because we spent a lot of time together really. I'd also just started seeing a girl I'd met at a mate's birthday party. Everything was going pretty ok I guess at that time...well until...you know...it happened.

The it Mark refers to is the point at which his life changed drastically. A series of what at the time, seemed to be inconsequential decisions, calculated risks to achieve a greater good. Or so he thought...

I guess I knew all about the dangers of what my mum called teenage antics, you know, drinking and doing stupid stuff just for the fun of it. Boys being boys, you know. But I'd never really considered that anything really bad would happen, you got told all of this stuff by your parents and at school and that, but it was just sort of...well...stuff that happened to other people. I don't remember all of what happened, the doctors said that I probably wouldn't get that memory back...and I'm kind of glad about that. I imagine in my head what happened, mostly because of what I've been told and the little bits that I can remember. They're just images and sounds really, and they get mingled up in what I imagine...but even that's been pretty hard to live with. 
It was only about the third time me and ----- had been out together, we went to a party...just a regular party, you know, just to hang out. Well...some of the others were heading in to town to try get in to some clubs, we didn't really go clubbing back then because the drinking age was still 20 years old and hardly anyone ever got in. At first I wasn't really in to it, but ----- was really keen and I thought well...ok... why not?...it just a bit of fun and I didn't wan't ---- to think I was too prim and proper...what an idiot I was aye. We were both pretty toasted by that time, and we'd walked down to the [train] station but there wasn't one for ages. So ----- called one of her friends because we couldn't be bothered walking all the way back to the party. It turned out that her friend was going to go in to town as well so we got picked up at the station. I'd had a bit to drink but I did sort of realise that her friend was pretty wasted, she'd only agreed to come out because she wanted to meet me. I never said anything...I just got in the car...stupid bloody idiot. We stopped and picked up some of the others who'd started walking back to the party, there ended up being seven of us in this little hatchback. She, ----- , was on my knee in the front seat and we had the belt around both of us. The road out where we were was deserted and I remember that we were going pretty fast, everyone was rolling about because we were going down a winding hill road and we were sat on top of each other...we thought it was really funny...and that's all I can remember clearly...I didn't remember what happened.

The car they were travelling in had apparently failed to make the turn on one of the tight corners on that road. Mark understood that witness's had heard the car skid and the sound of what was thought to be a tire blowout. They were found a short while later up-turned at the bottom of a steep bank. The left hand passenger side of the car had been crushed and the roof collapsed in. Mark still keeps the photos of the wreck, recreating his memories from those pictures. The driver was found not far from the car, having been thrown during the descent. She was pronounced dead at the scene. The two passengers, one girl who had been sitting on the others knee in the left hand back seat also died during the crash. The two others in the back seat suffered moderate head injuries as the roof had pressed in. In the front passenger seat, Marks girlfriend lay hunched under the collapsed metal, having suffered horrific injury to 
her cervical spine and upper torso.

Mark remembers when they were eventually cut from the wreck, seeing her body being pulled from above him, hanging limply...wrongly...unsurvivably.

I had heard a rumour that her neck was completely severed. That's one of the things that really gets to me, ...even if that wasn't exactly true...that's what I picture in my head from the things i've heard.

Mark suffered crush injuries to his shoulder and pelvis, the metal floor of the car had shattered his coccyx bone.

I couldn't move my legs for a while because of the swelling in my spine, an initially that's what the doctors thought was causing my problems controlling my bowels. When the swelling went down and everything else seemed to be working ok, like my legs and stuff, they couldn't figure out what was wrong. I just kept on having these...like accidents...I felt so useless, like a baby. I would get so angry, one time I put my fist through the wall...but I just couldn't control it. They had a look with a camera and did some tests where I had to try to hold in some liquid...but I couldn't. They said the [sphincter] muscle, like...you know how you keep everything in...well a bit of it was damaged. A bit of that muscle just was hanging...useless...and so everything was just leaking through. I had to get the bag [ostomy] put on because they said they couldn't fix it. I just blocked it all out aye, ... mum and dad, they were the ones who had to make all of the decisions because I wouldn't do anything. No one really knew that I had it done at first, but after a bit, when I did go back to school for seventh form, people sort of knew about it from rumours. No one said much though, maybe because of all the other stuff, the others that got killed...may be they just didn't know what to say about any of it. I never told anybody it was because I couldn't stop myself from crapping everywhere, I said it was just because of injuries.

Mark has had the ostomy for 12 years now and still hopes that one day a new treatment will surface and the sphincter muscle will be able to be repaired.

I really don't like going to...like quiet movies, especially with 
people who don't know about it (the bag). I'm always really anxious and can't just relax because I don't know when it (the noise) might happen, usually when the movie goes real quiet I can sorta feel the pressure coming. Interviews and exams are always a real bugger aye. When I was at college, it was like...in the middle of my maths exam... and those things are like 3 hours long aye, it started going and every one was giggling so I giggled too... the examiner didn't know me...didn't know about the bag. She came over to me and I was going all...like red in the face, 'cos it was real loud and she could hear it. Any way, she told me she didn't want filthy troublemakers in her exam and sent me to the principal. I ended up doing the rest of the exam in the principal's office, it was leaking at the end of it all. After all that he (the principal) told me I needed to "grow up" and be responsible for myself so I didn't always have these incidents. Like I did it on purpose or something... you know...like I want to get covered in my own crap to draw attention to myself.

I can remember at birthdays and Christmas and things, especially if my stoma was playing up...I just would avoid eating pretty much anything. I knew if I gave in and ate something I would make heaps of gas and the bag would fill up. I would miss out on ...like...catching up with people and enjoying myself and on top of that, someone would need to take me home if it leaked. I felt like everyone was always waiting for me to ruin the day. It's not so bad now, with the newer bags, they filter out the air better than before. There's still a smell though, especially if I have to take it off to change it, I try not to have to do that if I'm out because it smells so bad, way worse than the normal kind of smell.

I feel like a real dork sometimes when the guys go out for burgers or pizza and I just sit there and pick a chip or two. The first time I went down the pub...like when I just turned 20...my mates and my dad bought rounds of beers to celebrate being legal. Well, nobody told me about beers... what it does to the bag and stuff, suppose it wasn't important...that stuff. Any way I had one beer and the bag just...like well...filled up and imploded from the pressure. The worst thing was I forgot to bring my repair kit...that's what I 
call my bag of spare stoma stuff... I had to go home holding a towel under my shirt. I've got some better bags now... you know...better technology in like...air filters. If I'm real careful I can have a beer with my mates and not always look like a nancy boy with my glass of juice. Wish I didn't have to carry around a nappy bag like some mother with a baby...man if I could just go out with just my wallet in my back pocket...well I'd feel like a proper bloke.

Today Mark carries on, still never accepting that the ostomy is permanent, and perhaps it won't be. He keeps a keen eye on medical research and claims to regularly proposition his doctor to experiment a little bit. For Mark this is not a permanent ostomy, just a temporary measure until a suitable treatment is found. Mark's wife, who sat listening as he talked, rolled her eyes and smirked, shaking her head. "He'll get his bionic bowel one day", she said, "I'm sure of it". 


\section{CHAPTER FIVE}

\section{Adolescent Interrupted}

\section{$5.1 \quad$ Introduction}

The essence of the adolescent experience of living with an ostomy and the themes that communicate the meanings attributed to this experience are presented in this chapter. The embodiment of these themes is described as 'The adolescent interrupted'. Several core themes emerged: Stolen youth, denied rites of passage; All the world is a stage, feeling exposed in the limelight; Puppets in the hand of fate, uncertainty and loss of control; Through the looking glass, altered perceptions of self; Captivity, the soul held captive in a broken body; Never to walk alone, the struggle for independence and self reliance; lastly, On the outside looking in, disconnection and loneliness. The interrelationship of these core themes serves to describe the essence of the experience, explain intricacies and allow for their understanding. This embodied whole experience is represented graphically in Figure 1 below.

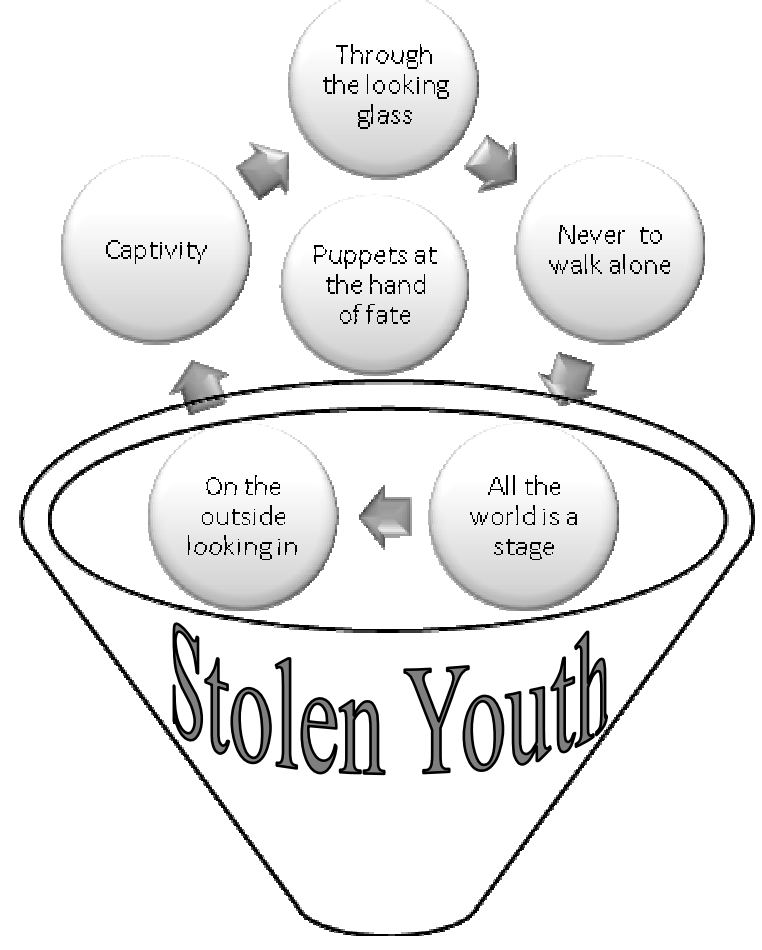

FIGURE 1: ADOLESCENT INTERRUPTED: THE CUP OF STOLEN YOUTH 


\subsection{Stolen youth: denied rites of passage}

Disruption and restriction were an overwhelmingly prominent theme within the data. Managing an ostomy, often in tandem with managing illness, resulted in many lost hours, missed opportunities, physical restrictions, and an inability to experience the social and emotional rites of passage associated with adolescence. As MartinMcDonald and Biernoff (2002) claim, adolescents need to experience these ritualised events and achieve socially constructed milestones in order navigate successfully, the journey to adulthood. James, Hope, Faith and Mark all reported a sense of regret bordering on grief in remembering all that could have been, should have been, but wasn't.

The night I went to go to the ball, the seventh form ball, it (the stoma) prolapsed and it was just like, great, it had to happen tonight, Murphy's law and all that...in the end I went to the ball, but I'll never forget that aye, always at the worst possible time. (James)

Social milestones were placed out of reach and their adolescent paths veered astray from their counterparts. Within the concept of stolen youth, I identified that there were overwhelming feelings of grief and loss associated not only of lost opportunities, but also of the person that existed before the surgery, before illness. The self was always referred to as separate entities, the self that existed before illness and surgery, the self that now exists and the self that was stolen, the 'what if' self.

I can't help wondering what I might've been able to achieve if I hadn't ever got sick, I try not to think about it too much because it's painful. (Faith)

The notion of carefree youth did not exist for these individuals, there is always a consciousness about everything, from dressing in the morning to contemplating what, or even whether to eat lest it should make the ostomy irritable and cause embarrassment.

I had to think about everything I was going to wear and make sure it wasn't noticeable. I used to get really upset because I wanted to wear the same kind of clothes and, you know, bikinis and tight things that the other girls were 
wearing, but the bag would poke out so I couldn't. (Hope)

I used to play soccer and other things like that, and I know I could probably protect it [the stoma] but I don't want to risk getting hit or the bag exploding or something so I flagged that. It's a bit sad but that's life. Even with the stoma I still get flare ups and find it hard to eat, that's the only frustrating thing is that I've had all of this stuff done and just sometimes I wish I could catch a break. (James)

Significant periods of absence from school, indeed, often the greater part of a school day would be lost due leaking stoma bags. The incessant leakages would also disrupt social activities and important life events, the so-called rites of passage and is consistent with the findings of Sturge et al. (1997).

I felt dirty, really dirty. I was sure everyone could smell it, they say 'oh no you can't', but there is always that sort of feeling like they're just trying not to upset me. (Hope)

The bag kept coming off...it was like being with a baby. I wouldn't eat properly, I was too frightened to put stuff into this bag because I knew it'd blow up and come off. (Mark)

I can remember on Christmas Day going out with the family, I could have a chicken cube or a beef cube with my water because I wasn't allowed to eat solids. The ironic thing is that when I could eat, I didn't want to because the bag would fill up. Even when it wasn't full it felt like the whole world could see it. (Faith)

Illness and surgeries also resulted in long periods of up to a year or more of hospitalisation and incapacitation. Social isolation had a heavy impact as these individuals would often spend many weeks with minimal interaction with peers.

I don't remember having any really close friends because I just wasn't around people long enough to form any. I would meet people at school who I thought were really nice, but then...you know...i'd be off sick for a bit and they'd just move on. I always missed out on stuff that was going on in school 
because I was always going home to change the bag or going to see doctors or whatever...you know? (Hope)

I think I spent something like two years pretty much hospitalised, I went to the hospital school and I had back braces and crutches until I was 17 years old. That kind of thing just makes you a social leper, no one wants to hang out with the freak. (Faith)

Recurrent illness and the demands of treatment regimens also had a significant impact.

There's always more appointments to go to, more tests you know?...I wish there would be one day without having to think about any of it, without having to remember to carry spare bags, be careful of what I eat and at the same time worry whether I've eaten enough. I just would like a day to be a kid without worries. (James)

It felt like I was always on this schedule, this controlled timetable of medications and finger pricks and the bag on top of that. (Hope)

\subsection{Captivity: the soul held captive in a broken body}

All people are constrained by the physical limitations of their body in some way. The experiences related in the stories of James, Hope, Faith and Mark's experiences demonstrate how extraordinary limitations can result in frustration, anger, grief, and regret.

Before I got sick my whole life was gymnastics, I'd get up at five in the morning, go to gym before school and then go to gym after school and compete in the weekends and I'd be in the nationals. I got second in New Zealand for floor and it was my biggest achievement just before I got sick. After the surgery, I just couldn't do it anymore, my bone and joints just wouldn't hold up because of the osteoporosis. (Faith)

These feelings are what contribute to the perception that they have somehow been cheated in life; that they have been denied the right to live and do as others do. The life that they imagined for themselves has been stolen as they are held captive in a 
broken body.

I wonder what it would've been like if the accident hadn't happened, maybe I would be playing for a national team. My bones and stuff were kind of stuffed from the accident and I can't do the athletic sort of stuff well anymore. (Mark)

It's kind of like having a really bad haircut, you really want to try and hide it but you can't so you live with it (Faith)

Razmoviz and Ziebland (2004) claim that the physical sensation of pain or of a loss of control over bodily functions can be intensely personal, but the significance attached to those experiences is inescapably informed by a wider understanding of what it means to exercise control over ones physical and emotional self and of the consequences of relinquishing that control. Pain was a prominent feature in the experiences of this study's participants, frequently interrupting their lives, preventing normal bodily function. Fear alone, of this pain often gave rise to limiting behaviours that further constrained their lives.

That was agony, you know, sometimes, you're walking in the street and you get it, this...this pain, and you can't really stop in the middle of the street sort of holding your stomach so you have to really grin and bear it. (James)

Pain made it difficult to function, as did narcotics prescribed to control the pain, which further interfered with their daily activities, studies and school attendance. They needed relief from pain but also needed to be alert to study and function in their daily lives. They often had to choose between pain relief, which made them feel "zonked" and rendered them unable to think, and the pain in order to go to school, take tests, and generally function.

Oh man the drugs, they just made you like a zombie...like a vegetable. I didn't want the pain, but sometimes it was better than spacing out. My mates felt awkward because I'd just nod or shake my head and not really try and make any conversation. (Mark)

Sometimes it was just unbearable and I'd just stop, you know, just stop and 
give in to the pain...curl up in agony. (James)

Often there was no effective pharmaceutical to relieve their pain, and so when it came, it was borne and became part of life. James became particularly tolerant, experiencing pain on a daily basis, closing his eyes to it, silently suffering in hope of avoiding having the surgery again, having the stoma again.

I would wake up during the night constantly, even if I was so exhausted, this gripping pain would drag me from my sleep. I missed a lot of fifth form, especially for the first and second spell because I needed to get control over it to function. (James)

You get used to having pain, you kind of turn off to it but it makes you kinda cold to other people's pain. I hope I don't become one of those cold hearted women that just says 'get over it' to thier kids. That would be horrible. (Faith)

At the beginning of their experiences, complaints of pain were reported to be not taken seriously or considered real. Faith reported that she had been led to believe her pain was psychological in nature, and that this deeply affected her self-perception. Being diagnosed with Crohns disease was in a way, a relief for Faith, a quantifiable physical reason for what she was experiencing.

All of these doctors were convinced that the pain was in my head, and after being told that so often, you know, you sort of start to believe it yourself. (Faith)

Adolescents are especially sensitive to what others think of them. Swift (1997) hypothesises that to be dismissed by a physician or nurse who is admired and respected as an authority figure often leads to doubt in themselves and their bodily symptoms. Swift emphasizes that health care providers, whose expert status engenders trust and high expectations in patients, should take complaints of symptoms seriously.

\subsubsection{Arrested development}

Freyer (2004) maintains that as a result of the adolescent's medical experiences, 
normal development is altered profoundly in the adolescent with disease, disability or serious illness. The physical changes normally associated with puberty may be delayed, and unwelcome physical changes often result from treatment, extensive scaring, swelling, severe weight loss, muscle weakness, disfigurement, disabilities, profound fatigue, and altered mental status. The experiences of the participants corroborate these findings.

I was also so swollen with steroids that I didn't even look like the same child, my parents were pretty much at the end of it you know. (Faith)

Lack of nutrients resulting from the inability to consume sufficient food and malabsorption from chronic inflammation and infection particularly affected James who expresses frustration at being so very thin.

I hate being this ridiculously skinny, it's not at all masculine and I always look sick even if I feel well. (James)

Freyer (2004) goes on to say that beyond these physical changes, serious illness may substantially interfere with critical life experiences necessary for achieving the normal developmental goals of adolescence. In addition to the prognosis itself, prolonged hospital stays, frequent outpatient visits, and intrusive daily medication regimens alter normal routines, impede school attendance and socialisation, and contribute poor self image and the perception of being radically different from their peers.

I mean, everyone just wants to fit in and be normal, you know, and you don't want all these rumours that get exaggerated going around about you when you can't set them straight. I just wanted to travel under the radar and do my thing like everyone else, and not walk around with a big sign on my back that says I have a bag. (James)

One particularly intrusive phenomenon commonly reported among the participants was the frequent and unwelcome passage of air from the stoma resulting in a popping or squelching against the plastic. This is one aspect that modern stomatherapy hasn't yet, it would seem, been able to resolve. 
It would always do it when you didn't want it to, when it was really quiet. Bag farts, that's what I call them...sometimes you just don't know when it's going to happen. (Faith)

It was, however, evident that for those who also live with debilitating illness, as James and Faith did with Crohns disease, the stoma actually facilitated the attainment of normalcy to some degree, and resulted in improved quality of life.

It was easier once I had the stoma because I had had so much problems with my bowels at that stage, the bag meant that I go [to the bathroom] more discreetly sort of thing....before it was like, well if I didn't go I would need to rush and could have a mess. (James).

Avoidance of social events, family functions, and extracurricular activities was still a common occurrence, even where symptoms of illness has been to some extent relieved.

I can remember at birthdays and Christmas and things, especially if my stoma was playing up...like getting blocked, or if the adhesions [Internal scarring from surgeries] were really bad, I just would avoid eating pretty much anything. I knew if I gave in and ate something I would get pains...like agony aye. I would miss out on ...like...catching up with people and enjoying myself and on top of that, someone would need to take me home. I felt like everyone was always waiting for me to ruin the day. (Mark)

Peer interactions were also reported to be commonly avoided and some would go to extremes in the attempt to lead a normal, uninterrupted social life.

I'd pretty much stop eating solids on a Friday night and I'd start eating solids again on a Sunday night because during the weekend I just wanted to wear nice clothes, so I'd just live on black coffee. I just knew if I didn't put too much solids in, the bag would stay flat and not do anything much. Then I could pretty much wear tighter clothes and do what I wanted without it showing up or having to deal with it. (Faith)

Such experiences give rise to feelings that life is beyond control and this can 
severely impact on the experience of living with an ostomy. The concept of losing control gives rise to the next theme.

\subsubsection{Growing up too soon}

Living with an ostomy and the circumstances surrounding its formation is invariably a harrowing experience for any individual. For an adolescent, the magnitude of such an ordeal is substantially greater. If chronic disease can affect the growth and maturation of adolescents, conversely, developmental changes in physical, psychological and social capacities may impact upon the course and management of chronic illness in adolescence, including both self-management by the young person and supervision and treatment strategies available to health professionals. At a young age, these adolescents are forced to confront a health crisis even very few adults would ever ordeal until relatively advanced age. The experiences of the participants in this study illustrate the enormity of such pressure on a yet still developing mind.

I didn't have a choice about surgery the next time, I was so sick by that stage that they couldn't even actually do it because of the condition I was in, you know... I didn't really want an ostomy again but it had to be done or they told me I would just die. (James)

Issues in regard to health, illness and mortality were reported to be the concerns of adults, and these adult concerns were thrust upon them during a time when such thoughts are inconceivable and far from the forefront of the mind. Consideration for the future was described to be an especially difficult and foreign experience for the adolescent who is primarily focused on the present. Considerable stress was associated with the need to seek and understand information and make choices about these adult concerns.

The prospect of declining health and physical limitation requires enormous maturity of mind to consider. At six years old, as Hope was or at 17 years old, as was Mark, the challenges are equally as difficult owing to the developmental differences in age. Forced to consider and understand the impact of radical treatments and surgery, the associated financial burdens and future implications of their decisions, the participants expressed that the essence of the proverbial carefree youth was lost. 


\subsection{Puppets at the hand of fate: uncertainty and loss of control}

The stories reflect the uncertainty present in their lives in managing an ostomy and living with the threat of relapsing illness. They were mere puppets in the hand of fate because of the unpredictable and often unreliable nature of an ostomy, and their actual or perceived inability to control their lives. The experiences that led to uncertainty included, disruption in life routines, concerns about the future, ambiguity, inconsistency, and unpredictability of symptoms, lack of information and conflicting information, constant worries about recurrence or disease progression, and changes in body function and appearance as is also reported by Mischler (1991).

I felt really like I had no control of things, I need to know that I can go and deal with things if I need to aye, and down there I didn't. Sometimes during the day I wouldn't know when it [the bag] was going to go, and if I'd eaten a certain amount of time before or if I had something that didn't agree with me it was bound to go during class. It was really stressful especially if I had a leak, everyone's eyes are on you if you have to interrupt and excuse yourself. (James)

Mischel (1999), claim that uncertainty has been found to cause emotional distress and difficulty in adjusting to a significant change in circumstance. The participants of this study were particularly affected by the uncertainty created by misinformation and lack of information they feel they received from health care providers. It was evident that their parents had battled to navigate a complex health system and needed to function as advocates, experts, and coordinators of their care rather than consumers. This finding is supported by those of McDonald (1996), who reported that parents often received conflicting, misleading or inaccurate information and instructions about treatments.

My parents were really irate that they might have been given the wrong advice, they felt really terrible that they had relied on this doctor to give them the right information, you know. (Hope)

McDonald (1996) argues, that while advocating for one's children is part of a parent's role, and has the potential to enhance empowerment, it can be detrimental, especially if the parents later have difficulty relinquishing this role. The 
continued need to assume this role into the adolescent period places them in a position of continued dependency on their parents at a time when independence and autonomy are developmentally sought after.

\subsection{All the world is a stage}

The development of peer relationships and self-image is in direct conflict with the demands of chronic illness, treatment regimens and management of an often unpredictable stoma. The extent to which these adolescent issues affected decision making and the management of illness and the stoma depended on its balance in relation to competing priorities. Often, only the absolute necessities such as an ostomy bag in need of emptying, would win the balancing game, and only then because it threatened punishment if its needs were not met. For Hope, her diabetes was a silent oppressor and therefore better able to be ignored in favor of calculated risk. Strict regimens and controlled diet were not conducive to fitting in with peers and enjoying a carefree lifestyle before adulthood could ensue.

I was never good at taking my medication or doing the sugar tests, I just sort of ignored it, pretended it wasn't there. I'd eat all the bad things as well, even though everyone told me that it was bad I always thought that I would be ok and they were just nagging. I got a bit sick sometimes with high blood sugars but I never really thought of it like damaging my body or dying. I didn't think any of that stuff was going to happen to me, I never really thought about the long term effects. (Hope)

While many adolescents with chronic illnesses manage their disease and treatment regimens extremely well, reduced adherence to medical regimens and poor disease self-management can be seen as developmentally appropriate in adolescence (Viner et al., 1999). Adherence to a treatment regimen requires appropriate cognitive capacities and personal organization as well as a personal belief that the treatment is required and beneficial (Vermeire et al., 2001).

The image that was projected to others was of utmost importance, especially for Hope and Faith, physical appearance equated directly with social acceptance. Perceiving themselves to be under scrutiny from the outside world meant that every venture out was met with trepidation. Having an ostomy created body image 
issues for most of the participants, consequently they focused on hiding the ostomy by wearing baggy clothing. Concealing their ostomy was important to them, as they did not want others to judge them or treat them differently.

I had to think about everything I was going to wear and make sure it wasn't noticeable. I used to get really upset because I wanted to wear the same kind of clothes and, you know, bikinis and tight things that the other girls were wearing, but the bag would poke out so I couldn't. I could never go swimming anyway back then, because the bags I had didn't stick properly if they got wet. I wore heaps of layers of clothing, baggy clothes, to try and hide it especially going into the changing rooms and getting your PE gear on and stuff. I'd have to go to the bathroom before and get changed so that it wasn't obvious that something was there. (Faith)

I used to look in the mirror and try to imagine just the half of my body without the stoma and what it would look like on the other side as well. Even with the scars, they look much less than they were, they seem nothing to me now. All the surgery scars would still be better than the stoma. (Hope)

\subsection{Through the looking glass}

Numerous challenges were met by the participants in the quest for self-concept and acceptance by society and the peer group. Lack of identification with peers was not solely related to physical differences in appearance. Significant concern was expressed about how they compared to friends in relation to academic and social achievements. Much doubt was placed in their ability to achieve the goals that each considered the mainstay in attaining adulthood. The demands of managing a chronic illness and the restrictions on life-style inherent in many disabling conditions increase dependence on the family, and carers, at a time when this should be decreasing (Eiser and Berrenberg, 1995). At the same time, young people may also become dissociated from their peer group, particularly in those with taxing medical conditions and those that mark them out as very different (Manworren, 1996).

Freiberg (1992) maintains that adolescents who have close, intimate friends have a better self-concept than those who have only superficial, fleeting friends. Each of the participants expressed a sense of comfort in being similar to their peers, 
fitting in with the crowd. The irony of adolescence is that in search of an individual identity, they want to be like everyone else in their peer group, to wear the same clothes, do the same things, go the same places.

\subsection{On the outside, looking in}

The peer relationships described were both supportive and unsupportive in equal distribution. Fear of losing potential friends and partners was a common theme in the experience of living with an ostomy. More often than not, the desire to preserve acceptable standing among others resulted in hesitation and avoidance of close or intimate relationships. They grieved their loss and this made them feel lonely and sometimes isolated.

Except for my family and a couple of friends I stopped myself from getting too close to anyone, especially boys, because I didn't really know how to tell people about it, it was just easier not to. (Hope)

Supportive friends often spent time with them at home when they were unable to go out and to socialise, and continued to call and include them in activities even when they often declined invitations. For these participants, the effects of good friends balanced the effects of unsupportive relationships and unfortunate reactions. It is possible that these friendships may have buffered, to some degree, the negative influences that living with an ostomy could have on self-concept.

\subsubsection{Sexual exploration}

Sexual exploration was often a source of internal and external conflict due to the physical presence of the stoma, physical discomfort and fear of rejection. The symptoms made exploring sexual relationships a difficult experience and placed a burden in relationships with partners who did not understand the extent of the discomfort. Erikson (1950) postulates that before intimacy can be achieved in a sexual relationship, a strong self-concept is needed to ensure that a mutual give and take can take place. He cautioned that sexual relationships are at risk of failure for those without a strong self-concept and identity and suggests that sexual intimacy has the potential to be affected throughout a lifetime.

\subsection{Never to walk alone}


Busen (2001) asserts that regression and dependency may occur when adolescents are under stress. Dealing with issues relating to surgery may be threatening to the adolescent's sense of control, privacy, peer relations, and body image. Fears related to these issues are not always articulated but may manifest in such behaviours as withdrawl, irritability, and refusal to co-operate with authority figures and hospital protocols. Inadvertently leaving the adolescent out of information gathering and decision making has the potential to increase dependency and further hinder the normal adolescent process of becoming independent.

The nurses and mum did everything for me, I just didn't even want to look at it [the stoma]. (Hope)

\subsubsection{Supportive connections}

A clear theme in these experiences was the supportive roles of parents, siblings, friends and others and the impact of those roles. The mother-child bond was accentuated among the study participants by their dependence on their mothers for support, care, and advocacy. Traditional developmental theory, it is suggested by Blos (1962) and Erikson (1950), requires separation before an autonomous identity is assumed. According to this theory, adolescents with an ostomy, who depend heavily on their mothers, would have difficulty completing the traditional task of separation and therefore be unable to develop an autonomous identity. This is disputed by Surrey (1991), who proposes that self-identity is fostered through the connectedness of relationships. Surrey's model supports a process that would allow the adolescent to move close to their mother, to be cared for when need required, and to move away when circumstances permitted. This closeness would serve to enhance development and, it is further suggested by Surrey that attachment between a mother and child is a necessary relational base for all other relationships to evolve. "Such an interconnected relationship would respond to the needs of both the mother and child since each is able to "care for, respond to, and attend to" each other's well-being" (Surrey, 1991, p. 37). This study's findings show that strong mother-child relationships did ease the disruption to daily life, assisted in their care, and buffered their relationships with school officials and healthcare providers.

All of the participants described in one way or another how difficult the experience 
could be. The restrictions imposed on them and their lifestyle, the unpredictability and subsequent feeling of loss of control, the pain they had to endure and the fact that they felt different to their peers. There was also emotional pain. Some found that illness and the ostomy was at times hard to deal with, causing great stress and anxiety almost on a daily basis. Hospitalisations were very difficult and they thought they would never get better with all of the complications. Overall, participants summed up what they needed most was support from all individuals important to them in their lives. 


\section{CHAPTER SIX \\ Significance and implications of the study}

\subsection{Introduction}

In this chapter, I discuss the strengths and limitations of the study with respect to research design and method. Implications for clinical practice, education, future research, and health policy in New Zealand are discussed in consideration of the findings of this study.

\subsection{Strengths and limitations of the study}

The use of narrative inquiry to inform my methodology was appropriate for this study. The study design is congruent with the aims of the study identified in chapter one. The aim of the study was not to produce generalisable findings, but to describe the experience of four people among this unique adolescent population. Their individual experiences are unique and bound exclusively to that time in which they were told. However, aspects of the experiences will have some commonality and may, therefore, resonate with others among the population and serve as a beginning to understanding. This research adds to the existing knowledge base and serves as a basis for consolidation, and improvement in the care of adolescents living with an ostomy.

In undertaking this research I recognised that my role as researcher, as well as being a nurse working in the specialty area could potentially create bias in the findings. Some of the participants had been patients of mine or possibly could be in the future. I did feel that for some of the participants there was a reluctance to divulge negative feelings or relate negative experiences in relation to nursing care in general or that which they received either in the unit or in the wider organisation where I work. The findings present both positive and negative views in relation to nursing care, though I received little negative information from the participants already known to me. I later considered also, how I might have been influenced in relating negative experiences if I was in some way connected to it. 


\subsection{Implications for practice}

The findings of this study, although based on a small population, nevertheless have implications for practice. The findings revealed that adolescents living with an ostomy not only need to have their physical needs taken care of, but their psychosocial concerns as well. Adolescents are biologically, cognitively, socially and emotionally distinct, each maturing at a different rate. Development in one area is not necessarily indicative of the overall level of development (Singleton, 2007). It is therefore important for nurses to be mindful of the developmental level of the adolescents with whom they are working and the impact that this can have.

Nurses are in a position where they are able to provide opportunities for these individuals to express their concerns in a supportive environment. As seen in the literature, ostomy surgery can alter one's body image and ultimately affect selfesteem. Identity forming is an essential part of the adolescent development process and implies the incorporation of any chronic condition in body image and one's self. This process is gradual, and adolescence is a time during which new questions regarding the cause, the nature and the outcome of any disease or disability arise. Findings in this study suggest that, because of the ostomy, these individuals felt different from their peers. Nurses need to recognise this and give the patient time to come to terms with changes in their body image. Developing an empathetic relationship is crucial in order to allow the individual to express these feelings and concerns.

Illness can serve as a constant reminder of vulnerability, deficit, and limitation and may hinder development of independence by creating a feeling of dependency. There is evidence that the level of adjustment to illness in early adolescence predicts disease control in the transition into young adulthood and that psychosocial interventions to improve self-management produce long-term behaviour change. Fostering the development of self-care skills will enhance self-esteem and autonomy, and empower the adolescent. Many adolescents may feel too tightly controlled and may ask for more freedom in managing their condition. Nurses need to respect adolescents need for rejection of adult support including parents and accept 
noncompliant behaviour while emphasising appropriate behaviour and setting limits.

Findings also suggest that support is an integral part of the experience. Nurses can be instrumental in assisting adolescents with an ostomy to explore and develop ways to manage and cope with pain and other symptoms by providing them information about resources. Assessment of the type and extent of social support is important when planning care. Attention and care should be given to opportunities to provide thorough assessment, education, support, and follow up information, including advocacy with specialists and involvement of social workers to assist the individual and their family.

Nurses are in key positions to assist adolescents with this disease and their families in navigating the multifaceted healthcare system. The participants in this study reported that often they did not receive adequate and consistent information. Information given to adolescents needs to be in simple terms. Communication has proved to be of widespread concern in caring for adolescents and its effectiveness is pivotal to achieving positive outcomes. Raised awareness of the reality of the experience can contribute to developments in the way nurses communicate with adolescents and their families. In working with adolescents, the treatment of disease, the prevention of ill health and the promotion of healthy behaviours are played out against a background of rapid physical, psychological, and social developmental changes. Continuity of care, privacy, and confidentiality are among the features of care that are most often asked for by adolescents. The adolescent needs to establish a safe and trusting relationship with those providing care.

\subsection{Implications for nursing education}

This study contributes to the existing body of knowledge on adolescents by helping nurses who care for this population understand their experience of living with an ostomy. It is important to teach nurses how to conduct complete and accurate health history and assessment, and in particular to explore sexuality. Age and stage of development are important variables for nurses and other healthcare providers to consider when treating adolescents. It is important to learn how to talk with adolescents, a skilled nurse who asks appropriate questions will elicit a complete and thorough assessment that may reveal more about the situation 


\subsection{Implications for further research}

This study supports the need for further research on adolescents living with an ostomy and provides a starting point for other directions. The participants in this study described having an ostomy and subsequent treatments as sources of disruption and interruption in their adolescent lives. Further qualitative studies may investigate the variables and a quantitative approach to quality of life issues may further elucidate the extent of this disruption and assist in developing interventions to minimise disruption and improve quality of life. All of the participants in this study were Caucasian and so further research could explore the cultural influences on the experience.

The long term health status of adolescents living with an ostomy is unknown. More specifically, the long term physical and emotional effects of surgical treatment and medical treatment are unclear. Longitudinal research beginning with teenagers or retrospective studies could explore these effects. Further, since treatments have often been adapted from adults, future studies specific to adolescents have the potential to enhance treatments unique to adolescents and thus improve their outcomes. Intervention studies are needed to explore lifestyle changes among adolescents living with an ostomy. Such studies could focus on nutrition, coping strategies, exercise, and alternative therapies to improve quality of life in this population.

\subsection{Implications for policy}

Implications for health and social policy include the need for further funding to create centres for the treatment of adolescents. The creation of such a centre has the potential to provide a multidisciplinary approach to the diagnosis and care of this population. A multidisciplinary centre would not only address surgical options, but also offer medical management, counselling, alternative therapies, nutritional support, exercise programs, and pain management. The model would also provide a venue for multidisciplinary research. Within the healthcare system, there is a need to set policy that coordinates care or adolescents, thus avoiding fragmentation of health care services for adolescents living with an ostomy.

\subsection{Summary}

In this chapter I have discussed the suitability of the methodology for the research 
project and outlined the strengths and limitations of the study. The findings of this study and their implications offer a variety of ways that nurses and other healthcare providers can improve the care of adolescents living with an ostomy. Understanding the antecedents and consequences of adolescent autonomy will facilitate the development of more appropriate health promoting interventions based on developmental needs. Recognising its impact on physical and emotional wellbeing is critical to developing appropriate treatments and interventions for adolescents living with an ostomy and thereby improves outcomes. 


\section{AFTERWORD}

\section{Final reflection}

The journey to completion of this thesis has been a great deal longer than envisaged. My perspective has been broadened and my understanding of the experience of these adolescents has deepened. The findings of the study vividly demonstrate the importance health professionals in influencing an experience. The reality of the experiences, as I read back on my findings, appear to demonstrate negatives with powerful description. What may not be so evident is that these individuals have fought their battles bravely and look back positively on the experience as a whole. The negatives and the positives are what have shaped who they are and who they will become. If those things had never been, they would never know. 


\section{APPENDIX A \\ Participant Contact Letter}

[Date]

Susan Garthwaite

Master of Nursing (Clinical) Student

Graduate School of Nursing, Midwifery and Health

Victoria University of Wellington

[Phone]

[E-mail]

\section{[Contact Name]}

[Contact Address]

Dear [Name],

My name is Susan Garthwaite, I am a nurse educator and staff nurse on the [Unit] at [The DHB]. I am also a student at Victoria University of Wellington undertaking a Master of Nursing (Clinical) degree. As a component of this degree I am carrying out a research project. For this project I wish to understand what it is like to live with a stoma during adolescence. This study has received ethical approval from the Central Regional Ethics Committee.

The [DHB] Stomatherapist, has identified you as meeting the criteria for my research and has forward your contact details to me. I will contact you a few days after sending this information to ascertain if you are interested and if so answer any questions you may have. I would sincerely appreciate your participation as I believe that hearing and understanding your experiences would greatly benefit future patients and nursing staff. You must understand, however, that you are under no obligation to volunteer as a participant in the study.

If you agree to participate in this study you would be required to meet with me for an interview of approximately one hour's duration. At that time you would discuss your experiences of living with a stoma during adolescence.

I look forward to talking with you.

Yours sincerely,

Susan Garthwaite. 


\section{APPENDIX B}

Participant Consent Form

Project title: The experience of adolescents living with a stoma: A narrative inquiry.

\section{Researcher details}

Susan Garthwaite

Master of Nursing (Clinical) Student

Graduate School of Nursing, Midwifery and Health

Victoria University of Wellington

$\mathrm{Ph}:$ [

E-Mail: [ ]

\section{REQUEST FOR INTERPRETER}

\begin{tabular}{|c|c|c|c|}
\hline English & I wish to have an interpreter. & Yes & No \\
\hline Maori & $\begin{array}{l}\text { E hiahia ana ahau ki tetahi kaiwhakamaori/kaiwhaka pakeha } \\
\text { korero. }\end{array}$ & $\mathrm{Ae}$ & Kao \\
\hline $\begin{array}{l}\text { Cook } \\
\text { Island }\end{array}$ & Ka inangaro au i tetai tangata uri reo. & $\mathrm{Ae}$ & Kare \\
\hline Fijian & Au gadreva me dua e vakadewa vosa vei au & Io & Sega \\
\hline Niuean & $\begin{array}{l}\text { Fia manako au ke fakaaoga e taha tagata fakahokohoko } \\
\text { kupu. }\end{array}$ & $\mathrm{E}$ & Nakai \\
\hline Samoan & Ou te mana'o ia i ai se fa'amatala upu. & Ioe & Leai \\
\hline Tokelaun & $\begin{array}{l}\text { Ko au e fofou ki he tino ke fakaliliu te gagana Peletania ki } \\
\text { na gagana o na motu o te Pahefika }\end{array}$ & Ioe & Leai \\
\hline Tongan & Oku ou fiema'u ha fakatonulea. & Io & Ikai \\
\hline
\end{tabular}

I have read and I understand the information sheet dated ( ) for volunteers taking part in the study designed to explore the experience of adolescents YES NO living with a stoma.

I have had the opportunity to discuss this study. I am satisfied with the answers I have been given.

I understand that taking part in this study is voluntary (my choice) and that I may withdraw from the study at any time. 
I understand that my participation in this study is confidential and that no material that could identify me will be used in any reports on this study.

I understand that stopping the interview will be discussed if it should appear harmful to me or that I may stop the interview at any time myself.

I understand that the interview will be taped and transcribed (written as spoken on the tape recording), and these records will be stored for ten years.

I understand that the transcribed story may be quoted in part or in full for the purpose of writing the research thesis or compiling reports.

YES NO

I understand these records may be used in further research based on this study within 10 years and that this has received ethical approval.

YES NO

I have had time to consider whether to take part.

YES NO

I know whom to contact if I have any ill effects from this study

YES NO

I know whom to contact if I have any questions about the study.

YES NO

I wish my G.P. to be informed of my participation in this research study.

YES NO

I have received a copy of The Health and Disability Consumer Code of Rights

YES NO

\section{I} hereby consent to take part in this study.

Signature of participant

Susan Garthwaite

Master of Nursing (Clinical) Student

Graduate School of Nursing,

Midwifery and Health

Victoria University of Wellington

Ph: [

E-Mail: [
Signature of witness

Witness name:

Project explained by: Susan Garthwaite Project role: Researcher Signature

If you would like to discuss this information further my supervisor contact details are:

Dr. Kathy Nelson

Lecturer

Graduate School of Nursing, Midwifery and Health

Victoria University of Wellington

Ph: [

E-Mail: [ ] 


\section{APPENDIX C Participant Information Sheet}

\section{Principal Investigator}

Susan Garthwaite

Master of Nursing (Clinical) Student

Graduate School of Nursing, Midwifery and Health

Victoria University of Wellington

$\mathrm{Ph}:$ [

E-mail: [

\section{Supervisor}

Dr. Kathy Nelson

Lecturer

Graduate School of Nursing, Midwifery and Health

Victoria University of Wellington

$\mathrm{Ph}$ : [

E-mail: [ ]

\section{Title}

The experience of adolescents living with a stoma: A narrative inquiry.

\section{Introduction}

You are invited to take part in the research project which is described in this information sheet. After you have received this sheet I shall contact you to ascertain if you are interested in taking part and if so answer any questions you may have. You are under no obligation to take part in this study if after reading this form you decide you do not wish to.

If you agree to participate in this study you would be required to meet with me for an interview of approximately one hour's duration. At that time you would discuss your experiences of living with a stoma during adolescence.

\section{About the Study}

The aims of the study are:

1. To explore the experience of being an adolescent living with a stoma.

2. To gain understanding of the experience of being an adolescent living with a stoma.

3. To use the information gathered to help others understand what it is to be an adolescent with a stoma and learn from their experiences.

4. To consolidate and improve care of adolescents with a stoma in the hospital and in the outpatient community setting. 


\section{Participants}

I invite you to take part in this research project. You would be one of four people that I will talk with.

You will have a choice of where the interview will take place, or a venue can be arranged to suit you. In the interest of safety, private homes will not be permitted.

I will ask you to have one interview which will take approximately one hour. You do not have to answer all the questions and the interview may be stopped at any time that you wish.

I will ask your permission for the interview to be tape recorded and transcribed (Written down as it has been spoken).

The tape recording and transcription will be destroyed in ten years' time following the completion of the research. If you would like a copy of the transcription, one will be made available for you.

\section{Disclaimer}

The researcher is an employee of [DHB] and may have had a previous professional relationship with you or may do so in the future.

Identities are protected, the researcher shall not divulge information obtained during the study for any purpose other than to assist the research.

Information obtained during the study will not have influence on any future relationship with [The DHB] service or provider.

Any sensitive material pertaining to staff or patients within the district health board which may arise during the interviews will warrant consultation with the research supervisor and will not be identifiable in the report.

\section{Benefits and risks}

The study will help staff working within the hospital and community setting to have a better understanding of what it is like to be an adolescent living with a stoma. It is anticipated that this information would be of benefit to not only hospital staff, but other adolescents and their family and friends.

It is known that it can be helpful for someone who has lived through a challenging or difficult experience to be able to talk with someone about what has happened. However, this may also sometimes be upsetting. In case you feel that the interview has raised matters with which you feel you need further help I will leave a sheet with the name of a counsellor you could contact. This would be at no financial cost to yourself for two sessions.

You will not be paid to take part in the research. You will be offered a book or petrol voucher to the value of $\$ 30$ in appreciation of your participation and to remunerate any travel costs you may have incurred. 
I am interviewing adults (over 18) who:

1. Have lived with or had a stoma formed during adolescence (12-19 yrs old)

2. Are aged between 18 and 30 years old

3. Are able to communicate in English

4. Are willing to share their experience with a researcher

\section{Participation}

Whether or not you participate in this study is entirely your choice. You do not have to take part, and if you choose not to, no further contact will be made.

If you do agree to take part you are free to withdraw from the study at any time, without having to give a reason, this will not affect my academic progress.

We will discuss stopping the interview if it seems too upsetting for you. Participation in this study will be stopped should any harmful effects appear or if it is felt to be not in your best interest to continue.

You can stop the interview yourself at any time that you wish.

\section{General}

Questions you may have.

Will my GP be told I am in the study?

If you wish I will tell your GP that you are taking part in this study.

What will happen at the end of the study?

If you say at the time of the interview that you want a transcription of the tape I would ring and arrange to get this to you when it is completed. I will leave a contact number for a counsellor, whom you could see twice at no cost to yourself if you feel you need counselling help as a result of issues raised in the interview.

Where can I get more information about the study?

I will contact you a few days after you receive this information. You may choose to make contact sooner or to speak to my academic supervisor Denise Blanchard at the Victoria University of Wellington using the contact details provided in this information sheet.

If I need an interpreter, can one be provided?

Participants in the study will be required to speak and understand English, however if at any point you feel you require an interpreter, one can be arranged for you. 
If you have any queries or concerns regarding your rights as a participant in this study you may wish to contact a Health and Disability Advocate,

Mid and lower North Island ph: 0800423638

\section{Confidentiality}

No material which could personally identify you will be used in any reports on this study unless you choose otherwise.

The person who transcribes the tape will sign an agreement of confidentiality.

Tapes and transcripts will be labelled with a pseudonym (fictitious name) as soon as they are completed, and will be handled only under this name from then on. They will be stored in a locked file, and will be destroyed ten years after the completion of the study.

For academic and personal safety reasons I will need to discuss the research with my supervisor at the Graduate School of Nursing, Midwifery and Health at Victoria University of Wellington, and also with a professional supervisor. Confidentially will be maintained in these situations.

\section{Results}

A report of the findings of the research will be sent to each participant.

At the end of the research I would expect to present reports to health professional groups and at relevant conferences. I will also seek to publish reports in professional journals. Publication usually takes one to two years following completion of the research. The thesis will be available at the Victoria University of Wellington general library. If you have any further suggestions as to how results might be useful, I will be pleased to hear them when we meet to discuss this information.

\section{Approval}

This study has received ethical approval from Central Regional Ethics Committee and [..] District Health Board.

\section{Please feel free to contact myself or my supervisor if you have any questions about this study.}




\section{APPENDIX D \\ Transcribers Confidentiality Agreement}

To ensure confidentiality for the persons being interviewed

$\mathrm{I}$,

state that I will not divulge any information contained in the transcripts I produce for the researcher Susan Garthwaite.

Signature

Date

Thank you for signing this agreement

Researcher

Susan Garthwaite

Signature Date 


\section{APPENDIX E \\ Interview Schedule}

\section{The experiences of adolescents living with a stoma}

\section{Motivation}

- What attracted you to be involved in this research?

\section{Narrative}

- Please describe your experience(s) of living with a stoma as an adolescent.

- Include anything that you think would help me to understand what it is like to be an adolescent with a stoma.

- I am interested in your memories, thoughts and feelings related to your experience(s).

The interview will continue primarily as the participant's narrative from this point. Questions will be asked to clarify and seek further information as needed throughout the interview. These are as follows:

- How did you feel?

- What happened next?

- What was this like?

- How did that go?

- How did you cope with this?

- What was your reaction?

- What was their reaction?

- What effect did this have on you?

- Did you feel prepared?

- What support did you receive?

- What were your concerns?

- Did you seek additional help?

Certain prompters may be used to obtain an exhaustive description of the experience and to maintain the flow of the narrative. These are as follows:

The participant may be asked to address:

- Changes in social situation in regard to having a stoma

- The effect of having a stoma on school and/or work life

- How or if they told friends and family about the stoma

- Their concerns about socialisation and reaction of friends

- Body image disturbances

- Support received from hospital/outpatient service or other organisation

- Was there any feelings of uncomfortableness in talking about what happened? 
- Were there any feelings of upset, numbness, trouble thinking clearly, vivid memories or sensory experiences, difficulty sleeping, bad dreams, anxiety or physical problems?

- Did the experience cause you to re-evaluate your life or make changes to future plans?

- Expectations for the future

\section{Closure}

- Is there anything else you would like to tell me?

- What are your initial thoughts about the interview?

\section{Thanks}

- Thank you very much for sharing your experience with me, you have shared some valuable information. 


\section{APPENDIX F \\ Ethics Committee Approval}

Health

and

Disability

Ethics

Committees

20 December 2006
Central Regional Ethics Committee

Ministry of Health Level 2 1-3 The Terrace

PO Box 5013

Wellington

Phone (04) 4962405

Fax (04) 496219

stokes вalley

Lower Hutt

Dear Susan

experience of adoiescents fiving with a stoma - A narrative inquiry

Hutt Valley DHB

The above study has been given ethical approval by the Central Regional Ethics Committee.

Accreditation

The Committee involved in the approval of this study is accredited by the Health Research Council and is constituted and operates in accordance with the Operational Standard for Ethics Committees. April 2006.

Final Report

The study is approved until August 2007. A final report is required at the end of the study and a form to assist with this is available from the Administrator. If the study will not be completed as advised, please forward a progress report and an application for extension of ethical approval one month before the above date. Report forms are available from the administrator.

\section{Amendments}

It is also a condition of approval that the Committee is advised of any adverse events, if the study does not commence, or the study is altered in any way, including all documentation eg advertisements, letters to prospective participants.

Please quote the above ethics committee reference number in all correspondence.

It should be noted that Ethics Committee approval does not imply any resource commitment or administrative facilitation by any healthcare provider within whose facility the research is to be carried out. Where applicable, authority for this must be obtained separately from the appropriate manager within the organisation.

Yours sincerely

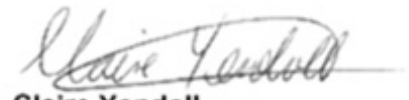

Claire Yendoll

Central Ethics Committee Administrator

Email: claire_yendoll@moh.govt.nz 


\section{REFERENCES}

Age of Majority Act, No. 137, New Zealand Statutes (1970).

Alma-Ata Declaration (1978). In: Report of the International Conference on Primary Health Care, Alma-Ata, USSR, 6-12 September 1978. Geneva, World Health Organisation.

Atkinson, P., \& Silverman, D. (Eds.). (1997). Kundera's immortality: The interview society and the invention of the self. Qualitative Inquiry, 3, 304-325.

Atkinson, R. (1997). Adolescence. Maine: University of Southern Maine.

Bailey, P., \& Tilley, S. (2002). Storytelling and the interpretation of meaning in qualitative research. Journal of Advanced Nursing, 38(6), 574-583.

Barton, S. (2004). Narrative inquiry: Locating aboriginal epistemology in a relational methodology. Journal of Advanced Nursing, 45(5), 519-526.

Beitz, J. M. (1999). The lived experience of having an ileoanal reservoir: A phenomenologic study. Journal of Wound, Ostomy and Continence Nursing, 26(4), 185-200.

Beitz, J. M., \& Rager Zuzelo, P. (2003). The lived experience of having a neobladder. Western Journal of Nursing Research, 25(3), 294-316.

Benner, P. (1984). From novice to expert: Excellence and power in clinical nursing practice. Menlo Park, CA: Addison-Wesley.

Black, P. (2004). Psychological, sexual and cultural issues for patients with a stoma. British Journal of Nursing, 13(12), 692-697.

Blos, P. (1962). On adolescence. New York: The Free Press.

Blum, R. W., Resnick, M. D., Nelson, R., \& St. Germaine, A. (1991). Family and peer issues among adolescents with spina bifida and cerebral palsy. Pediatrics, 88, 280-285.

Boykin, A., \& Schoenhofer, S. O. (1991) Story as link between nursing practice, ontology, epistemology. Journal of Nursing Scholarship. 23(4), 245-248. 
British Paediatric Association. (1996). The needs and cares of adolescents (Report). London: British Paediatric Association.

Brown, H., \& Randle, J. (2005). Living with a stoma: A review of the literature. Journal of Clinical Nursing 14, 74-81.

Bruner, J. (1990). Acts of meaning. Cambridge, MA: Harvard University Press.

Brydolf, M., \& Segesten, K. (1996). Living with ulcerative colitis: Experiences of adolescents and young adults. Journal of Advanced Nursing, 23, 39-47.

Busen, N. H. (2001). Perioperative preparation of the adolescent surgical patient. AORN, 73(2), 337-363.

Cadman, D., Rosenbaum, P., Boyle, M., \& Offord, D. R. (1991). Children with chronic illness: Family and parent demographic characteristics and psychosocial adjustment. Pediatrics, 87, 884-889.

Canadian Department of Justice. (1985). Criminal Code, No. C-46. Canadian Statutes. Retrieved 21st February, 2008 from http://www.justice.gc.ca /en/showdoc/cs/c-46.html.

Canadian Paediatric Society, Adolescent Health Committee. (2008, February). Age Limits and adolescents. Retrieved from http://www.cps.ca /english/statements /am /ah03-02.htm

Care of Children Act, No. 90, New Zealand Statutes (2004).

Carlsson, E., Berglund, B., \& Nordgren, S. (2001). Living with an ostomy and short bowel syndrome: Practical aspects and impact on daily life. Journal of Wound, Ostomy and Continence Nursing, 28(2), 96-105.

Casati, J., Toner, B., De Rooy, E., Drossman, D., \& Maunder, R. (2000). Concerns of patients with inflammatory bowel disease. A review of emerging themes. Digestive Diseases and Sciences, 45(1), 26-31.

Cepeda, M. L., Allen, F. H., Cepeda, N. J., \& Yang, Y. (2000). Physical growth, sexual maturation, body image and sickle cell disease. Journal of the National Medical Association, 92, 10-14.

Chase, S.E. (2005). Narrative Inquiry: Multiple lenses, approaches, voices. In N. Denzin \& Y. Lincoln (Eds.), Handbook of Qualitative Research (3rd ed., pp. 651-678). California: Sage Publications. 
Clandinin, J., \& Connelly, M. (2000). Narrative inquiry: Experience and story in qualitative research. San Francisco: Jossey-Bass.

Clandinin, J., \& Connelly, M. (1994). Personal experience method. In N. Denzin \& Y. Lincoln (Eds.), Handbook of Qualitative Research (pp. 413-427). Thousand Oaks: Sage Publications.

Coffey, A. \& Atkinson, P. (1996). Making sense of qualitative data: Complementary research strategies. Thousand Oaks, CA: Sage Publications.

Collins. (1979). Collins dictionary of the English Language. London: Collins.

Crimes Act, No. 43, New Zealand Statutes (1961).

Daniel, J. M. (2001). Young adults' perceptions of living with chronic inflammatory bowel disease. Gastroenterology Nursing, 25(3) 83-64.

Dashiff, C. (2000). Data collection with adolescents. Journal of Advanced Nursing, 33(3), 343-349.

Decker, J. W. (2000). The effects of inflammatory bowel disease on adolescents. Gastroenterology Nursing, 23(2), 63-66.

Deeny, P., \& McCrea, H. (1991). Stoma care: The patient's perspective. Journal of Advanced Nursing, 16, 39-46.

Denning, S. (2004). Telling tales. Harvard Business Review, 82(5), 122-129.

Dollard, J. (1949). Criteria for the life history (2 $2^{\text {nd }}$ ed.). New York: Peter Smith.

Drewery, W., \& Bird, L. (2004). Human development in Aotearoa: A journey through life. (2nd ed.). Sydney: McGraw-Hill.

Dudley-Brown, S. (1996). Living with ulcerative colitis. Gastroenterology Nursing, 19(2), 60-64.

Education Act, No. 80, New Zealand Statutes (1989).

Eiser, C., \& Berrenberg, J. (1995). Assessing the impact of chronic disease on the relationship between parents and their adolescents. Journal of Psychosomatic Research, 39, 109-114.

Elkind, D. (1981). The hurried child: growing up too fast too soon. California: Addison- Wesley. 
Emden, C. (1998a). Theoretical perspectives on narrative inquiry. Collegian 5(2), 30-35.

Emden, C. (1998b). Conducting a narrative analysis. Collegian 5(3), 34-39.

Erikson, E. (1950). Childhood and society. New York: W. W. Norton \& Co.

Erikson, E. (1968). Identity: Youth and crisis. New York: W. W. Norton \& Co.

Erwin-Toth, P. (1999). The effect of ostomy surgery between the ages of 6 and 12 years on psychosocial development during childhood, adolescence, and young adulthood. Journal of Wound, Ostomy and Continence Nursing, 26(2), 77-85.

Estes, C. (1995). Women who run with the wolves: Myths and stories of the wild women archetype. New York: Ballantyne Books.

Everall, R. D., Bostick, K. E. \& Paulson, B. L. (2005). I'm sick of being me: Developmental themes in a suicidal adolescent. Adolescence, 40(160), 693-708.

Federation of New Zealand Ostomy Societies. (2007). Retrieved 21st February, 2008 from http://www.ostomyinternational.org /newzealand.html.

Frank, A. W. (1995). The wounded storyteller: Body, illness and ethics. Chicago: University of Chicago Press.

Freiberg, K. L. (1992). Human development: A life span approach. (4 $\left.{ }^{\text {th }} \mathrm{ed}.\right)$. Boston: Jones and Bartlett.

Freud, S. (1925). Some psychical consequences of the anatomical distinction between the sexes. In J. Strachey (Ed. and Trans.), The standard edition of the complete psychological works of Sigmund Freud (Vol. 19, pp. 248258). London: Hogarth Press.

Freyer, D. R. (2004). Care of the dying adolescent: Special considerations. Pediatrics, 113(2), 381-388.

Gambling Act, No. 51, New Zealand Statutes (2003).

Gaydos, H. L. (2005). Understanding personal narratives: An approach to practice. Journal of Advanced Nursing, 49(3), 254-259. 
Gerhardt, U. (1990). Qualitative research on chronic illness: The issue and the story. Social Science and Medicine, 30, 1149-1159.

Ghosh, S., Drummond, H., \& Ferguson, A. (1998). Neglect of growth and development in the clinical monitoring of children and teenagers with inflammatory bowel disease. British Medical Journal, 317, 120-21.

Gillis, A., \& Jackson, W. (Eds.). (2002). Research for Nurses: Methods and interpretation. Philadelphia: F.A. Davis Company.

Goodfellow, J. (1997). Narrative Inquiry: Musings, methodology and merrits. In J Higgs (Ed.). Qualitative research: Discourse on methodologies (pp. 6174). Sydney: Hampden Press.

Gooszen, A., Geelkerken, R., Herman, J., Lagaay, M., \& Gooszen, H. (2000). Quality of life with a temporary stoma. Diseases of the Colon \& Rectum, 43, 650-655.

Gray, A. (1987). Teenangels: Being a New Zealand teenager. Wellington: Allen \& Unwin/Port Nicholson Press.

Hall, G. S. (1904). Adolescence: Its psychology and its relations to physiology, anthropology, sociology, sex, crime, religion, and education. New York: Appleton.

Havighurst, R. J. (1952). Developmental tasks and education. New York: David McKay.

Hawkes, T. (1972). Metaphor. London: Methuen \& Co.

Heinrich, K. T. (1992). Create a tradition: Teach nurses to share stories. Journal of Nursing Education. 31(3), 141-143.

Hodges, H. (1997). Seeking balance to dialectic tensions in teaching through philosophic inquiry, Image: Journal of Nursing Scholarship, 29, 349-354.

Huebner, A., (2000). Adolescent growth and development. Virginia Cooperative Extension.

Hughes, A. (1991). Life with a stoma. Nursing Times, 87(25), 67-68.

Hyden, L. (1997). Illness and narrative. Sociology of Health \& Illness, 19(1), 4869. 
Jack, D. (1991). Interview analysis: Listening for meaning. In S. Gluck \& D. Patai (Eds.), Women's words: The feminist practice of oral history (pp. 18-23). New York: Routledge.

Junkin, J., \& Beitz, J. (2005). Sexuality and the person with a stoma. Journal of Wound, Ostomy and Continence Nursing, 32(2), 121-128.

Karadag, A., Mentes, B., Uner, A., Irkorucu, 0., Ayaz, S., \& Ozdan, S. (2003). Impact of stomatherapy on quality of life in patients with permanent colostomies or ileostomies. International Journal of Colorectal Disease, $18,234-238$.

Kelly, M. P. (1991). Coping with an ileostomy. Social Science and Medicine, 33(2), 115-125.

Kelly, T. \& Howie, L. (2007). Working with stories in nursing research: Procedures used in narrative analysis. International Journal of Mental Health Nursing, 16, 136-144.

Kelman, G., \& Minkler, P. (1989). An investigation of quality of life and selfesteem among individuals with ostomies. Journal of Enterostomal therapy, 16, 4-11.

Kleinman, A. (1988). The illness narratives: Suffering, healing and the human condition. New York: Basic Books.

Klopp, A. L. (1990). Body image and self-concept among individuals with stomas. Journal of Enterostomal Therapy, 17, 98-105.

Koch, T. (1998). Story telling: Is it really research? Journal of Advanced Nursing, 28(4), 882-890.

Kokkonen, J. (1995). The social effects in adult life of chronic physical illness since childhood. European Journal of Pediatrics, 154, 676-681.

Kreffing, L. (1991). Rigour in qualitative research: The assessment of trustworthiness. The American Journal of Occupational Therapy, 45(3), 214-222.

Kyngas, H., Kroll, T., \& Duffy, M. (2000). Compliance in Adolescents with chronic diseases: A review. Journal of Adolescent Health, 26, 379-388.

Lakoff, G., \& Johnson, M. (1980). Metaphors we live by. Chicago: University of Chicago Press. 
Land Transport Act, No. 110, New Zealand Statutes (1998)

Lask, B., Jenkins, J., Nabarro, L., \& Booth, I. (1987). Psychosocial sequelae of stoma surgery for inflammatory bowel disease in childhood. Gut, 28, 1257-1260.

Leight, S. B. (2002). Starry night: Using story to inform aesthetic knowing in women's health nursing. Journal of Advanced Nursing, 37(1), 108-114.

Lieblich, A., Tuval-Mashiach, R., \& Zilber, T. (1998). Narrative research: Reading, analysis and interpretation. (Vol. 47). Thousand Oaks, CA: Sage.

Lincoln, Y., \& Guba, E. (1985). Naturalistic inquiry. California: Sage Publications.

Lincoln, Y., \& Guba, E. (2000). Paradigmatic controversies, contradictions, and emerging confluences. In N. Denzin \& Y. Lincoln (Eds.). Handbook of Qualitative Research (2nd ed., pp. 163-188), California: Sage Publications.

MacDonald, H. (1996). Mastering Uncertainty: Mothering the child with asthma. Pediatric Nursing, 22, 55-59.

Males, M. (1997). Adolescents: Daughters or alien sociopaths? Lancet, 349, S13-S16.

Manderson, L. (2005). Boundary breaches: The body, sex and sexuality after stoma surgery. Social Science and Medicine, 61, 405-415.

Manworren, R. (1996). Developmental effects on the adolescent of a temporary ileostomy. Journal of Wound Ostomy and Continence Nursing, 23(4), 210-217.

Marriage Act, No. 92, New Zealand Statutes (1955).

Martin-McDonald, K., \& Biernoff, D. (2002). Initiation into a dialysis dependant life: An examination of rites of passage. Nephrology Nursing Journal, 29 (4), 347-352.

Martinsson, E. S., Josefsson, M., \& Ek, A. (1991). Working capacity and quality of life after undergoing an ileostomy. Journal of Advanced Nursing, 16, 1035-1041. 
McEldowney, R. (2002). Shape-shifting: Stories of teaching for social change in nursing. Unpublished Doctor of Philosophy, Victoria University of Wellington, New Zealand.

McLaughlin, D., \& Tierney. W. G. (Eds.). (1993). Naming silenced lives: personal narratives and processes of educational change. New York: Routledge.

McLeod, J. (2001). Qualitative Research in Counselling and Psychotherapy. London: Sage Publications.

McVey, J., Madill, A., \& Fielding, D. (2001). The relevance of lowered personal control for patients who have stoma surgery to treat cancer. The British Journal of Clinical Psychology, 40, 337-360.

Michaud, P. A., Suris, J. C., \& Viner, R. (2004). The adolescent with a chronic condition. part 1: Developmental issues. Archives of Disease in Childhood, 89, 938-942.

Michaud, P., Blum, R., \& Ferron, C. (1998). Bet you I will! Risk or experimental behaviour during adolescence? Archives of Pediatrics and Adolescent Medicine, 152, 224-226.

Mishel, M. H. (1999). Uncertainty in chronic illness. Annual Review of Nursing Research, 17, 269-294.

Mishler, E. (1986). Research interviewing: Context and narrative. Cambridge, MA: Harvard University Press.

Mishler, E. (1991). Once upon a time. Journal of Narrative and Life History, 12 (2/3), 101-108.

Motta, G. J. (1987). Life span changes: Implications for ostomy care. Enterostomal Therapy, 22(2), 333-339.

Munhall, P. \& Oiler, C. (1986). Nursing Research: A qualitative perspective. Norwalk CT: Appleton-Century-Crofts.

National Minimum Drinking Age Act, No. 158, United States Congress (1984). Retrieved 1st June, 2007 from http//www.youthrights.org.

Newton, A. Z. (1995). Narrative Ethics. Cambridge, MA: Harvard University Press. 
Nugent, K., Daniels, P., Stewart, B., Patankar, R., Johnson, C., \& Chir, M. (1999). Quality of life in stoma patients. Diseases of the Colon \& Rectum, 42(12), 1569- 1574.

O'Brien, B. K. (1999). Coming of age with an ostomy. The American Journal of Nursing, 99(8), 71-76.

Overcash, J. A. (2004). Narrative research: A viable methodology for clinical nursing. Nursing Forum, 39(1), 15-22.

Owen, J. (2008). Papageorgiou, A. The lived experience of stigmatisation in patients after stoma reversal. Gastrointestinal Nursing, 6(4), 26-33.

Palladino, G. (1997). Teenagers: An American history. New York: Basic Books.

Pennebaker, J. W. (1997). Opening up: The healing power of emotional expression. New York: Guilford Press.

Pennebaker, J. W., \& Seagal, J. D. (1999). Forming a story: The health benefits of narrative. Journal of Clinical Psychology, 55, 1243-1254.

Ellis, C., \& Bochner, A. (2000). Autoethnography, personal narrative, reflexivity: Researcher as subject. In N. Denzin \& Y. Lincoln (Eds.), Handbook of qualitative research (2nd ed., pp. 733-768). Thousand Oaks, CA: Sage.

Koch, T., \& Harrington, A. (1998). Reconceptualising rigour: The case for reflexivity. Journal of Advanced Nursing, 28(4), 882-890.

Kohlberg, L. (1984). The psychology of moral development: The nature and validity of moral stages. San Francisco: Harper \& Row.

Mead, M. (1928). Coming of age in Samoa: A study of adolescence and sex in primitive societies. New York: Penguin.

Persson, B., \& Hellstrom, A. (2002). Experiences of Swedish men and women 6 to 12 weeks after ostomy surgery. Journal of Wound, Ostomy and Continence Nursing 29(2), 103-108.

Peterson, G. W., Steinmetz, S. K., \& Wilson, S. M. (2005). Parent-Youth Relations: Cultural and Cross-Cultural Perspectives. Haworth Press.

Piaget, J. (1969). The Formal Operational Stage, The theory of stages of cognitive development. New York: McGraw-Hill. 
Piwonka, M, A., \& Merino, J. M. (1999). A multidimensional modelling of predictors influencing the adjustment to a colostomy. Journal of Wound, Ostomy and Continence Nursing, 26(6), 298-305.

Pless, I., Cripps, H., Davies, J., \& Wadsworth, M. (1989). Chronic physical illness in childhood: Psychological and social effects in adolescence and adult life. Developmental Medicine and Child Neurology, 31, 746-755.

Pless, I., Power, C., \& Peckham, C. (1993). Long-term psychosocial sequelae of chronic physical disorders in childhood. Pediatrics, 91, 1131-1136.

Polkinghorne, D. E. (1988). Narrative knowing and the human sciences. Albany: State University of New York Press.

Polkinghorne, D. E. (1995). Narrative configuration in qualitative analysis. In A. Hatch \& R. Wisniewski (Eds.), Life history and narrative. London: Falmer.

Priest H., Roberts P., \& Woods, L. (2002). An overview of three different approaches to the interpretation of qualitative data. part 1: Theoretical issues. Nurse Researcher, 10(1), 30-42.

Prostitution Reform Act, No. 28, New Zealand Statutes (2003).

Ramrakha, S., Bell, M. L., Paul, C., Dickson, N., Moffitt, T. E., Caspi, A. (2007). Childhood behaviour problems linked to sexual risk taking in young adulthood: A birth cohort study. Journal of Child and Adolescent Psychiatry, 46, 1272-1279.

Rayhorn, N. (2001). Treatment of inflammatory bowel disease in the adolescent. Journal of lnfusion Nursing, 24, 255-262.

Redman, R.W. (2005). The power of narratives. Research and Theory for Nursing Practice, 19(1), 5-7.

Redwood, R. (1999). Information point: narrative and narrative analysis. Journal of Clinical Nursing, 8, 654.

Reynaud, S. N., \& Meeker, B. J. (2002). Coping styles of older adults with ostomies. Journal of Gerontological Nursing, 28(5), 30-36.

Rheaume, A., \& Gooding, B. (1991). Social support, coping strategies, and longterm adaptation to ostomy among self-help group members. Journal of Enterostomal Therapy, 18, 11-15. 
Richardson, L. (1990). Writing strategies: Reaching diverse audiences. (Vol.21). Newbury Park, CA: Sage.

Richardson, L. (2000). Writing: A method of inquiry. In N. Denzin \& Y. Lincoln (Eds.), Handbook of qualitative research (2nd ed.). Thousand Oaks, CA: Sage.

Riessman, C. K. (1990). Strategic uses of narrative in the presentation of self and illness: A research note. Social Science and Medicine, 30, 1195-1200.

Riessman, C. K. (1993). Narrative analysis. Newbury Park: CA: Sage Publications.

Rozmovits, L. \& Ziebland, S. (2004). Expressions of loss of adulthood in the narratives of people with colorectal cancer. Qualitative Health Research, 14(2), 187-203.

Sale of Liquor Ammendment Act, No. 92, New Zealand Statutes (1999).

Salter, M. J. (1992). What are the differences in body image between patients with a conventional stoma compared with those who have had a conventional stoma followed by a continent pouch? Journal of Advanced Nursing, 17, 841-848.

Sandelowski, M. (1991). Telling stories: Narrative approach in qualitative research. Image: Journal of Nursing Scholarship, 23,161-166.

Sandelowski, M. (1993). Rigor or rigor mortis: The problem of rigor in qualitative research revisited. Advances in Nursing Science, 16(2), 1-8.

Santos, V. L., \& Sawaia, B. B. (2001). The pouch acting as a mediator between being a person with an ostomy and being a professional: Analysis of a pedagogical strategy. Journal of Wound, Ostomy and Continence Nursing, 26(4), 206-214.

Santrock, R. (2004). Adolescence. New York: Macmillan Publishing Company.

Shipes, B. (1987). Psychosocial issues: The person with an ostomy. Enterostornal Therapy, 22(2), 291-302.

Silva, M., Ratnayake., G., \& Deen, K. (2003). Quality of life of stoma patients: Temporary ileostomy versus colostomy. World Journal of Surgery, 27, 421-424. 
Silverman, D. (2000). Doing qualitative research: A practical handbook. London: Sage Publications.

Simon, D. (2002). Puberty in chronically diseased patients. Hormone Research, 57(2), S53-S56.

Simpson, J. A., \& Weiner, E. S. (Eds.). (1989). Oxford English Dictionary (2nd ed.). Oxford: Oxford University Press.

Singleton, L. (2007). Developmental differences and their clinical impact in adolescence. British Journal of Nursing, 16(3), 140-143.

Steifen, V. (1997). Life stories and the shared experience. Social Science and Medicine, 45(1), 33-112.

Stivers, C. (1997). Reflections on the role of personal narrative in social science. In D. T. Meyers (Ed.), Feminists rethink the self. Boulder, CO: Westview Press.

Sturge, C., Garralda, M. E., Boissin, M., Dore, C. J., \& Woo, P. (1997). School attendance and juvenile chronic arthritis. Rheumatology, 36, 1218-1223.

Surrey, J. L. (1991). The self in relation: A theory of women's development. In J. V. Jordan, A. G. Kaplan, J. B. Miller, I. P. Striver, \& J. L. Surrey (Eds.), Women's growth in connection (pp. 51-67). New York: The Guilford Press.

Swift, P. (1997). Optimisation of insulin treatment in children. Annals of Medicine, 29, 419-424.

Thomas, C., Madden, F., \& Jehu, D. (1987). Psychological effects of stomas - I. Psychosocial morbidity one year after surgery. Journal of Psychosomatic Research, 31(3), 311-316.

Turner, J. S., \& Helms, D. B. (1987). Lifespan development (3rd ed.). New York: Holt, Rinehart and Winston.

United Nations. (2005). World Youth Report 2005: Young People Today, and in 2015. United Nations.

United Ostomy Association of America (2007). What is an ostomy. Retrieved June 24, 2007, from http://www.uoaa.org/ostomy_info.

Van Kaam, A. (1969). Existential crisis and human development. Journal of Humanistic Psychology, 7(1), 63-74. 
Van Manen, M. (1997). Researching lived experience. Human science for an action sensitive pedagogy. Toronto: The Althouse Press.

Vermeire, E; Hearnshaw, H; Van Royen, P; Denekens, J. (2001). Patient adherence to treatment: Three decades of research. Clinical Journal of Pharmcology \& Therapeutics, 26(5), 331-342.

Vezeau, T. (1994). Narrative inquiry in nursing. In P. Chinn \& J. Watson (Eds.), Art \& aesthetics in nursing. New York: National League for Nursing Press.

Viner R. (1999). Transition from pediatric to adult care: Bridging the gaps or passing the buck? Archives of Disease in Childhood, 81, 271-275.

Viner, R. \& MacFarlane, A. (2000). Provision of age appropriate health services has been ignored. British Medical Journal, 321, 1022.

Vygotsky, L. S. (1978). Mind in society: The development of higher psychological processes. Cambridge, MA: MIT Press.

Whaley, J., \& Wong, R. (1996). The nursing of sick children. New York: McGraw Hill.Williamson, M. L. (1987). The nursing diagnosis of body image disturbance in adolescents dissatisfied with their physical characteristics. Holistic Nursing Practice, 1(4), 52-59.

Wolman, C., Resnick, M., Harris, L., \& Blum, R. (1994). Emotional well-being among adolescents with and without chronic conditions. Journal of Adolescent Health, 15, 199-204.

Wood, P., \& Giddings, L. (2003). Revealing storied lives-life story narrative inquiry in nursing and midwifery: An interview with Rose McEldowney. Nursing Praxis in New Zealand, 19(2), 4-17.

Woodgate, R. (1998). Adolescents' perspectives of chronic illness: It's Hard. Journal of Pediatric Nursing 13(4), 210-223.

World Health Organisation. (1999). Programming for adolescent health and development. Geneva: World Health Organisation. 